\title{
Pneumologie interdisziplinär
}

\author{
M. Kopp, C. Vogelberg, M. Dübbers, E. Paditz
}

18.1 Anatomische und physiologische entwicklungsabhängige Besonderheiten - 415

18.2 Angeborene Fehlbildungen - 415

18.2.1 Angeborene Fehlbildungen von Larynx, Trachea und Bronchien - 415

18.2.2 Angeborene Fehlbildungen der Lunge -416

18.2.3 Fehlbildungen der Thoraxwand -417

18.3 Angeborene Lungenerkrankungen - 418

18.3.1 Primäre ziliäre Dyskinesie $\quad-418$

18.3.2 Alpha-1-Antitrypsin -419

18.4 Akute und chronische Entzündung der oberen Luftwege - 419

18.4.1 Akute Rhinitis - 419

18.4.2 Chronische Rhinitis -419

18.5 Akute und chronische Entzündung der Trachea und des Bronchialsystems - 420

18.5.1 Stenosierende Laryngotracheitis (Pseudokrupp) -420

18.5.2 Epiglottitis -420

18.5.3 Akute Bronchitis - 421

18.5.4 Chronische Bronchitis - 422

18.5.5 Bronchiolitis und obstruktive Bronchitis -422

18.5.6 Rezidivierende Infekte der Atemwege - Infektanfälligkeit - 423

18.6 Akute und chronische Entzündung der Lunge - 424

18.6.1 Pneumonie -424

18.6.2 Asthma bronchiale -426

18.6.3 Exogen-allergische Alveolitis -431

18.7 Bronchiolitis obliterans -432

18.8 Bronchiektasen -433

18.9 Interstitielle Lungenerkrankungen - 434 
18.10 Systemkrankheiten mit Beteiligung der Lunge - 434

18.10.1 Sarkoidose -434

18.10.2 Neuromuskuläre Erkrankungen und Ateminsuffizienz - 435

18.11 Aspiration - 436

18.11.1 Fremdkörperaspiration -436

18.12 Thoraxtrauma und Erkrankungen der Pleura - 437

18.12.1 Pneumothorax -437

18.12.2 Pleuritis -437

18.13 Tumoren der Lunge und der Pleura $\quad-439$

18.13.1 Gutartige Neoplasien - 439

18.13.2 Maligne Tumoren -439

18.14 Schlafmedizin - 439

18.14.1 Schlafbezogene Atmungsstörungen - 440

18.14.2 Neurologisch und psychosomatisch bedingte Schlafstörungen -442 


\subsection{Anatomische und physiologische ent- wicklungsabhängige Besonderheiten}

C. Vogelberg

Die Atemfrequenz eines Kindes ist von seinem Alter abhängig: Neugeborene atmen 35- bis 55-mal pro Minute, 6-Jährige hingegen etwa 25-mal. Der horizontale Verlauf der Rippen beim Säugling lässt eine wirksame Erweiterung des Thorax nicht zu, sodass diese auf eine Zwerchfellatmung angewiesen sind und eine Atemregulation im Wesentlichen nur über die Frequenz möglich ist. Einziehungen beim Neugeborenen mit Atemnot entstehen, wenn die Lungen weniger beweglich als die Brustwand werden. Während der Inspiration entwickelt das Kind kräftige diaphragmatische Kontraktionen, um die Lunge mit Luft zu füllen. Dies lässt einen starken negativen intrapleuralen Druck entstehen; als Folge kollabiert die Brustwand nach innen an Punkten kleinsten Widerstandes: Einziehungen interkostal, subkostal, substernal und jugulär resultieren.

$(7$

Neugeborene und Säuglinge sind obligate Nasenatmer, daher kann ein Schnupfen im Säuglingsalter zu einer erheblichen Beeinträchtigung des Kindes bis hin zur notwendigen Krankenhausaufnahme führen.

Stöhnen entsteht, wenn das Neugeborene zur Steigerung des endobronchialen Drucks zum Beginn der Ausatmung kurz die Glottis verschließt und nach deren Öffnung die Luft mit einem „stöhnenden" Geräusch entweicht.

In Abhängigkeit vom Entwicklungsstand der luftleitenden Atemwege ergeben sich bei Kindern altersspezifische physiologische Besonderheiten der Lungenfunktion, die auch für die weitere Entstehung und den Verlauf von Erkrankungen von besonderer Bedeutung sind.

Bis etwa zum 5. Lebensjahr sind die peripheren Atemwege (ab 15. Generation) disproportional eng und dementsprechend ihre Durchlassfähigkeit gegenüber den zentralen Atemwegen unerwartet niedrig. Sie tragen in diesem Alter noch zu ca. 50\% des gesamten Atemwegswiderstands bei. Erst nach dem 4. Lebensjahr kommt es zu einer raschen Größenzunahme der Atemwege und daraus resultierend zu einer Abnahme des Widerstands der peripheren Atemwege.

Auf der Basis dieser Besonderheit wird jeder Infekt der Atemwege bei Säuglingen und Kleinkindern einen größeren Einfluss auf die Durchlassfähigkeit der peripheren Atemwege haben als im späteren Leben. Es kommt zu erheblichen Störungen hinsichtlich Belüftung (Giemen!) und Gasaustausch. Beim größeren Kind bzw. beim Erwachsenen werden Störungen mit gleicher Lokalisation (z. B. im Rahmen von Bronchitis, Bronchiektasen oder Mukoviszidose) dagegen oft „stumm“ bleiben. Die Tendenz der jungen Kinder zur schnellen Obstruktion der kleinen Atemwege ist ursächlich dafür, dass in diesem Altersbereich Atelektasen und rezidivierende Infektionen häufiger zu beobachten sind.

Als weitere, entwicklungsabhängige Besonderheiten und Risikofaktoren für die Entstehung und den Verlauf von bronchopulmonalen Erkrankungen im frühen Kindesalter sind zu nennen:

- Weichheit des Knorpels von Larynx und großen Bronchien, sodass bei größeren Druckschwankungen in den Atemwegen eine Kollapsneigung besteht.

- Die Bronchien junger Kinder besitzen relativ viele Schleimdrüsen. Entzündungen oder Irritationen führen deshalb zu einer stärkeren sekretbedingten Obstruktion.

- Ein inadäquater Hustenmechanismus (schwacher Reflex, horizontale Rippenstellung) und die beschriebene Kollapsneigung verhindern eine optimale Bronchialreinigung.

\subsection{Angeborene Fehlbildungen}

M. Kopp

\subsubsection{Angeborene Fehlbildungen von Larynx, Trachea und Bronchien}

\section{Stridor congenitus}

\section{- Pathogenese}

Kongenitale Fehlbildungen, die den Kehlkopfeingang, das Kehlkopflumen oder die Trachea einengen, führen postnatal - bei geringerer Ausprägung auch erst im Rahmen des ersten Luftwegsinfekts - zu einem ziehenden, juchzenden oder schnarchenden Atemgeräusch.

8

Dieser Stridor tritt bei extrathorakal gelegenen Hindernissen (häufigste Lokalisation) bei der Inspiration, bei unterhalb der oberen Thoraxapertur liegenden Stenosen (unteres Drittel der Trachea, Hauptbronchien) exspiratorisch auf.

Prinzipiell kann es sich um dynamische (Malazie) und fixierte Stenosen handeln. Weitere Ursachen eines kongenitalen Stridors, die differenzialdiagnostisch berücksichtigt werden müssen, sind in - Tab. 18.1 dargestellt.

\section{- Klinik}

Neben dem meist inspiratorischen Stridor kann es in Abhängigkeit vom Grad der Einengung zu tiefen jugulären, sternalen und epigastrischen Einziehungen kommen. Ein hinzukommender Luftwegsinfekt verschlimmert in der Regel die Situation. Der Stridor ist oft lageabhängig mit Besserung in Bauchlage oder beim Überstrecken des Halses.

\section{- Diagnose}

Bei einer leichten Form des Stridor congenitus mit Beginn in den ersten Lebenswochen, der nicht mit einer Gedeihstörung einhergeht, ist keine weitere Diagnostik indiziert. Gibt es Zweifel an der Diagnose oder persistiert der Stridor über das erste Lebensjahr hinaus, so muss mittels flexibler Bronchoskopie, Echokardiographie und ggf. Schnittbildgebung die Ätiologie eines persistierenden Stridors zweifelsfrei geklärt werden.

- Tab. 18.1 Differenzialdiagnose des Stridors

\begin{tabular}{|c|c|c|}
\hline \multirow[t]{2}{*}{ Pharynxbereich } & Angeboren & $\begin{array}{l}\text { Laryngomalazie } \\
\text { Laryngozele oder -zyste } \\
\text { Hämangiom, Lymphangiom }\end{array}$ \\
\hline & Erworben & $\begin{array}{l}\text { Krupp } \\
\text { Epiglotittis } \\
\text { Rekurrensparese }\end{array}$ \\
\hline \multirow[t]{2}{*}{$\begin{array}{l}\text { Trachea - } \\
\text { Bronchien }\end{array}$} & Angeboren & $\begin{array}{l}\text { Tracheomalazie } \\
\text { Bronchomalazie } \\
\text { Hämangiom, Lymphangiom } \\
\text { Gefäßfehlbildung }\end{array}$ \\
\hline & Erworben & $\begin{array}{l}\text { Fremdkörper } \\
\text { Tumoren }\end{array}$ \\
\hline \multirow[t]{2}{*}{ Andere } & Angeboren & $\begin{array}{l}\text { Makroglossie, Glossoptose } \\
\text { Mikrognathie }\end{array}$ \\
\hline & Erworben & Tonsillenhyperplasie \\
\hline
\end{tabular}




\section{- Therapie}

Leichte bis mittelschwere Verläufe auf der Basis einer Malazie von Epiglottis, Kehlkopf oder Trachea bedürfen keiner besonderen Therapie. Verschlechterungen im Rahmen akuter Infekte müssen $u$. U. stationär überwacht werden. Sehr schwere Verläufe machen eine Beatmung oder in seltenen Fällen eine Tracheotomie nötig. Eine nichtinvasive nächtliche CPAP-Atemunterstützung („,continuous positive airway pressure") kann in Einzelfällen die Tracheotomie umgehen. Andere Ursachen (z. B. primäre und sekundäre Stenosen, Tumoren, Zysten) können operativ beseitigt werden. Bei Hämangiomen kann eine Behandlung mit Betablockern erfolgen ( $\$ Kap. 30).

D Cave

Bei der Bronchoskopie müssen Hämangiome aufgrund der Blutungsgefahr mit äußerster Vorsicht inspiziert werden.

\section{- Prognose}

Die Weichheit des Knorpels von Kehlkopf oder Trachea nimmt mit zunehmendem Lebensalter ab, sodass der Stridor bei den meisten Kindern nach 6-18 Monaten abklingt.

\section{Stenosen durch Fehlbildungen von großen Gefäßen}

> Kap. 20.

\subsubsection{Angeborene Fehlbildungen der Lunge}

Angeborene Lungenfehlbildungen sind selten Erkrankungen. Hierzu zählen u. a. folgende Krankheitsbilder:

Agenesie bzw. Aplasie Die Agenesie/Aplasie einer Lunge (meist links) ist mit dem Leben vereinbar, geht aber oft mit gehäuften bronchopulmonalen Infekten einher. Die Kinder sind vermindert belastbar. Begleitende Fehlbildungen (besonders Herz, Ösophagus u. a.) finden sich in 50-75\% der Fälle. Die Therapie beschränkt sich auf die Bekämpfung der rezidivierenden Infektionen in dem fehlgebildeten Lungenabschnitt.

Hypoplasie Eine Hypoplasie ( Kap. 4.7) der Lunge kann sowohl durch primäre teratogene Schädigungen, eine Hypo- oder Aplasie der A. pulmonalis wie aber auch durch Einwirkungen von außen entstehen, die die weitere Entwicklung einer primär normal angelegten Lunge behindern (z. B. Zysten, Zwerchfellhernien). Fast immer wird die Hypoplasie des Lungengewebes von einer Hypoplasie der zuständigen Arterie begleitet und oft bestehen Fehlbildungen in anderen Organen (Herz, Zwerchfell, Niere).

Zystische Lungenfehlbildungen sind seltene Anomalien. Durch die pränatalen Sonographie werden sie zunehmend häufiger diagnostiziert. Die meisten Kinder bleiben zunächst symptomfrei. Selten treten Symptome bereits in den ersten Lebensmonaten auf (z. B. Atemnotzustände, pulmonale Infektionen). $\mathrm{Zu}$ den angeborenen parenchymatösen Lungenfehlbildungen zählen primär die kongenitalen pulmonalen Atemwegsmalformationen (CPAM), bronchogene Zysten, das lobäre kongenitale Lungenemphysem und die bronchopulmonalen Sequester (BPS).

Kongenitale pulmonale Atemwegsmalformation (CPAM) Die CPAM (früher: kongenitale zystisch-adenomatoide Malformation, CCAM), ist eine angeborene, hamartöse, gutartige Veränderung eines Teils der Lunge mit einer Inzidenz von etwa 1/10.000-1/30.000. Der betroffene Lungenabschnitt zeigt dabei solide und v. a. zysti- sche Veränderungen des Lungengewebes. Die Pathogenese der CPAM ist nicht endgültig geklärt. Die Einteilung der CPAM erfolgt in 5 Typen basierend auf der Zystengröße und der Zellcharakteristika nach Stocker. Da der Verlauf bereits intrauterin sehr variabel sein kann, ist für die Beurteilung ein erfahrener Kinderpneumologe notwendig. Die CPAM kann bis etwa zur 28. Schwangerschaftswoche an Größe zunehmen und danach an Größe wieder abnehmen. Die Indikation und der Zeitpunkt einer möglichen Operation müssen vor dem Hintergrund der aktuellen Beschwerden, eines möglichen Entartungsrisikos sowie dem Risiko der rezidivierenden pulmonalen Infekte individuell abgewogen werden.

Bronchogene Zysten Vom Bronchialsystem ausgehende Zysten sind intra- oder extrapulmonal gelegene, kugelförmige Hohlräume von wechselnder Größe. Sie können Luft oder Flüssigkeit enthalten und haben primär eine Verbindung zum Bronchialbaum, die meist aber obliteriert ist. Bronchogene Zysten machen etwa die Hälfte aller Lungenfehlbildungen aus. Die extrapulmonalen Zysten (meist solitär) entstehen in der 4.-5., die intrapulmonalen (meist multipel) in der 8. Embryonalwoche wohl durch vermehrte Ausknospung oder Wachstum von versprengten Zellen. Bronchogene Zysten können lange Zeit symptomlos bleiben und werden teilweise auch zufällig bei einer Röntgenaufnahme entdeckt. Bedeutung erlangen sie durch Kompression von Bronchien oder Lungenparenchym (Reizhusten, Stridor, chronische Bronchitis) bzw. durch rezidivierende Infektionen (Pneumonie). Die Therapie erfolgt durch chirurgische Entfernung aller extrapulmonalen Zysten. Bei intrapulmonaler Lage ohne Zeichen für Kompression und Infektion kann unter Beobachtung abgewartet werden.

Kongenitales lobäres Emphysem Unter einem lobären Emphysem versteht man eine Überblähung eines oder auch mehrerer Lungenlappen. Dies kommt durch einen Ventilmechanismus zustande: Bei der Inspiration tritt Luft in den betroffenen Bereich ein, die bei der Exspiration nicht mehr entweichen kann. Ursachen hierfür können u. a. eine Knorpeldysplasie, Gefäßanomalien oder Stenosierungen von außen z. B. durch eine bronchogene Zyste oder ein Teratom sein. Histologisch findet man eine normale Lungenarchitektur mit überblähten Alveolen. Im Unterschied dazu findet man bei dem sog. Iobulären Emphysem alveoläre Strukturanomalien. Die klinische Symptomatik beginnt fast immer direkt in der Neonatalzeit, wenn die Kinder mit einer progredienten Tachypnoe und Dyspnoe auffallen.

Lungensequestration Bei der Lungensequestration besitzt der vom normalen Lungengewebe anatomisch und funktionell völlig getrennte Teil eine amorphe histologische Struktur. Besteht keine Verbindung zur gleichseitigen Lunge und ist eine eigene Pleura vorhanden, spricht man von extralobärer - im Gegensatz zur intralobären - Sequestration.

Bedeutsam ist für Diagnose und Operation, dass die versorgende Arterie immer direkt aus der Aorta entspringt (in 25\% dabei aus der Aorta abdominalis)!

Klinisch machen sich diese Fehlbildungen durch rezidivierende Pneumonien, Lungenabszesse oder unter dem Bild von Bronchiektasen bemerkbar, die meist im Unterlappen (links > rechts) ablaufen (- Abb. 18.1).

Die Behandlung ist chirurgisch, wobei meist chronisch entzündetes umgebendes Lungengewebe mit entfernt werden muss.

Angeborene Fehlbildungen des Zwerchfells \ Kap. 22. 

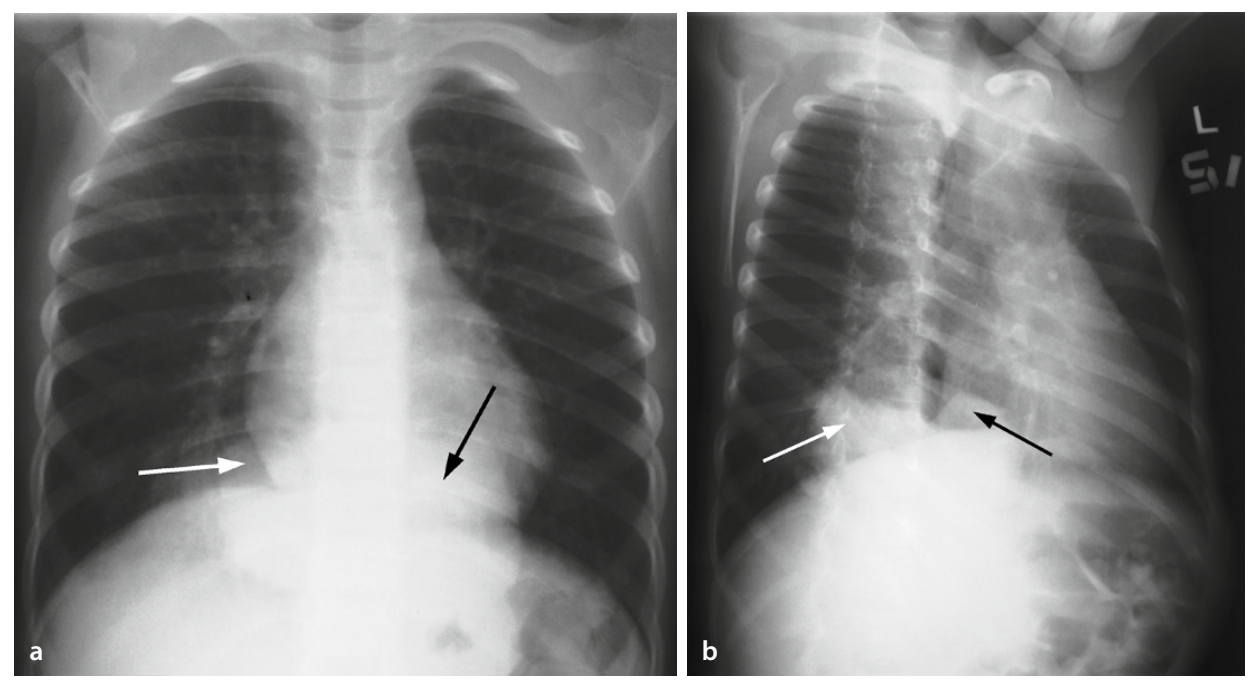

- Abb. 18.1 Rundliche Verschattungen beidseits der Wirbelsäule (Pfeile) bei doppelseitiger Lungensequestration: a posterior-anteriorer, b schräger Strahlengang

\subsubsection{Fehlbildungen der Thoraxwand}

\section{Dübbers}

\section{Trichterbrust (Pectus excavatum)}

Die Trichterbrust ist mit fast $90 \%$ der Fälle die häufigste Form der Thoraxwanddeformität und tritt mit einer Inzidenz von etwa 1:400 Lebendgeburten auf. Jungen sind etwa 3-mal häufiger betroffen. Hinsichtlich der Entstehung werden Fehlbildungen der knorpeligen Rippenanteile sowie ungleiche Zugwirkungen der Muskulatur diskutiert. Zumeist tritt die Trichterbrust als isolierte Fehlbildung auf. Die familiäre Häufung sowie eine Assoziation mit dem Marfan- oder Ehlers-Danlos-Syndrom ist beschrieben. Eine spontane Rückbildung ist selten und nach dem 6. Lebensjahr nicht mehr zu erwarten.

\section{- Klinik und Diagnose}

Klinisch imponiert die trichterförmige Einziehung der vorderen Thoraxwand zumeist bereits im frühen Kindesalter (• Abb. 18.2).
Die Ausprägung und Symmetrie ist variabel und kann insbesondere während der Phase des raschen Wachstums in der Pubertät weiter progredient sein. Häufig begleitend findet sich eine Kyphoskoliose. Die charakteristische Körperhaltung ist geprägt durch einen nach vorne gebeugten Oberkörper mit hängenden Schultern. Die körperliche Leistungsfähigkeit der Betroffenen ist meist nicht beeinträchtigt, ebenso sind kardiopulmonale Einschränkungen zumeist nicht nachweisbar. Neben dem typischen klinischen Erscheinungsbild zeigt die Thoraxröntgenaufnahme in 2 Ebenen das Ausmaß des Trichters sowie evtl. Veränderungen des Herzschattens oder eine Skoliose. Die CT-Untersuchung des Thorax wird zur Objektivierung der Trichterkonfiguration und Planung der Operation favorisiert. Als Maß für die Quantifizierung des Befunds dient der CT-Index nach Haller (Querdurchmesser des Thorax dividiert durch den Abstand Sternum-Wirbelsäule an der tiefsten Stelle des Sternums), wobei ein Wert von 2,5 als normal gilt.

EKG, Echokardiographie und Spirographie komplettieren die Diagnostik.
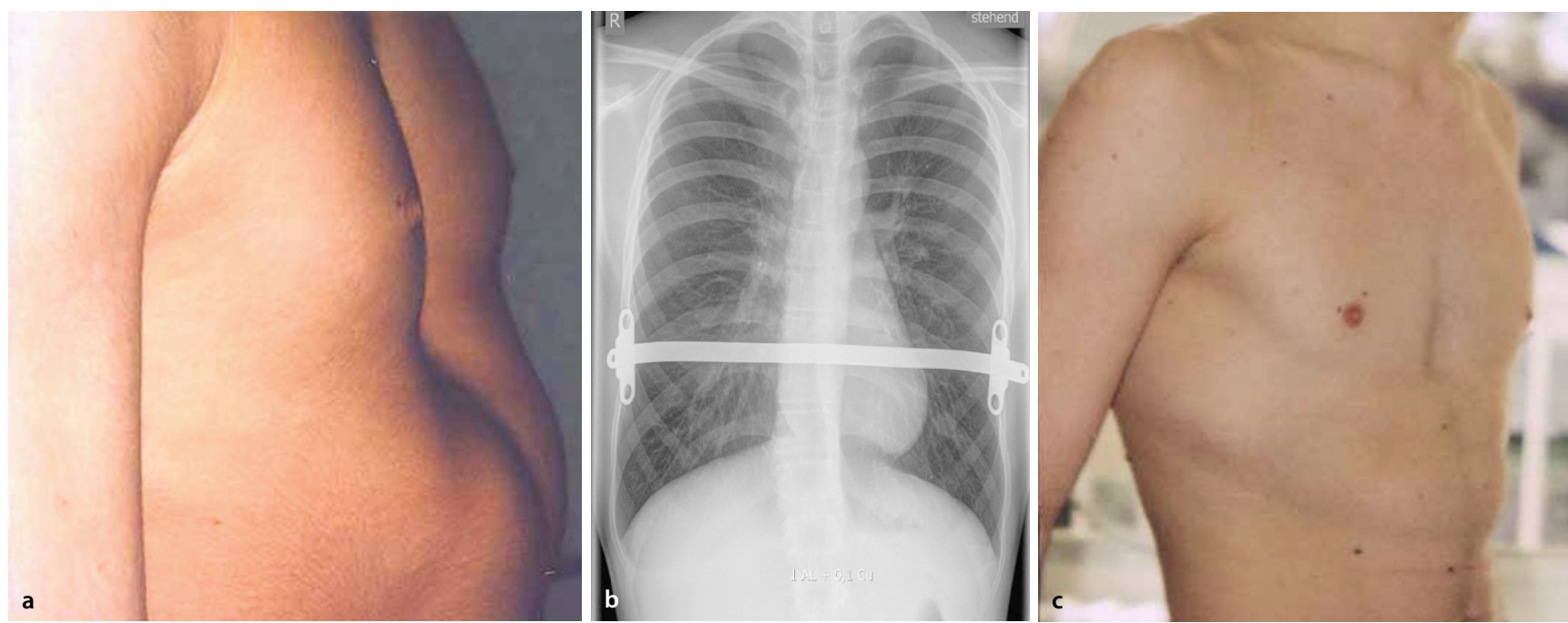

- Abb. 18.2 Minimal-invasive Behandlung der Trichterbrust. a Trichterbrust präoperativ, b Röntgendarstellung des substernal implantierten Metallbügels, c postoperativer Aspekt 


\section{- Therapie}

Mit zunehmendem Alter empfindet ein Großteil der Betroffenen das Erscheinungsbild des Brustkorbs als störend und im Alltagsleben beeinträchtigend. Das Entblößen des Oberkörpers bereitet vielen Patienten v. a. in der Pubertätsphase Scham, sodass ein nicht unerheblicher Leidensdruck entstehen kann. Subjektiv werden dann auch häufig Atemnot oder eine körperliche Leistungseinschränkung beklagt. Haltungsübungen sowie gezielte Maßnahmen zum Muskelaufbau der Brustwand sind stets hilfreich und bei milden Formen womöglich ausreichend. Konservative Methoden wie die Saugglocken-Applikation werden an einigen Zentren eingesetzt, haben sich jedoch nicht flächendeckend durchgesetzt. Allgemein akzeptierte Faktoren für die OP-Indikation sind ein Haller-Index $>3,25$, die Kompression oder Verdrängung des Herzens oder der Nachweis einer restriktiven respiratorischen Störung in der Diagnostik. Im Kleinkindesalter operierte Patienten neigen zu häufigeren Rezidiven während der Pubertät. Allgemein wird daher ein Operationszeitpunkt frühestens ab dem 8. Lebensjahr und rechtzeitig vor Ende der Adoleszenz empfohlen. Die minimalinvasive Trichterbrustkorrektur nach Nuss (MIRPE) stellt mittlerweile die wohl am häufigsten angewendete Technik insbesondere bei jüngeren Patienten dar. Unter thorakoskopischer Kontrolle erfolgt hier die Implantation eines oder mehrerer Metallbügel unter das Brustbein ohne Notwendigkeit zusätzlicher Osteotomien (• Abb. 18.2). Der Trichter wird hierbei durch Drehung des Bügels nach oben gedrückt. Die Entfernung des Bügels erfolgt meist nach 2-3 Jahren. Offene Operationsverfahren mit Aufrichtung des Sternums z. B. durch quere Sternotomie und Rippenosteotomien mit oder ohne Implantation von Brustwandstabilisatoren (OP nach Ravitch oder Rehbein) werden bei komplexen Deformitäten sowie älteren Patienten weiterhin durchgeführt.

\section{- Prognose}

Die Ergebnisse der operativen Therapie der Trichterbrust sind überwiegend sehr gut.

Komplikationen sind u. a. intraoperative Verletzungen und Blutungen der Brustwand oder der Brustorgane, die postoperative Dislokation des Bügels oder das Rezidiv.

\section{Kielbrust (Pectus carinatum)}

Die Kielbrust ist im Vergleich zur Trichterbrust mit einem Anteil von 5-10\% der Patienten mit Brustwanddeformität deutlich seltener. Auch hier werden Störungen der sternocostalen Knorpelstrukturen diskutiert, letztendlich ist die Ätiologie jedoch unklar. Es besteht eine familiäre Häufung.

\section{- Klinik und Diagnose}

Die Diagnose wird häufig erst nach dem 10. Lebensjahr gestellt, da sich meist erst unter dem Wachstumsschub eine unterschiedlich stark ausgeprägte symmetrische oder asymmetrische Vorwölbung im Bereich des Sternums und/oder parasternal ausbildet. Nur wenige Patienten zeigen diese Veränderungen bereits im Kleinkindalter. Spinale Anomalien oder eine Skoliose sind bei $15-30 \%$ der Patienten beschrieben. Physiologische Beschwerden bereitet die Kielbrust-Deformität meist nicht, sodass eine Korrektur überwiegend aufgrund des äußeren Erscheinungsbildes erfolgt. Eine Röntgenthoraxuntersuchung kann begleitende Wirbelsäulenveränderungen oder den zeitlichen Verlauf der Deformität dokumentieren. Die Computertomographie des Thorax dient insbesondere der präoperativen Planung.

\section{- Therapie}

Der Versuch einer konservativen Therapie mittels Druckpelotte (Bracing) ist bei jüngeren Patienten möglich, der Vorteil dieser Be- handlung jedoch insgesamt umstritten. Die operative Korrektur erfolgt ähnlich den Prinzipien der bei Trichterbrust eingesetzten Verfahren (minimal-invasiv/offene Thorakoplastik) und zeigt insgesamt gute Ergebnisse.

\section{Seltene Thoraxdeformitäten}

Das Poland-Syndrom beschreibt eine Aplasie oder Hypoplasie des M. pectoralis major mit assozierten Fehlbildungen der ipsilateralen Rippen, des Arms und der Hand. Das Jeune-Syndrom ist durch einen glockenförmigen, zu kleinen und rigiden Thorax charakterisiert, was zumeist frühzeitig im Säuglingsalter zur respiratorischen Insuffizienz führt. Sternumdefekte sind seltene angeborene Mittelliniendefekte, welche sich in unterschiedlicher Ausprägung bis hin zur Ectopia cordis zeigen. Die Prognose richtet sich hier zumeist nach den kardialen Begleitfehlbildungen. Die offene operative Korrektur seltener Thoraxdeformitäten sollte Zentren mit entsprechender Expertise vorbehalten bleiben.

\subsection{Angeborene Lungenerkrankungen}

M. Kopp

Zystische Fibrose > Kap. 19.

\subsubsection{Primäre ziliäre Dyskinesie}

\section{- Definition}

Die primäre Ziliendyskinesie („primary ciliary dyskinesia“, PCD) ist eine phänotypisch und genetisch heterogene Erkrankung, die überwiegend autosomal-rezessiv vererbt wird. Die Erkrankung ist charakterisiert durch eine Fehlfunktion respiratorischer Flimmerhärchen (Zilien), embryonaler Zilien und Spermienschwänze. Im Respirationstrakt kommt es hierdurch zu einer gestörten Mukusclearance und rezidivierenden bzw. chronischen Infektionen der oberen und unteren Atemwege. Männliche Infertilität auf Grund einer Spermiendysmotilität ist bei einer PCD häufig ( 60\%). Die embryonale Ziliendysfunktion ist dafür verantwortlich, dass die Hälfte der PCD-Patienten einen Situs inversus (Kartagener-Syndrom) aufgrund einer zufälligen Anordnung der Links-RechtsKörperasymmetrie aufweist. Neben den angeborenen Formen kann es im Rahmen von chronisch-entzündlichen Erkrankungen der Atemwege auch zu einer sekundären Fehlfunktion der Zilien kommen. Die Inzidenz liegt zwischen 1:15.000 und 1: 20.000 in der weißen Bevölkerung.

\section{- Klinik}

Der individuelle Krankheitsverlauf der PCD ist sehr heterogen. Die pulmonalen Beschwerden bei PCD-Patienten sind durch die gestörte mukoziliäre Clearance erklärbar, die zu einer bakteriellen Besiedelung führt. So kommt es zu rezidivierenden bzw. chronischen Infektionen wie Otitis media, Sinusitis, Bronchitiden und Pneumonien mit chronischem, oft produktivem Husten. Die pulmonalen Beschwerden und Veränderungen sind ähnlich wie bei der zystischen Fibrose. Im fortgeschrittenen Stadium kann es zur Bronchiektasenbildung kommen. Die klassische Trias des Kartagener-Syndroms besteht aus Situs inversus, chronische Sinusitis und Bronchiektasen.

\section{- Diagnose}

Rezidivierende oder chronische Erkrankungen der Atemwege wie Rhinitis, Otitis, Sinusitis oder Bronchitis sowie das Vorliegen eines 
Situs inversus können hinweisend auf eine PCD sein. Hinweisend kann insbesondere eine Rhinitis sein, die bereits in der Neonatalperiode auftritt. Die Diagnose einer PCD kann nicht durch eine isolierte Untersuchung gesichert werden. Sie stützt sich neben der Anamnese auf die Befunde des erniedrigten nasalen NO, der Videomikroskopie nach einfachem Bürstenabstrich des Nasenepithels, der Elektronen- und Immunfluoreszenzmoikroskopie und der Genetik. Differenzialdiagnostisch müssen andere schwere Lungenerkrankungen wie z. B. die zystische Fibrose ausgeschlossen werden.

\section{- Therapie}

Eine kausale Therapie der PCD gibt es nicht. Ziel von symptomatischen Therapiemaßnahmen muss die Vermeidung von pulmonalen Komplikationen sein. Zu den zur Verfügung stehenden symptomatischen Maßnahmen zählen u. a. die Physiotherapie, Sekretolytika, Inhalationstherapie mit hypertoner Kochsalzlösung und antiinflammatorischen sowie antiobstruktiven Medikamenten, Impfungen und eine gezielte antibiotische Therapie bei Infektionen. Patienten mit einer Zilienfunktionsstörung sollten in einer spezialisierten Ambulanz in regelmäßigen Abständen von einem Kinderpneumologen betreut werden.

\subsubsection{Alpha-1-Antitrypsin}

\section{- Definition}

Alpha-1-Antitrypsin (A1-AT) ist ein Akute-Phase-Protein, das in der Leber synthetisiert wird und verschiedene Proteinasen hemmt. Ein Mangel an Proteaseinhibitoren führt zur Leberzirrhose und zum Lungenemphysem. Das Strukturgen ist auf Chromosom 14q31-32.2 lokalisiert. Von dem Glykoprotein sind mehr als 75 Allele bekannt. Der Austausch von wenigen Aminosäuren führt zu einer veränderten Tertiärstruktur des Proteins; hierdurch wird offenbar die Ausschleusung aus den Hepatozyten gehemmt. Die genotypischen Varianten wurden nach ihrer elektrophoretischen Mobilität benannt (Pi-Typisierung). Der homozygote Pi-Typ ZZ hat in der mitteleuropäischen Bevölkerung eine Häufigkeit von etwa 1:2.000-1:5.000. Er geht mit einer Serumrestaktivität von 10-20\% der Norm einher (•Tab. 18.2).

\section{- Pathogenese}

A1-AT inaktiviert Proteasen aus aktivierten Neutrophilen. Ein Überschuss an Proteasen, insbesondere der neutrophilen Elastase, führt zur Zerstörung extrazellulärer Strukturproteine wie dem Elastin. Ein Ungleichgewicht zwischen Proteasen und A1-AT führt daher zur Destruktion von Lungengewebe mit irreversiblem Verlust der elastischen Rückstellkraft, Überdehnung der Alveolarwände und Ausbildung eines Emphysems.

\begin{tabular}{|c|c|c|}
\hline Phänotyp & Serumspiegel in $\mathrm{mg} / \mathrm{dl}$ & Emphysemrisiko \\
\hline MM & $150-350$ & Nicht erhöht \\
\hline SS & $100-140$ & Nicht erhöht \\
\hline$M Z$ & $90-150$ & Nicht erhöht \\
\hline SZ & $45-80$ & $20-50 \%$ \\
\hline $\mathrm{ZZ}$ & $15-50$ & $80-100 \%$ \\
\hline Null-Null & 0 & $100 \%$ \\
\hline
\end{tabular}

\section{- Klinik}

Die emphysematischen Veränderungen der Lunge führen erst zu Symptomen, wenn ca. 25\% der Lunge umgebaut sind. Dies ist 1 erst nach dem 12. Lebensjahr zu erwarten. Dann können Atemnot, eine chronische Bronchitis, ein unproduktiver Husten sowie bronchiale Hyperreaktivität und rezidivierende Pneumonien auftreten.

Bei einem Icterus gravis bzw. prolongatus oder einer unklaren pulmonalen Symptomatik sollte der A1-AT-Serumspiegel bestimmt werden.

\section{- Diagnose}

Diagnoseweisend ist die Bestimmung von A1-AT im Serum. Bei Serumspiegeln $<120 \mathrm{mg} / \mathrm{dl}$ sollte eine PI-Typisierung veranlasst werden. Mit Hilfe der Lungenfunktionsprüfung können Veränderungen, die durch einen Verlust der elastischen Rückstellkraft bedingt sind, erfasst werden. Hier fallen initial eine Erhöhung des Residualvolumens und reduzierte Flussraten auf.

\section{- Therapie}

Für Erwachsene ist die i.v.-Behandlung mit A1-AT zugelassen. Auch bei Kindern ist wohl eine Substitution sinnvoll, auch wenn keine Daten über Langzeitverläufe vorliegen. Bei einem fortgeschrittenen Stadium ist eine Lungen-Leber-Transplantation indiziert.

\subsection{Akute und chronische Entzündung der oberen Luftwege}

M. Kopp

\subsubsection{Akute Rhinitis}

Die akute Rhinitis ist eine virale (u. a. durch Rhino-, Parainfluenza-, Influenza-, RS-, oder Adenoviren verursachte; Kap. 14) Entzündung der oberen Atemwege, die mit wässriger Rhinorrhö, nasaler Obstruktion und evtl. weiteren Allgemeinsymptomen (Abgeschlagenheit, Gliederschmerzen) einhergeht. Die Diagnose wird klinisch gestellt. Eine Virusanzüchtung aus dem Nasensekret ist überflüssig, serologische Untersuchungen sind unzuverlässig. Nukleinsäureamplifikationstechniken wie die Virus-PCR können zum Virusnachweis eingesetzt werden. Der klinische Nutzen dieser Erregerdiagnostik wird allerdings kontrovers diskutiert.

\subsubsection{Chronische Rhinitis}

- Definition

Die chronische Rhinitis ist eine chronische Entzündung der Nasenschleimhaut, die oft mit purulenter Rhinorrhö und/oder nasaler Obstruktion einhergeht.

\section{- Ätiopathogenese und Diagnose}

Im Kindesalter kann eine chronischen Entzündung der Nasenschleimhaut u. a. durch große adenoide Vegetationen (Rachenmandelhyperplasie), durch eine anatomische Fehlanlage (Choanalatresie, Lippen-Kiefer-Gaumenspalte) durch Polypen, Nasennebenhöhleninfektionen, durch Aeroallergene oder durch einen Fremdkörper (einseitige Symptomatik) hervorgerufen werden. Sie kann auch im Rahmen von Systemerkrankungen (PCD, zystische Fibrose, Sarkoidose, Wegen-Granulomatose) auftreten. Schließlich kann der chronische Abusus von toxischen Substanzen (wie z. B. abschwellende Nasentropfen) zu einer chronischen Rhinitis führen (Privinismus). 
Bei einer chronischen Rhinitis wird eine diagnostische Abklärung empfohlen. Dabei sind insbesondere auf eine Rachenmandelhyperplasie oder eine anatomische Fehlanlage zu achten.

C Cave

Im Säuglings- und Kleinkindesalter führt eine dauerhafte Behinderung der Nasenatmung zu einer chronischen Mundatmung. In der Folge davon verändert sich die Position der Zunge, es kommt zu einer maxillären und mandibulären Fehlstellung mit Ausbildung der sog. adenoiden Fazies.

\section{- Therapie}

Die Therapie ist zunächst symptomatisch und besteht aus abschwellenden Nasentropfen (3-5 Tage). Ggf. kommen topische Steroide zum Einsatz. Das weitere therapeutische Vorgehen richtet sich nach der Ursache der chronischen Rhinitis. Die Besonderheiten der Therapie der allergischen Rhinitis sind in $>$ Kap. 11.6 dargestellt.

\subsection{Akute und chronische Entzündung der Trachea und des Bronchialsystems}

C. Vogelberg, M. Kopp

\subsubsection{Stenosierende Laryngotracheitis (Pseudokrupp)}

\section{- Definition}

Die stenosierende Laryngotracheitis (syn. viraler Krupp, Pseudokrupp) ist ein akutes Krankheitsbild mit der klassischen Symptomtrias „inspiratorischer Stridor, bellenden Husten und Heiserkeit“ sowie evtl. einer Dyspnoe.

\section{- Ätiopathogenese}

Pathophysiologisch liegt eine Schleimhautschwellung vor, die von den Stimmbändern aus bis weit in die Trachea reichen kann. Die häufigsten Erreger sind Parainfluenza-Viren Typ I-III (66\%), RS (Respiratory Syncytial)-Viren (10\%) sowie gelegentlich InfluenzaA- und-B-Viren.

\section{- Klinik}

Die Symptome beginnen meistens nachts oder in den frühen Morgenstunden. Oft geht für 1-3 Tage ein Infekt der oberen Atemwege mit Rhinitis und mildem Fieber voraus. Je nach Schweregrad tritt die Symptomtrias nur bei Aufregung oder bereits in Ruhe auf. Der Allgemeinzustand ist meist wenig beeinträchtigt. Bei schweren Verläufen werden Dyspnoe mit subkostalen, interkostalen und jugulären Einziehungen, Zyanose oder Blässe beobachtet. Betroffen sind v. a. Kleinkinder, im Schulkindesalter ist die stenosierende Laryngotracheitis selten. Häufig kommt es bereits in der Häuslichkeit nach Hochnehmen des Kindes und während der Fahrt ins Krankenhaus zu einem Nachlassen der Symptome.

( Im Gegensatz zur Epiglottitis ist beim Pseudokrupp der Allgemeinzustand oft nur wenig beeinträchtigt, das begleitende Fieber nur mäßig hoch, es bestehen keine Schluckbeschwerden und kein Speichelfluss.

\section{- Diagnose}

Neben der Anamnese (Impfstatus Diphtherie und HiB!) ist die klinische Untersuchung entscheidend. Hier werden die Vitalparameter inklusive der transkutanen $\mathrm{O}_{2}$-Sättigung und der Temperatur erhoben. Invasiven Maßnahmen wie z. B. Blutabnahme oder Infusionsanlage können die Dyspnoe verstärken. Eine Erregerdiagnostik ist beim unkomplizierten Infektkrupp nicht notwendig.

\section{- Differenzialdiagnose}

Hierzu zählen die Epiglottitis, Diphtherie, EBV-Tonsillitis mit „kissing tonsils“, Fremdkörperaspiration, tonsilläre oder retropharyngeale Schwellung durch Abszedierung, Hämangiom, Laryngomalazie, allergisches Glottisödem, Hypokalzämie, bakterielle Tracheitis und eine mediastinale Raumforderung.

\section{- Therapie}

Die Therapie richtet sich nach der Ausprägung der Symptomatik (-Tab. 18.3). Der positive Effekt einer Steroidgabe bei stenosierender Laryngotracheitis ist klar belegt. Bei rektaler Anwendung ist die Resorption mit $20-80 \%$ jedoch sehr variabel, weshalb eine orale Gabe nach Möglichkeit zu bevorzugen ist. Im Stadium IV ist die frühzeitige und ggf. wiederholte Gabe von i.v.-Steroiden die am besten abgesicherte Therapieform. Die Inhalation von Adrenalin wirkt über eine $a$-sympathomimetisch bedingte Schleimhautabschwellung innerhalb von wenigen Minuten für die Dauer von etwa $2 \mathrm{~h}$. Der mittelfristige Verlauf wird durch die Adrenalininhalation nicht beeinflusst, sodass die gleichzeitige Steroidgabe sinnvoll ist.

Wiederholte Inhalationen, maximal 1- bis 2-stündlich, sind möglich. Wichtig ist die Überwachung der Nebenwirkungen (Tachykardie $>180 / \mathrm{min}$ in Ruhe, Übelkeit, Blässe, Unruhe). Bei einem viralen Krupp besteht keine Indikation zu einer antibiotischen Therapie.

\section{- Prognose}

Rund 15\% aller Kinder erkranken einmalig an einem Krupp, bis 15\% der Kinder benötigen eine stationäre Behandlung.

\subsubsection{Epiglottitis}

\section{- Definition}

Bei der Epiglottitis handelt es sich um eine Entzündung der Epiglottis meist durch Haemophilus influenzae Typ b (HiB), selten durch andere Bakterien. Aufgrund der einsetzenden Bakteriämie kommt es zu einer generalisierten Erkrankung, die immer ein medizinischer Notfall ist.

\section{- Klinik und Diagnose}

Die Entzündung und damit das Anschwellen der Epiglottis nach bakterieller Infektion ist die Hauptursache dieses sehr akuten Krankheitsbilds. Die entzündlich vergrößerte Epiglottis verlagert sich nach hinten und verlegt so den Larynxeingang und die Atemwege. Der akute Atemwegsverschluss kann zur Erstickung führen. Meist binnen Stunden entwickeln sich hohes Fieber, Schluckschmerzen, deutlich reduzierter Allgemeinzustand, heisere Stimme mit inspiratorischem Stridor, Speichelfluss, kloßige Sprache („hot potatoe voice“), karchelnde Atmung. Das Kind wird ruhig, will v. a. Sitzen mit Abstützen der Arme nach vorne („tripode position“) als Ausdruck des Einsatzes der Atemhilfsmuskulatur, und verhindert jegliches Sprechen (Schmerzen). Die Untersuchung ergibt sofortige Druckdolenz über dem Kehlkopf bei leichter Berührung, hohes Fieber und blass-graues Hautkolorit. Die Diagnose wird anhand der typischen Anamnese und Klinik gestellt (IDifferenzialdiagnose: - Tab. 18.4). 
- Tab. 18.3 Symptomatik der stenosierenden Laryngotracheitis

\begin{tabular}{|c|c|c|}
\hline Stadium & Symptomatik & Therapie \\
\hline I & $\begin{array}{l}\text { Bellender Husten, Heiser- } \\
\text { keit, leiser Stridor bei Erre- } \\
\text { gung }\end{array}$ & $\begin{array}{l}\text { Kühle Luft, aufrechte Körperposition } \\
\text { Beruhigung } \\
2 \mathrm{mg} / \mathrm{kgKG} \mathrm{Prednisolon} \mathrm{oder} 0,15 \mathrm{mg} / \mathrm{kgKG} \text { Dexamethason p.o. (bei ungünstiger oraler Applikations- } \\
\text { möglichkeit } 100 \mathrm{mg} \text { Prednisolon oder Prednison Supp.) } \\
\text { Ausreichend Flüssigkeit }\end{array}$ \\
\hline II & $\begin{array}{l}\text { Stridor in Ruhe, beginnende } \\
\text { Dyspnoe, leichte juguläre } \\
\text { Einziehungen }\end{array}$ & $\begin{array}{l}\text { Inhalation mit Adrenalin (z. B. Infectokrupp 1-2 ml der gebrauchsfertigen Lösung, bei HF >180/min } \\
\text { beenden) } \\
2 \mathrm{mg} / \mathrm{kgKG} \mathrm{Prednisolon} \mathrm{oder} 0,15 \mathrm{mg} / \mathrm{kgKG} \text { Dexamethason p.o. (bei ungünstiger oraler Applikations- } \\
\text { möglichkeit } 100 \mathrm{mg} \text { Prednisolon oder Prednison Supp.) } \\
\text { Ab diesem Stadium in der Regel stationäre Aufnahme }\end{array}$ \\
\hline III & $\begin{array}{l}\text { Ruhe-Dyspnoe, deutliche } \\
\text { thorakale Einziehungen, } \\
\text { Blässe, Tachykardie } \\
>160 / \text { min }\end{array}$ & $\begin{array}{l}\text { Stets stationäre Aufnahme } \\
\text { Inhalation mit Adrenalin (s. o.), ggf. Inhalation wiederholen } \\
2 \mathrm{mg} / \mathrm{kgKG} \text { Prednisolon oder 0,15 mg/kgKG Dexamethason p.o. oder i.v., ggf. Steroidgabe wiederholen } \\
\text { BGA und Überwachung des Blutdruckes }\end{array}$ \\
\hline IV & $\begin{array}{l}\text { Hochgradige Dyspnoe mit } \\
\text { zunehmender Ateminsuffi- } \\
\text { zienz, Zyanose, Erstickungs- } \\
\text { gefahr, Bradykardie, Somno- } \\
\text { lenz }\end{array}$ & $\begin{array}{l}\text { Intensivmedizinische Überwachung } \\
\text { Venöser Zugang, } \mathrm{O}_{2} \text {-Gabe, evtl. Sedierung } \\
\text { Ggf. Intubation, Tracheotomiebereitschaft } \\
\text { Inhalation mit Adrenalin (s. o.), ggf. Inhalation wiederholen } \\
0,6 \mathrm{mg} / \mathrm{kgKG} \text { Dexamethason oder } 2-5 \mathrm{mg} / \mathrm{kgKG} \text { Prednisolon i.v., ggf. Steroidgabe wiederholen }\end{array}$ \\
\hline
\end{tabular}

- Tab. 18.4 Differenzialdiagnosen der Epiglottitis mit zugehörigen Symptomen

Symptomkomplex

Mundgeruch, Halslymphknoten, Anginaanamnese

Schluckbeschwerden, reduzierter Allgemeinzustand, hohes Fieber, kloßige Sprache, Speicheln

Süßlicher Mundgeruch

Diphtherie (DiphtherieImpfung?)

Allergieanamnese

Glottisödem

Älteres Kind, Epiglottitissymptome, grobblasige Rasselgeräusche

Chronisch rezidivierender Verlauf Bellender Husten

Tracheitis mit Pus

Fremdkörper im Larynx, Reflux Pseudokrupp

(C) Cave

Jede Manipulation oder Inspektion ohne Intubations- und Narkosebereitschaft ist strikt zu unterlassen! Das Kind muss mit ärztlicher Begleitung unter dauernder $\mathrm{O}_{2}$-Gabe in die Klinik eingewiesen werden.

Die Epiglottitis ist viel seltener als die stenosierende Laryngotracheitis; wegen der Bedrohlichkeit darf die Diagnose jedoch nicht verpasst werden.

\section{- Therapie und Prognose}

Die Inspektion des Rachens darf nur von einem erfahrenen Intensivmediziner in Intubationsbereitschaft erfolgen. Eine unkontrollierte Racheninspektion kann zu einer kritischen Atemwegsobstruktion führen.

Neben der Sicherung der Atemwege ist eine i.v.-Antibiose meist mit einem Cephalosporin über 4-7 Tage indiziert.
Bei rechtzeitiger Therapie ist die Prognose sehr gut. Die Immunisierung gegen $\mathrm{HiB}$ im Rahmen des Grundimmunisierungsprogramms ist die beste Prophylaxe. Rezidive sind selten. Die Krankheit kann auch im Erwachsenenalter (sehr viel seltener) auftreten.

\subsubsection{Akute Bronchitis}

\section{- Definition}

Die akute Bronchitis ist eine Erkrankung der Bronchialmukosa mit einer Symptomdauer von weniger als 4-6 Wochen.

\section{- Pathogenese}

Überwiegend findet eine primäre Infektion mit Viren (>90\%), seltener mit Bakterien statt; letztere wird häufiger im Rahmen von Grunderkrankungen beobachtet. Toxische akute Bronchitis, z. B. nach Exposition von Rauch in Brandherden, ist anamnestisch einfach zu erfassen.

\section{- Pathophysiologie}

Die Grundlage bildet eine Entzündung mit Schwellung der Mukosa, Abschilferung und Zerstörung des Bronchialepithels, Hypersekretion der Becherzellen, interstitiellem Ödem sowie leukozytärer und lymphozytärer Infiltration des Stromas.

- Klinik

Eine akute banale Bronchitis sieht man meist im Zusammenhang mit einem viralen Infekt der oberen und mittleren Atemwege. Die häufigsten Erreger sind RSV, Adeno-, Rhino-, Influenza- und Parainfluenzaviren. Husten ist das vorherrschende Symptom, meist in Kombination mit seröser Rhinitis und leichtem Fieber. Der Husten ist zunächst eher trocken und löst sich dann in einer Phase von Hypersekretion (feuchter Husten). Das Allgemeinbefinden ist nur wenig beeinträchtigt, die Dauer der Erkrankung beträgt in der Regel 7-14 Tage. 


\section{- Diagnose}

Diese ist anhand der Klinik und Anamnese einfach. Der Rachenraum kann etwas gerötet sein, über den Lungenfeldern hört man mittel- bis grobblasige Rasselgeräusche. Weitergehende Untersuchungen erübrigen sich.

\section{- Differenzialdiagnose}

In der Differenzialdiagnose muss an die beginnende, protrahiert chronisch verlaufende Bronchitis, das Asthma, die toxische akute Bronchitis nach Inhalation von Gasen oder Flüssigkeit (Aspiration), eine Fremdkörperaspiration oder auch an eine Pertussiserkrankung gedacht werden.

\section{- Therapie, Prognose}

Diese ist meist symptomatisch und besteht aus fiebersenkenden Maßnahmen, ausreichender Flüssigkeitszufuhr und Inhalation von isotoner Kochsalzlösung ggf. unter Zusatz von $\beta$-Sympatomimetika. Antitussiva sollten nicht eingesetzt werden. Antihistaminika sind nicht indiziert, für Mukolytika gibt es nur für wenige pflanzliche und synthetische Substanzen eine Wirksamkeitsevidenz. Bei Verdacht auf bakterielle Superinfektion kann eine antibiotische Therapie in Einzelfällen gerechtfertigt sein.

Die Prognose ist bei unkompliziertem Verlauf sehr gut. Ein Übergang in eine chronisch verlaufende Bronchitis ist möglich (z. B. bei weiterbestehender Irritation und Rauchen). Die Entstehung von Bronchiektasien nach akuter unkomplizierter Bronchitis wird kaum beobachtet.

\subsubsection{Chronische Bronchitis}

Der bakterielle Superinfekt als Komplikation bei akuter viraler Bronchitis kann Ursache einer prolongierten Bronchitis mit Übergang in ein chronisches Stadium sein.

8 Von chronischer Bronchitis spricht man dann, wenn die Symptome der Bronchitis, v. a. Husten und Auswurf, über mehr als 3 Monate anhalten.

\section{- Epidemiologie}

Chronische Bronchitis sehen wir im Kindesalter v. a. bei ständiger Exposition von Luftschadstoffen (v. a. Zigarettenrauch). Eine chronische Bronchitis kann aber Zeichen einer anderen zugrunde liegenden Krankheit sein und bedarf daher immer der erweiterten diagnostischen Abklärung.

\section{- Pathophysiologie}

Das durch die Wegbereiter (Viren, toxische Substanzen, Allergene) verletzte Bronchialepithel kann die lokalen Abwehrmechanismen wie Zilienschlag und Immunabwehr (z. B. sekretorisches IgA) nicht aufrechterhalten. Es erfolgt eine bakterielle Invasion mit leukozytärem Infiltrat, Ödem und Hypersekretion und Bildung von fibrinösen Ablagerungen. Dabei kommen v. a. Staphylokokken, Pneumokokken, HiB und Moraxella catharralis infrage Die Reparation erfolgt über Fibroblasten, was zu einer signifikanten Narbenbildung führen kann. Der Aufbau des Bronchialepithels mit zilienschlagenden Zellen ist damit beeinträchtigt, ein Circulus vitiosus beginnt.

\section{- Klinik}

Der chronische, meist gegen Morgen akzentuierte, $\mathrm{z}$. T. auch anfallsartige Husten mit Schleimproduktion ist das vorherrschende Symptom. Das vorerst noch bestehende Fieber verschwindet nach einigen
Tagen, der Auswurf wird gelb, gelb-grün oder grün-bräunlich. Meist besteht wenig Atemnot. Über den Lungenfeldern auskultiert man grob- bis mittelblasige Rasselgeräusche, Giemen und Pfeifen. Akute Komplikationen können u. a. eine Pneumonie oder Pleuraerguss in Folge der Ausdehnung eines Infekts, Hämoptoe, Atelektasen, Pneumothorax oder eine akute Ateminsuffizienz sein.

\section{- Diagnose}

Diese beruht v. a. auf der Anamnese und der auffallenden Klinik des lange andauernden Hustens. Die radiologische Untersuchung ergibt meist Transparenzminderungen im Hilusbereich mit Doppelkonturen entlang der mittleren und größeren Bronchien („Peribronchitis“). Die erweiterte Diagnostik umfassen Blutbild, Blutsenkungsreaktion, CRP, Tuberkulinhauttest, Serumimmunglobulinbestimmung evtl. mit Subklassenbestimmung (Ausschluss Immundefekt), Bestimmung von Alpha-1-Antitrypsin, Schweißtest (Ausschluss CF) und ggf. Bronchoskopie und Schnittbildgebung (MRT oder CT der Lunge, Ausschluss Bronchiektasen, idiopathische Lungenfibrose, exogen allergische Alveolitis). Diese Analysen sind entsprechend der klinischanamnestischen Wahrscheinlichkeit in einem zeitlichen Stufenverfahren vorzunehmen. Eine Pertussisinfektion ist auszuschließen.

Das Entfernen von toxischen Quellen (Zigarettenrauch) oder Allergenen ist von entscheidender Bedeutung.

Bei fehlender Grundkrankheit ist meist eine Antibiotikatherapie über 10-14 Tage, am besten entsprechend einem bakteriellen Antibiogramm aus dem Bronchialsekret (Auswurf, angehusteter Rachenabstrich) durchzuführen. In einzelnen Fällen kann auch eine längerfristige Antibiotikabehandlung notwendig sein. Eine Inhalationstherapie mit $\beta_{2}$-Agonisten oder Ipatropiumbromid in $\mathrm{NaCl}$ hilft meist, die Symptomatik zu lindern. Ohne klare Indikation ist die Verabreichung von inhalativen Steroiden sinnlos. Mukolytika sind von fraglicher Wirksamkeit.

\subsubsection{Bronchiolitis und obstruktive Bronchitis}

\section{- Definition}

Die Bronchiolitis ist eine Entzündung der Bronchiolen, die typischerweise im ersten Lebensjahr auftritt. Die obstruktive Bronchitis ist eine entzündliche Erkrankung der Schleimhäute der Bronchien mit z. T. erheblicher Schleimhautschwellung, Hypersekretion und mit unterschiedlich ausgeprägtem Bronchospasmus, der besonders im zweiten und dritten Lebensjahr bedeutsam ist.

Die Ursachen der Bronchiolitis und obstruktiven Bronchitis sind in über 90\% der Erkrankungen eine Virusinfektion. In den ersten 2-9 Monaten liegt der Bronchiolitis sehr häufig eine Infektion mit RS-Viren zu Grunde. Bei 2-3\% dieser Säuglinge kommt es zu einer besonders schweren Entzündung v. a. der kleinen Bronchien und Bronchiolen mit erheblicher Schleimhautschwellung und intraluminaler Zelldesquamation. Mit zunehmendem Alter spielen insbesondere Rhinoviren neben Parainfluenza Typ III, Adenoviren und selten Mykoplasmen als Erreger eine Rolle.

Die Übergänge zwischen obstruktiver Bronchitis und Bronchiolitis sind fließend. Eine Unterscheidung wird im deutschen (anders als im angloamerikanischen) Sprachraum aufgrund des klinischen Hauptbefunds getroffen:

- Bronchiolitis: Charakteristisches Knisterrasseln (feinblasiges Rasselgeräusch), das am Ende der Inspiration in den distalen, sekretgefüllten Atemwegen entsteht (crackles).

- Obstruktive Bronchitis: Überblähung und deutliches exspiratorisches Giemen („wheezing“). 


\section{- Pathogenese}

Wie der Terminus beschreibt, werden bei der Bronchiolitis v. a. die Bronchioli terminales betroffen. Immerhin können viral bedingte histologische Veränderungen auch in den größeren Bronchien und in der Trachea und nicht nur in den Bronchioli gesehen werden. Meist handelt es sich um lymphoplasmazelluläre Infiltrationen mit Bronchialnekrose, Zelldesquamation und Ödembildung.

( Kinder aus atopischen Familien scheinen für eine Bronchiolitis und obstruktive Bronchitiden anfälliger zu sein. Man nimmt an, dass eine Bronchiolitis und rezidivierende obstruktive Bronchitiden für späteres Asthma prädisponieren.

\section{- Klinik}

Das Krankheitsbild beginnt meist langsam als banaler Schnupfen über 2-3 Tage. Dann beherrschen zunehmende Atemnot, Dyspnoe, Tachypnoe, Husten, in- und exspiratorisches Stöhnen, inspiratorisch beobachtbare interkostale, subkostale und suprasternale Einziehungen, Nasenflügeln und wechselnde Zyanose das klinische Ausdrucksbild. Fieber kann vorhanden sein. Die Säuglinge können sich sehr rasch pulmonal erschöpfen und brauchen u. U. Atemhilfe inkl. Intubation. Durch die Anoxie des Gehirns kommt es unter Umständen zu einer Bewusstseinstrübung.

\section{- Komplikationen}

Akute Komplikationen sind v. a. durch die sich entwickelnde Ateminsuffizienz programmiert: Intubation, Beatmung, Pneumothorax, Herzinsuffizienz.

\section{- Diagnose}

Das klinische Bild, das Alter, der Zeitpunkt der Präsentation (Wintermonate) und die Anamnese sind wegweisend für die Diagnose. Es besteht eine deutliche Atemnot, auskultatorisch imponieren Giemen und verlängertes Exspirium z. T. mit Knisterrasseln, durch die Überblähung der Lungen wird häufig die Leber palpabel. Das Blutbild ist meist normal oder „viral“. Im Röntgenbild finden sich die auffallenden Zeichen der Lungenüberblähung (tief liegendes Zwerchfell, horizontal gestellte Rippen, interkostale Vorwölbungen), multiple kleinere subsegmentale Dys- oder Atelektasen und eine peribronchiale Strukturvermehrung. Die kompromittierte $\mathrm{O}_{2}$-Aufnahme wird durch Tachypnoe kompensiert und führt damit zu einem Absinken des kapillären $\mathrm{pCO}_{2}$. Steigt dieser an, muss an die beginnende globale Ateminsuffizienz gedacht werden.

\section{- Differenzialdiagnose}

Alle zu einer akuten Atemsymptomatik im Säuglingsalter führenden Ursachen können eine obstruktive Bronchitis/Bronchiolitis vortäuschen: erster Asthmaanfall, beginnende virale oder bakterielle Pneumonie, zystische Fibrose, Aspiration, Keuchhusten, Fremdkörperaspiration etc.

\section{- Therapie}

Säuglinge mit Zyanose, Tachydyspnoe ( $>60 / \mathrm{min}$ ), arteriellem (kapillärem) $\mathrm{pCO}_{2}>45 \mathrm{mmHg}$ oder $\mathrm{pO}_{2}<60 \mathrm{mmHg}$ unter Zimmerluft müssen dringend überwacht werden und brauchen vorerst angefeuchteten Sauerstoff. Dabei kann die perkutan gemessene $\mathrm{O}_{2}$ Sättigung (Pulsoxymetrie) als Orientierungshilfe ( $>92 \%$ als Grenze) gelten. Auf eine genügende Flüssigkeitszufuhr (Magensonde oder i.v.) und freie obere Atemwege (Nasentropfen, Nasenspülung) ist zu achten.

Bei der Bronchiolitis verschafft eine Inhalation mit Bronchodilatatoren meist wenig Linderung. Die Inhalation mit hypertoner
Kochsalzlösung (3-6\%) kann in Einzelfällen ebenso wie die Inhalation mit Adrenalin effektiv sein.

Für die obstruktive Bronchitis ist eine Inhalation mit Bronchodilatatoren (Betamimetika, Parasympatolytika) die Therapie der Wahl. Die Inhalation mit Steroiden ist sehr wahrscheinlich nicht entscheidend für den Verlauf. Die i.v.-Gabe von Steroiden ( $2 \mathrm{mg} / \mathrm{kgKG} /$ Tag Prednisolonäquivalent als Einzeldosis) hingegen lässt positive Effekte erwarten. Eine antivirale Therapie mit Ribavirin, Anti-RSV-Antikörpern etc. ist bedingt wirksam. Bei schweren Verlaufsformen kann die Anwendung einer Atemhilfe (z. B. CPAP, Highflow-Therapie) hilfreich sein.

Besonders gefährdete Säuglinge (z. B. Frühgeborene <28. SSW mit bronchopulmonaler Dysplasie) sollten in den Wintermonaten durch die passive Immunisierung mit einem RSV-AK (Palivizumab) geschützt werden.

\section{- Prognose}

Die meist selbstlimitierende Erkrankung dauert in der Regel 4-7 Tage; komplizieren können den Verlauf eine bakterielle Superinfektion oder die schwere Ateminsuffizienz mit der Notwendigkeit der Intubation und Beatmung.

\subsubsection{Rezidivierende Infekte der Atemwege - Infektanfälligkeit}

Wiederholte Atemwegserkrankungen sind im Kleinkindesalter sehr häufig. Im Praxisalltag stellt sich daher oft die Frage, ob bei einem Kind Häufigkeit und Schweregrad der Erkrankungen im Rahmen der „physiologischen Infektanfälligkeit“ liegen. Als „normal“ wird in den einzelnen Altersgruppen die in •Tab. 18.5 aufgeführte Infekthäufigkeit gesehen.

Berücksichtigt man zusätzlich, dass die meisten Virusinfektionen zu Schleimhautschäden führen, deren Ausheilung 4-6 Wochen dauert, so ergeben sich hieraus in der kalten Jahreszeit lange Krankheitsepisoden. Bei Kindern mit intensiven sozialen Kontakten (Gemeinschaftseinrichtung) ist zusätzlich die Reinfektionsgefahr groß. Mit diesen Informationen kann man die oft sehr besorgten und auch belasteten Eltern etwas beruhigen.

Umgekehrt sollten folgende Faktoren Anlass sein, über die Differenzialdiagnose eines Immundefekts nachzudenken: rezidivierende tiefe Haut- oder Organabszesse, eine persistierende Candidainfektion nach dem 1. Lebensjahr, eine Gedeihstörung oder eine positive Familienanamnese mit einem primären Immundefekt (unklare Todesfälle im Kleinkindesalter eingeschlossen). Weitere Verdachtsmomente sind:

- $\geq 8$ Otitiden/Jahr,

- $\geq 2$ Sinusitiden/Jahr,

- Tab. 18.5 Physiologische Infekthäufigkeit

\begin{tabular}{|l|l|l|l|}
\hline $\begin{array}{l}\text { Alter } \\
\text { (Jahre) }\end{array}$ & $\begin{array}{l}\text { Respiratorische } \\
\text { Infekte pro Jahr }\end{array}$ & $\begin{array}{l}\text { Standard- } \\
\text { abweichung }\end{array}$ & Maximum \\
\hline$<1$ & 6,1 & $\pm 2,6$ & 11,3 \\
\hline $1-2$ & 5,7 & $\pm 3,0$ & 11,7 \\
\hline $3-4$ & 4,7 & $\pm 2,9$ & 10,5 \\
\hline $5-9$ & 5,5 & $\pm 2,6$ & 8,7 \\
\hline $10-14$ & 2,7 & $\pm 2,2$ & 7,2 \\
\hline
\end{tabular}


- $\geq 2$ Majorinfektionen (Sepsis, Osteomyelitis, Meningitis, septische Arthritis, Empyem, Organabszesse),

- $\geq 2$ Pneumonien/Jahr,

- eine lange antibiotische Therapie (>2 Monate) ohne Effekt $(\triangleright$ Kap. 11).

( $)$ Der wichtigste Rat an die Eltern ist, einem Kind mit rezidivierenden Atemwegsinfektionen genügend Zeit zur Erholung zu lassen. Antibiotika sind nur in Ausnahmefällen indiziert.

\subsection{Akute und chronische Entzündung der Lunge}

M. Kopp, C. Vogelberg

\subsubsection{Pneumonie}

\section{- Definition}

Die Pneumonie ist definiert als eine Entzündung des Lungengewebes, die auf eine Infektion mit Krankheitserregern zurückgeht. Die meisten Pneumonien im Kindesalter, insbesondere in der Altersgruppe von 6 Monaten bis 3 Jahre, werden durch Viren (RSV, Parainfluenza-, Adeno-, und Influenza-Viren) verursacht. Bei den bakteriellen Pneumonien gibt es für die unterschiedlichen Altersgruppen ein charakteristisches Erregerspektrum (•Tab. 18.6).

\section{- Einteilung}

Neben den in • Tab. 18.6 aufgeführten Einteilungen nach Verlauf (akut/chronisch) oder Erreger (viral/bakteriell) berücksichtigt die pathologisch-anatomische Einteilung die Lokalisation. In • Abb. 18.3 sind klassische Befunde einer Bronchopneumonie, einer interstitiellen Pneumonie und einer Lobär- oder Segmentpneumonie dargestellt. Für das Säuglings- und Kleinkindesalter ist die Bronchopneumonie typisch, während ältere Kinder häufiger an einer meist durch Pneumokokken verursachten Lobär- oder Segmentpneumonie erkranken. Primär abszedierende Pneumonien werden oft durch S. aureus verursacht.

Schließlich wird eine primäre, meist ambulant erworbene Pneumonie, bei der ein gesundes Individuum erkrankt, von einer sekundären Pneumonie aufgrund eines Immundefekts oder einer Grundkrankheit (CF, PCD) unterschieden. Je nach Art der Grundkrankheit findet sich ein charakteristisches Keimmuster, z. B. bekapselte Erreger bei humoralen Immundefekten, und Pilze, Viren oder Parasiten (Pneumocystis jirovecii) bei T-Zelldefekten.

\section{- Epidemiologie}

Im Kindes- und Vorschulalter beträgt die Inzidenz ca. 40 Pneumonien/1.000 Kinder pro Jahr, im Schulkindesalter etwa 10-15 Pneumonien/1.000 Kinder pro Jahr.

Prädisponierende Erkrankungen für bakterielle Pneumonien sind u. a. eine gestörte mukoziliäre Clearance (CF, PCD), neuromuskuläre Erkrankungen sowie Herzfehler, bei denen ein Links-rechtsShunt mit vermehrter Lungendurchblutung besteht. Schließlich können virale Infektionen (Influenza, Masern) eine bakterielle Pneumonie bahnen.

\section{- Klinik}

Bei Neugeborenen und jungen Säuglingen stehen unspezifische Allgemeinsymptome im Vordergrund: $u$. a. Trinkunlust oder Trinkverweigerung, Erbrechen, Apathie, Temperaturinstabilität mit Hypothermie oder Fieber, kühle Akren oder ein geblähtes Abdomen.
- Tab. 18.6 Häufigste Erreger der Pneumonie im Kindesalter in den einzelnen Altersgruppen. (Mod. nach: DGPI-Handbuch, 4. Aufl.)

\begin{tabular}{|c|c|c|c|}
\hline & Viren & Bakterien & Pilze \\
\hline $\begin{array}{l}\text { Neugebore- } \\
\text { nenpneu- } \\
\text { monie }\end{array}$ & $\begin{array}{l}\text { RSV } \\
\text { Parainfluenza- } \\
\text { viren Adenovi- } \\
\text { ren } \\
\text { CMV, HSV, VZV }\end{array}$ & $\begin{array}{l}\text { B-Streptokokken } \\
\text { E. coli } \\
\text { Klebsiellen } \\
\text { L. monozytogenes } \\
\text { S. aureus } \\
\text { Chlamydia tracho- } \\
\text { matis }\end{array}$ & \\
\hline $\begin{array}{l}\text { Ambulant } \\
\text { erworbene } \\
\text { Pneumonie }\end{array}$ & $\begin{array}{l}\text { RSV } \\
\text { Parainfluenza-, } \\
\text { Influenzaviren } \\
\text { Adenoviren }\end{array}$ & $\begin{array}{l}\text { S. pneumoniae } \\
\text { H. influenzae } \\
\text { M. pneumoniae } \\
\text { B. pertussis }\end{array}$ & \\
\hline $\begin{array}{l}\text { Nosokomial } \\
\text { erworbene } \\
\text { Pneumonie }\end{array}$ & $\begin{array}{l}\text { RSV } \\
\text { Parainfluenza-, } \\
\text { Influenzaviren } \\
\text { Adenoviren } \\
\text { CMV, HSV, VZV }\end{array}$ & $\begin{array}{l}\text { E. coli } \\
\text { Klebsiellen } \\
\text { S. aureus } \\
\text { H. influenzae }\end{array}$ & $\begin{array}{l}\text { Candida } \\
\text { albicans } \\
\text { Aspergillus }\end{array}$ \\
\hline $\begin{array}{l}\text { Aspirations- } \\
\text { pneumonie }\end{array}$ & & $\begin{array}{l}\text { Gramnegative } \\
\text { Bakterien und } \\
\text { Anaerobier (z. B. } \\
\text { Bacteroides, Pep- } \\
\text { tostreptococcus) }\end{array}$ & \\
\hline $\begin{array}{l}\text { Pneumonie } \\
\text { bei Immun- } \\
\text { defizienz }\end{array}$ & $\begin{array}{l}\text { CMV, VZV, HSV, } \\
\text { HHV-6 }\end{array}$ & $\begin{array}{l}\text { S. aureus } \\
\text { P. aeruginosa } \\
\text { "Opportunisten" }\end{array}$ & $\begin{array}{l}\text { Candida } \\
\text { albicans } \\
\text { Aspergillus }\end{array}$ \\
\hline
\end{tabular}

Im Kleinkind- und Schulkindesalter ist die klinische Präsentation anders: $\mathrm{Zu}$ den Allgemeinsymptomen zählen in dieser Altersgruppe Fieber, z. T. mit Schüttelfrost, allgemeines Krankheitsgefühl, Unruhe, Brust- und/oder Bauchschmerzen. So kann z. B. eine basale Pneumonie mit Erguss von der Symptomatik wie eine akute Appendizitis imponieren.

Bei den organspezifischen Symptomen besteht in beiden Altersgruppen fast immer eine Tachypnoe, Dyspnoe (Nasenflügeln, juguläre und/oder interkostale Einziehungen), eine Tachykardie, Husten und ggf. eine Zyanose.

Der Auskultationsbefund kann bei zentralen Pneumonien unauffällig sein. Die klinischen Beschwerden gehen den radiologischen Veränderungen einige Tage voran.

\section{- Diagnose}

Körperliche Untersuchung Die Diagnose einer Pneumonie ergibt sich aus dem klinischen Befund. Neben den oben dargestellten Symptomen treten bei der körperlichen Untersuchung klassischerweise eine Tachypnoe, Dyspnoe sowie feinblasige, ohrnahe, hochfrequente Rasselgeräusche, ein abgeschwächtes Atemgeräusch und bei lobärem Befall eine Klopfschalldämpfung auf.

An eine Mykoplasmeninfektion muss bei begleitendem Exanthem, Krämpfen oder Bewusstseinstrübung sowie einer milder Begleithepatitis oder Arthritis gedacht werden. Umgekehrt ist bei Kindern unter 3 Jahren und einer Fieberdauer von $\leq 2$ Tagen eine Mykoplasmeninfektion sehr unwahrscheinlich.

Thoraxröntgenaufnahme Die Thoraxröntgenaufnahme im sagittalen Strahlengang ist nach wie vor der Goldstandard in der Diagnostik der Pneumonie. Eine Seitaufnahme ist nur in Ausnahmefällen 

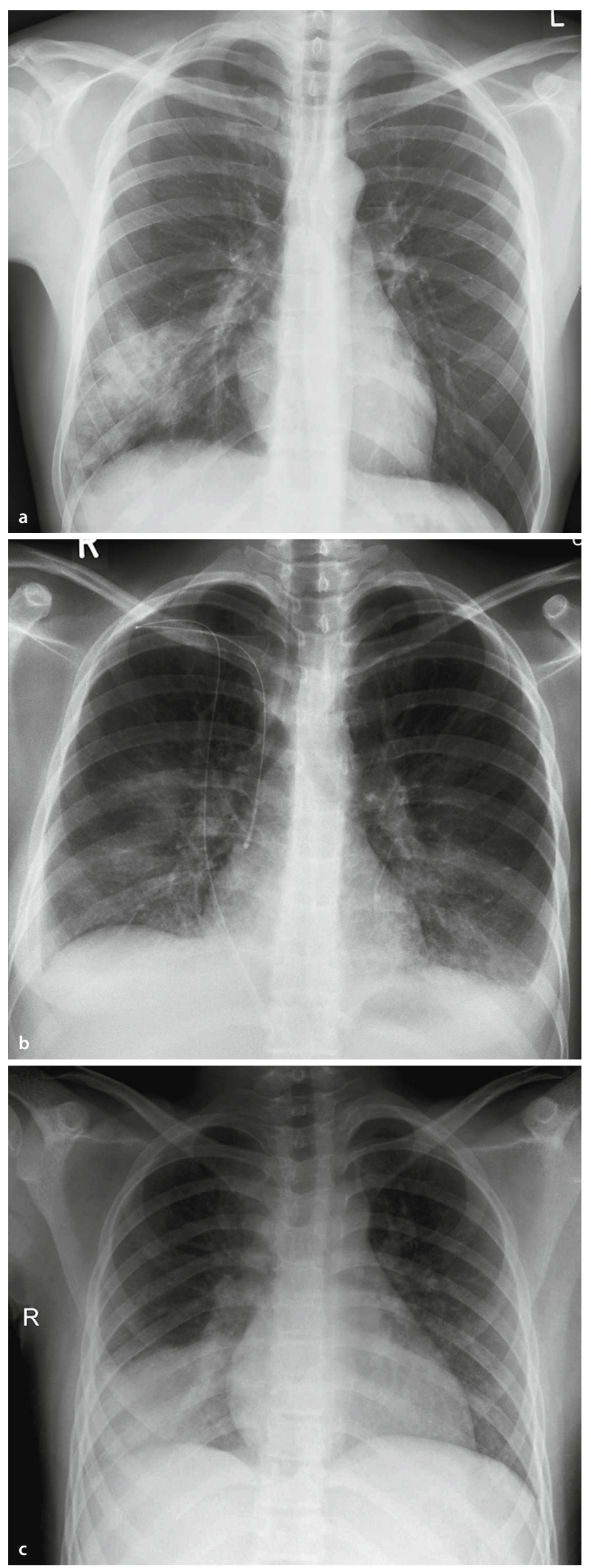

- Abb. 18.3 Radiologische Beispiele für Pneumonien. a Bronchopneumonie, $\mathbf{b}$ interstitielle Pneumonie, c Lobärpneumonie notwendig, wenn die Übersichtsaufnahme nicht ausreichend beurteilbar ist. Die radiologischen Veränderungen hinken der Klinik um einige Tage hinterher. Umgekehrt bilden sich die radiologischen Veränderungen erheblich langsamer zurück als die Beschwerden. Eine abschließende Röntgenkontrolle ist meist nicht indiziert. In den Fällen, in denen eine Kontrollaufnahme gemacht werden muss, sollte diese erst nach 4-6 Wochen erfolgen. Die verschiedenen radiologischen Charakteristika der Pneumonie sind in $\bullet$ Abb. 18.3 dargestellt.

Labor Im Blutbild findet sich je nach Ätiologie eine Leukozytose mit Linksverschiebung oder eine Lymphozytose. Die Blutsenkungsgeschwindigkeit und das CRP sind in der Regel erhöht. Weiterhin sind eine Blutkultur und eine kapilläre Blutgasanalyse abzunehmen.

Erregerdiagnostik Zum Nachweis einer bakteriellen Pneumonie kann neben der Blutkultur, die nur bei einem kleinen Teil der Patienten positiv ist, ein Rachenabstrich, ein Nasopharyngealsekret oder bei älteren Kindern auch ein induziertes Sputum gewonnen werden. Zum Erregernachweis kann bei viralen Pneumonien für RS-, Adenooder Influenzaviren der Antigennachweis aus dem Nasopharyngealsekret hilfreich sein. Die Polymerasekettenreaktion (PCR) als Genamplifikationsverfahren gewinnt in der molekularbiologischen Diagnostik v. a. für die Mikroorganismen an Bedeutung, die nur schwer oder gar nicht anzüchtbar sind, wie z. B. Mykoplasmen oder Aspergillen. Eine serologische Diagnostik ist meist wenig aussagekräftig. Bei allen persistierenden Verschattungen, bei Patienten mit zusätzlichen Symptomen (Gewichtsverlust, Nachtschweiß) muss eine Tuberkulose ausgeschlossen werden.

C Cave

Trockener, quälender Reizhusten und septisches Fieber müssen bei immunsupprimierten Kindern an eine Pneumocystisjirovecii-Pneumonie denken lassen.

\section{- Differenzialdiagnose}

Differenzialdiagnosen der bakteriellen Pneumonie sind zunächst virale bzw. durch Pilze verursachte Pneumonien. Nichtinfektiöse Ursachen, die radiologisch wie eine Pneumonie imponieren, lassen sich meist durch die Anamnese und Laborparameter von einer Pneumonie abgrenzen. Ursachen hierfür können u. a. sein:

- Fremdkörperaspiration,

- Atelektase,

- Asthma bronchiale,

- Inhalation toxischer Substanzen („Pneumonitis“),

- Raumforderungen (Thymus, Tumoren),

- interstitielle Lungenerkrankungen.

\section{- Therapie}

Stationäre versus ambulante Therapie Unkomplizierte Pneumonien können ambulant zu Hause behandelt werden. Die Indikation zu einer primären stationären Aufnahme ist in der Regel gegeben, wenn eines der folgenden Kriterien erfüllt ist:

- Säugling <6 Monate,

- unzureichende orale Aufnahme des Antibiotikums,

- deutliche Allgemeinbeeinträchtigung,

- Notwendigkeit von i.v.-Rehydratation oder $\mathrm{O}_{2}$-Zufuhr.

Indikation einer antibiotischen Therapie Die zweite Entscheidung betrifft die Indikation zu einer antibiotischen Therapie. Diese ergibt sich nicht allein aus dem Röntgenbild oder aufgrund von Entzündungswerten (z. B. CRP). In der Bewertung der vorliegenden 
Befunde spielt der klinische Gesamtzustand die entscheidende Rolle. So sprechen z. B. Giemen beim Kleinkind, eine begleitende seröse Rhinitis und/oder Konjunktivitis sowie ein unspezifisches Exanthem eher für virale Infektionen. Hochfieberhafte Erkrankungen mit allgemeinem Krankheitsgefühl, Einziehungen und Tachypnoe sprechen eher für eine bakterielle Infektion.

Auch der Nachweis von bakteriellen Erregern im Nasopharyngealsekret (Pneumokokken, $\mathrm{HiB}$, Moraxella catarrhalis) repräsentiert zunächst lediglich die vermehrte Kolonisation auf einem möglicherweise durch die Virusinfektion vorgeschädigten - respiratorischen Epithel und ist nicht per se als Hinweis auf eine bakterielle Genese zu bewerten.

Anhaltspunkte für eine kalkulierte antibiotische Therapie finden sich in - Tab. 18.7. Die Dauer der antibiotischen Therapie beträgt 7-10 Tage bzw. 5 Tage über Entfieberung hinaus, bei Mykoplasmenpneumonie 14 Tage.

Supportive Therapie Hierzu zählen folgende Maßnahmen:

- Gabe von angefeuchtetem Sauerstoff bei einer transkutanen Sättigung $<95 \%$,

- Antipyrese bei Fieber $>39^{\circ} \mathrm{C}$,

- reichlich Flüssigkeitszufuhr (1,5-mal den Tagesbedarf),

- rasche Mobilisierung, ggf. Physiotherapie,

- Inhalation mit $0,9 \% \mathrm{NaCl}$, oder bei Indikation mit $\beta_{2}$-Sympathomimetikum.

\section{- Komplikationen}

Der parapneumonische Erguss und das parapneumonische Empyem haben eine Inzidenz zwischen $0,5-5$ pro 100.000 Kinder. Die meisten parapneumonischen Ergüsse sind durch S. pneumoniae und S. aureus bedingt. Dabei wird zwischen einem Transsudat und einem Exsudat unterschieden ( $\downarrow$ Abschn. 18.12). Etwa $1 / 3$ der Kinder klagen über Thorax- und/oder Bauchschmerzen. Kleine Ergüsse können mit einer symptomatischen Therapie und durch Gabe von Antiphlogistika rein konservativ therapiert werden. Größere Ergüsse erfordern meist ein interdisziplinäres Vorgehen mit Punktion des Ergusses und ggf. thoraxchirurgischer Intervention. Die Prognose ist im Kindesalter gut, in der Regel haben die Kinder keine funktionellen Beeinträchtigungen.

\section{- Prognose}

Ambulant erworbene Pneumonien heilen bei einer adäquaten Therapie ohne Residuen aus. Während in Entwicklungsländern Pneumonien bei den Haupttodesursachen sind, liegt die Letalität in Deutschland weit unter $1 \%$.

\subsubsection{Asthma bronchiale}

\section{- Definition}

Asthma bronchiale ist definiert als eine chronisch entzündliche Erkrankung der Atemwege mit reversibler Obstruktion wechselnder Intensität ausgelöst durch unterschiedliche Stimuli auf dem Boden einer bronchialen Hyperreagibilität.

Vor diesem Hintergrund wird verständlich, dass für die Therapie v. a. inhalative Steoride eine zentrale Bedeutung haben und dass die Lungenfunktion in Ruhe oder im symptomfreien Intervall völlig unauffällig sein kann. Erst eine Provokationstestung führt bei diesen Patienten zu einer messbaren Verengung der Atemwege mit Abfall der Fluss-Volumen-Parameter, wodurch die als bronchiale Hyperreaktivität bezeichnete Überempfindlichkeit der Atemwegsschleimhaut quantifiziert werden kann.
- Tab. 18.7 Initialtherapie bei einer ambulant erworbenen, bakteriellen Pneumonie

\begin{tabular}{|l|l|l|}
\hline Altersstufe & \multicolumn{2}{|l|}{ Antibiotikum } \\
\hline Neugeborene 1-28 Tage & 1. Wahl & $\begin{array}{l}\text { Aminopenicillin \& } \\
\text { Aminoglykosid }\end{array}$ \\
\hline $\begin{array}{l}\text { Ambulant erworbene Pneumo- } \\
\text { nie bei Säuglingen 1.-3. Monat }\end{array}$ & 1. Wahl & Cefuroxim \\
\hline $\begin{array}{l}\text { Säuglinge ab 4. Monate bis } \\
\text { Kinder 9 Jahre }\end{array}$ & 1. Wahl & Ampicillin/Sulbactam \\
\hline Bei Verdacht auf atypische Pneumpicillin \\
\hline Kinder $>9$ Jahre & 2. Wahl & Cefuroxim \\
\hline Kinder $\leq 9$ Jahre & 1. Wahl & Ampicillin \\
\hline Bei Pleuraempyem oder abszendierender Pneumonie \\
\hline Kinder $>9$ Jahre & 2 Wahl & Doxycyclin \\
\hline & 1. Wahl & Doxycyclin \\
\hline Altersunabhängig & 2. Wahl & Erythromycin \\
\hline
\end{tabular}

Von einer Reversibilität der Obstruktion spricht man, wenn es nach Inhalation mit einem Bronchodilatator zu einer Verbesserung eines Obstruktionsparameters, z. B. der Ein-Sekunden-Kapazität $\mathrm{FEV}_{1}$ oder des Atemwegswiderstands kommt. Mit dem Definitionsmerkmal „reversible Obstruktion“ ist das Asthma bronchiale von anderen Atemwegserkrankungen differenzialdiagnostisch abzugrenzen, bei denen eine fixierte Verengung der Atemwege vorliegt.

Bei Kindern liegt bei etwa $85 \%$ eine allergische Mitbeteiligung vor. Die anamnestische Erfassung „exogener Stimuli“ beinhalten daher Fragen nach dem tageszeitlichen Höhepunkt der Beschwerden, saisonalen Schwankungen und der Haustierhaltung. Neben den Allergien spielen überwiegend virale Atemwegsinfektionen als Auslöser eine Rolle.

\section{- Epidemiologie}

Die Häufigkeit von Asthma bronchiale schwankt weltweit ganz erheblich zwischen $2 \%$ und $20 \%$. Sie ist besonders gering in Ländern mit niedrigem sozioökonomischem Lebensstandard. Es zeigt sich eine deutliche Abhängigkeit von Faktoren des „,westlichen Lebensstils“, sodass mit dessen Verbreitung in den letzten 40 Jahren auch eine Zunahme der Erkrankung zu verzeichnen ist. In Deutschland liegt die Asthmaprävalenz bei Kindern- und Jugendlichen etwa bei 8\%. Dabei sind bis zum Ende der Pubertät doppelt so viel Jungen wie Mädchen betroffen. Nach der Pubertät sind beide Geschlechter annähernd gleich betroffen.

\section{- Ätiologie}

Eine genetische Steuerung für das Auftreten des Asthma bronchiale ist wahrscheinlich. Dabei können 2 zumindest primär voneinander unabhängige Faktoren zur Erkrankung führen, die sich sekundär jedoch gegenseitig verstärken. Ein Faktor ist die bronchiale Hyperreaktivität, der andere die allergische Disposition (Atopie). Bis zu $16 \%$ aller Menschen (je nach Alter und Nachweismethode) lassen Hinweise für eine bronchiale Überempfindlichkeit erkennen. Allerdings nur die Hälfte dieser Personen erkrankt manifest. Im Rahmen 


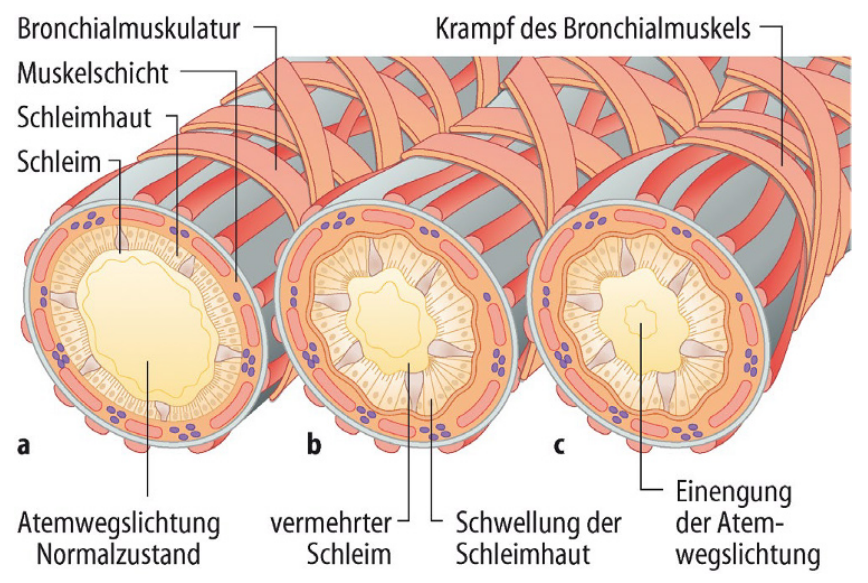

- Abb. 18.4 Pathogenese der Atemwegsobstruktion bei Asthma bronchiale

einer chronischen Entzündung der Bronchialschleimhaut kann die Hyperreaktivität auch neu erworben werden.

Die allergische Disposition in Form einer überschießenden Immunantwort des IgE-Systems (Typ-I-Allergie) ist ebenfalls genetisch verankert. Aber auch hier gilt, dass nur ein Teil der sensibilisierten, d. h. spezifisches-IgE-bildenden Individuen manifest erkrankt. Die familiäre und eigene Atopiebelastung scheint auch der entscheidende Faktor zu sein, ob aus einer obstruktiven Bronchitis im frühen Kindesalter („wheezy babys") ein Asthma bronchiale wird.

Asthma bronchiale wird heute zunehmend als ein Oberbegriff für eine reversible Atemwegsobstruktion mit ganz unterschiedlichen Auslösern, klinischen Verläufen und pathophysiologischen Veränderungen verstanden („Asthmasyndrom“).

\section{- Pathogenese, Pathophysiologie}

Die Atemnot eines Asthmapatienten kommt über eine Strömungsbehinderung durch Obstruktion in den Atemwegen zustande. Diese wird verursacht durch (• Abb. 18.4):

- Kontraktion der glatten Bronchialmuskulatur,

- Hyperämie, Ödem und entzündliche Infiltration der Schleimhaut,

- Verstopfung des Atemwegslumen durch Schleim (Hyperkrinie) und abgelöste Bronchialepithelzellen.

Basis der Obstruktion ist die bronchiale Hyperreaktivität, über die verschiedene Auslösungsfaktoren zur Wirkung kommen (• Abb. 18.5). Für den kindlichen Asthmatiker sind dabei von besonderer Bedeutung:

- Allergenkontakt (z. B. Pollen, Hausstaubmilben, Tierhaare),

- Infekte der Atemwege,

- körperliche Belastungen.

Durch diese Triggermechanismen kommt es zu einer Stimulation von intraepithelial gelegenen Mastzellen, Basophilen und alveolären Makrophagen, die über immunologische Prozesse (Brückenbildung zwischen 2 IgE-Antikörpern auf einer Mastzelle) oder rezeptorgesteuerte Mechanismen (adrenerg, cholinerg) Mediatoren freisetzen. Diese Mediatoren (z. B. Histamin) führen nach einem Allergenkontakt innerhalb von wenigen Minuten zu einer bronchialen Sofortreaktion unter dem Bild einer akuten Bronchialobstruktion (• Abb. 18.6).

Parallel zum Degranulationsvorgang der Mastzellen kommt es auch zur Neugenerierung von Lipidmediatoren, die in ihrer biologischen Wirkung die des Histamins um ein Vielfaches übertreffen und
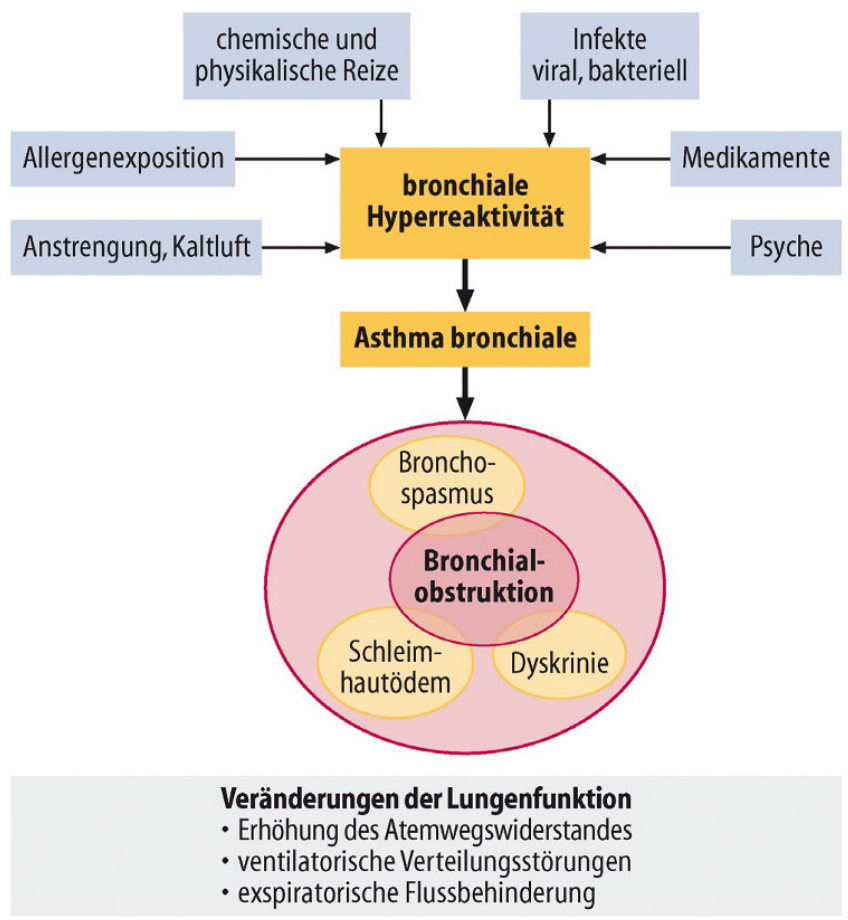

- Abb. 18.5 Auslösung und Pathophysiologie eines Asthmaanfalls
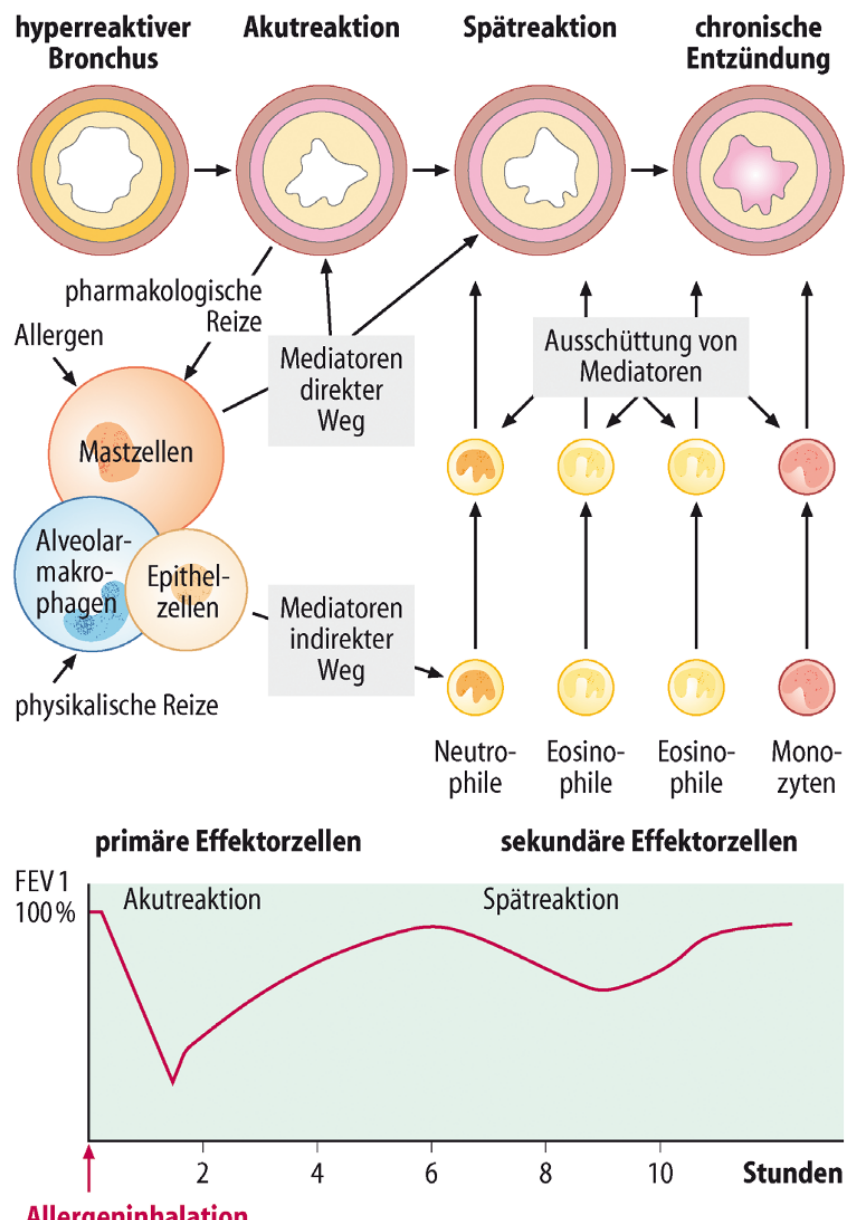

Allergeninhalation

- Abb. 18.6 Schematische Darstellung des Reaktionsablaufs einer asthmatischen Reaktion am Bronchus mit Akut- und Spätreaktion 
zu einer länger anhaltenden Bronchokonstriktion führen. Es sind dies insbesondere die Leukotriene $\mathrm{C}_{4}, \mathrm{D}_{4}, \mathrm{E}_{4}$ (= „slow reacting substance of anaphylaxis") sowie Prostaglandin $\mathrm{D}_{2}$ und der plättchenaktivierende Faktor (PAF). Gleichzeitig setzen Mastzellen und auch andere Zellen, wie Eosinophile, Makrophagen und Thrombozyten, chemotaktisch wirkende Mediatoren frei, die eine 2. Phase, nämlich die Spätreaktion einleiten.

Durch die chemotaktisch wirkenden Mediatoren - in erster Linie Leukotrien $\mathrm{B}_{4}$, neutrophiler-chemotaktischer Faktor (NCF), eosinophiler-chemotaktischer Faktor (ECF) und plättchenaktivierender Faktor (PAF) - werden Entzündungszellen, wie Neutrophile, Eosinophile und Makrophagen, angelockt. Sie wandern in die Bronchialschleimhaut ein, setzen eigene Mediatoren frei und halten dadurch den Entzündungsprozess aufrecht. Die chronische asthmatische Entzündung wird zu einem weiteren Anstieg der bronchialen Hyperreaktivität führen.

- Klinik

Die Leitsymptome sind anfallsartige, vorwiegend exspiratorische Atemnot mit Husten, Kurzatmigkeit und Giemen. Gelegentlich können anstrengungsinduzierte Beschwerden oder ein persistierender, oft nächtlicher Husten das einzige Symptom sein. Im klinischen Alltag begegnen uns dabei unterschiedliche Erscheinungsformen:

- rezidivierende Bronchitis,

- chronischer Husten,

- Asthmaanfall und

- Status asthmaticus.

Rezidivierende Bronchitis Die rezidivierende Bronchitis ist eine besondere Verlaufsform und häufig die erste klinische Asthmamanifestation bei jungen Kindern. Allerdings wird nicht aus jeder rezidivierenden (obstruktiven) Bronchitis in den 3 ersten Lebensjahren ein Bronchialasthma. Die relative Neigung zur Atemwegsobstruktion bei Infekten ist in dieser Altersgruppe vorwiegend durch anatomische und funktionelle Besonderheiten bedingt und verliert sich bei einem Großteil der Kinder wieder. Der Übergang in ein Asthma - bei 15-30\% zu beobachten - ist besonders zu erwarten bei familiärer Atopiebelastung, eigener Disposition (atopische Dermatitis, erhöhtes IgE und positive Allergietests in den ersten Lebensjahren) und über das 3./4. Lebensjahr hinaus anhaltenden Beschwerden.

Das klinische Erscheinungsbild ist gekennzeichnet durch eine Verlängerung des Exspiriums und, exspiratorische Atemnebengeräusche (Giemen, Brummen), die teilweise schon auf Distanz, auf jeden Fall aber bei der Auskultation des meist überblähten Thorax zu hören sind. Die Beeinträchtigung des Allgemeinbefindens kann sehr unterschiedlich sein und reicht vom „fröhlichen Giemer“ bis zum schwer kranken Kind.

Rezidivierender Husten An die Möglichkeit, dass ein anfallsweise auftretender, schwer stillbarer Reizhusten die alleinige klinische Erscheinungsform des Asthma bronchiale darstellen kann, wird nicht immer gedacht. Typischerweise tritt er dann in besonderen Situationen auf: nachts im Schlaf, bei körperlichen Belastungen, bei Wetter- oder Temperaturwechsel sowie bei Nebel und hoher Luftverschmutzung.

Asthmaanfall Der Asthmaanfall beginnt in der Regel ebenfalls mit Husten (die Kinder „husten sich in die Atemnot hinein") und ist v. a. durch eine plötzlich einsetzende und sich vielfach bis zur bedrohlichen Atemnot steigernde exspiratorische Dyspnoe gekennzeichnet. Die Patienten reduzieren ihre körperliche Aktivität und stützen oft zur Fixierung des Schultergürtels die Arme auf, um damit den Ein- satz der Atemhilfsmuskulatur zu ermöglichen (Orthopnoe). Der Thorax ist überbläht und die heftigen Atemanstrengungen führen zu Einziehungen (interkostal, jugulär, epigastrisch) bei der Einatmung. Die Kinder haben einen ängstlichen Gesichtsausdruck, sehen blass, im fortgeschrittenen Stadium zyanotisch aus. Auskultatorisch hört man ein raues, oft aber auch ein sehr leises und von Giemen überdecktes Vesikuläratmen. Zeitweise ist über einzelnen Lungenabschnitten das Atemgeräusch völlig aufgehoben, bedingt durch die regional unterschiedliche Ausprägung der bronchialen Obstruktion (ventilatorische Verteilungsstörung). Die Exspirationsphase ist verlängert. Pfeifende, giemende und brummende Geräusche können zu hören sein, sowie infolge der starken Überblähung der hypersonore bis tympanitische Klopfschall.

Status asthmaticus Der Status asthmaticus ist definiert als schwerer Anfall, der über mehr als $\mathbf{2 4} \mathbf{~ h}$ anhält und in dieser Zeit nicht auf adäquate Therapiemaßnahmen anspricht. Der Status asthmaticus ist ein intensivmedizinischer Notfall.

D Cave

Das Leiserwerden von Atem- und Nebengeräuschen im Rahmen eines schweren Asthmaanfalls ist ein Alarmsignal für die weitere Verschlechterung.

\section{- Komplikationen}

Durch den Einriss überblähter Alveolen kann es zum Pneumomediastinum und/oder Pneumothorax kommen. Gelegentlich bilden sich bei starker Schleimhautschwellung und Sekretverlegung auch Atelektasen aus. Bei einem chronischen Asthmaverlauf - insbesondere durch nicht ausreichende Therapie - bedingt die Flussbehinderung eine erhöhte Zwerchfellaktivität mit verstärktem Zug auf das Thoraxskelett (Glocken- oder Fassthorax).

\section{- Diagnose}

Zur Einschätzung eines akuten Asthmaanfalls sind erforderlich:

- kurze Anamnese (Asthmatyp?, Auslöser?, bisherige Therapie?, Einsatz von Betamimetika?),

- klinische Untersuchung (Tachy-/Dyspnoe?, Zyanose, seitengleiches Atemgeräusch?, endexspiratorisches Giemen?, transkutane Sättigung?),

- Bestimmung der Blutgase, des Blutbildes und CRP,

- Thoraxröntgenbild (Überblähung? Pneumothorax? Pneumonie? Fremdkörper?).

Die Basisdiagnostik bei Verdacht auf Asthma bronchiale sollte folgende Schritte enthalten:

- Differenzierte Anamnese: Bei der Anamnese sind drei Themenkomplexe zu erfragen:

- „Beeinträchtigung im Alltag“: Besteht nächtlicher Husten? Besteht morgendlicher Husten? Kann das Kind durchschlafen? Schnarcht das Kind nachts?

- „Beeinträchtigung bei körperlicher Anstrengung“: Besteht Husten bei Anstrengung? Muss das Kind beim Sport pausieren? Wie belastet sich das Kind beim Sport?

- „Umgebungsanamnese“: Wer ist in der Familie von atopischen Erkrankungen betroffen? Gibt es zu Hause Tiere? Besteht eine Passivrauchexposition? Wie oft werden Medikamente genommen ( $\beta_{2}$-Mimetika)? Gibt es Hinweise für das Vorliegen einer atopischen Dermatitis oder einer allergischen Rhinitis?

- Bei der körperlichen Untersuchung sollten auch die oberen Atemwege mit im Fokus sein. Hier ist z. B. auf die Behinderung 
der Nasenatmung bei Kindern mit allergischer Sensibilisierung gegen Hausstaubmilben, Tierhaare und Pollen zu achten.

- Lungenfunktionsprüfung zur Einschätzung der Obstruktion und Überblähung der Atemwege. Die Lungenfunktion bietet sich zur Überprüfung des Therapieerfolgs im Verlauf an. Die Reversibilität einer vorhandenen Obstruktion kann mit dem Bronchospasmolysetest (Inhalation eines schnell wirkenden $\beta_{2}$-Sympathomimetikums) geprüft werden. Ist die Lungenfunktion in Ruhe normal, kann das Verhalten der Werte nach einer Laufbelastung oder einer inhalativen Provokation mit Histamin oder Metacholin Auskunft über die bronchiale Reaktivität geben.

- Exhaliertes Stickstoffmonoxid zur Einschätzung der bronchialen Inflammation. Diese Methode macht aber nur bei einem allergischen Asthma Sinn und ist auch nicht bei jedem Patienten aussagekräftig.

- Allergologische Laboruntersuchungen: Sie umfasst Hauttestungen (Prick-, selten Intrakutantest), Serumuntersuchungen (spezifische IgE-Antikörper) sowie u. U. Provokationstests an bestimmten Organen (Auge, Nase, Bronchien). Dabei sollte möglichst klar werden, ob erkannte Sensibilisierungen auch klinisch bedeutsam sind.

- Röntgenuntersuchung: Röntgenaufnahmen von Thorax und Nasennebenhöhlen sind nur bei der initialen Untersuchung bzw. ganz konkreten Fragestellungen (z. B. Pneumothorax?) indiziert.

- Differenzialdiagnostische Untersuchungen: Schweißtest, Alpha-1-Antitrypsin, bei spezieller Fragestellung ggf. Immunglobuline mit Subklassen und Impfantikörper (Immundefekt).

\section{- Differenzialdiagnose}

- Chronische Bronchitis, Bronchiolitis obliterans,

- exogen allergische Alveolitis,

- zystische Fibrose,

- primäre ziliäre Dyskinesie,

- Fremdkörperaspiration,

- rezidivierende Entzündungen bei Immundefekt,

- exogene Kompression der Atemwege (Lymphome, Lymphknoten, Gefäße),

- strukturelle Atemwegsdefekte (z. B. Bronchomalazie)

- funktionelle Atemstörungen (z. B. Stimmlippendysfunktion).

\section{- Therapie}

Um langfristig ein therapeutisches Bündnis mit den Patienten und den Eltern einzugehen, ist es wichtig, dass Asthma bronchiale als eine chronische Erkrankung der Atemwege verstanden wird. Eine kurzzeitige, rein symptomatische Therapie ist daher auf lange Sicht unwirksam.

Ziele der Asthmatherapie sind:

- Symptomfreiheit, ohne dass ein Notfallmedikament eingenommen werden muss (Betamimetikum),

- altersentsprechende Belastbarkeit,

- normale Lungenfunktion,

- keine notfallmäßigen Arztvorstellungen,

- keine Medikamentennebenwirkungen,

- normale psychische und psychosoziale Entwicklung Die Grundsätze der Therapie umfassen drei Säulen:

- Meidung von Triggerfaktoren,

- medikamentöse Therapie, bestehend aus - antiobstruktiver Bedarfsmedikation für den Notfall und

- antiinflammatorischer Basismedikation,

- spezifische Immuntherapie (SIT).
Meidung von Triggerfaktoren Bei Kindern mit einem allergischen Asthma ist die Allergenmeidung eine wichtige Therapiesäule. Bei einer Sensibilisierung gegen Katzen- oder Hundeepithelien sollte der Kontakt mit den entsprechenden Tieren vermieden werden. Eine Hausstaubmilbensanierung umfasst u. a. die Umhüllung der Matratze mit einem milbendichten Überzug und das Waschen von Kuscheltieren, Kissen und Decken alle 3-4 Monate sowie das wöchentliche Wechseln der Bettwäsche. Unspezifische Triggerfaktoren wie Tabakrauch sind ebenfalls zu meiden.

Medikamentöse Therapie Mit der medikamentösen Therapie werden 2 grundlegende Strategien verfolgt. Unabhängig vom Schweregrad der Erkrankung soll bei akut auftretenden Beschwerden eine schnelle und sichere Beseitigung der Bronchialobstruktion erzielt werden. Geeignet und empfohlen sind dafür kurz wirksame inhalative $\beta$-Mimetika (Bedarfsmedikation).

Die Dauermedikation (Basistherapie) besteht in der regelmäßigen Anwendung von Medikamenten mit dem Ziel, die asthmatische Entzündungsreaktion zu unterdrücken und dadurch langfristig eine Kontrolle der Symptome und einen günstigen Krankheitsverlauf zu erreichen. Beginn und Umfang der Basistherapie hängen vom Schweregrad der Erkrankung ab. Hier werden folgende Schweregrade unterschieden:

- Intermittierendem Asthma: Intermittierend Husten, leichte Atemnot, symptomfreies Intervall $>2$ Monate; Lungenfunktion: Nur intermittierend obstruktiv, Lungenfunktion dann oft noch normal. Im Intervall ohne pathologischen Befund).

- Geringgradig persistierendes Asthma: Intervall zwischen Episoden <2 Monate; Lungenfunktion nur episodisch obstruktiv.

- Mittelgradig persistierendes Asthma: An mehreren Tagen/ Woche und auch nächtliche Symptome; Lungenfunktion auch im Intervall obstruktiv.

- Schwergradig persitierendes Asthma: Anhaltende tägliche Symptome, häufig auch nachts; Lungenfunktion zeigt deutliche Obstruktion

Steuerungselement zur Intensivierung oder Reduzierung der Therapie ist dabei die erreichte Asthmakontrolle (• Abb. 18.7). Das Ausmaß der Asthmakontrolle soll in regelmäßigen Abständen etwa alle 3-6 Monate überprüft werden. Dabei soll festgehalten werden, ob die Therapieziele erreicht wurden und eine Anpassung der Therapie im Sinne einer Intensivierung oder Reduktion der Asthmamedikamente notwendig ist.

Ziel ist es, mit der geringstmöglichen Zahl von Asthmamedikamenten in der niedrigstmöglichen Dosis eine optimale Krankheitskontrolle zu erreichen.

Die Behandlung sollte auf der Stufe einsetzen, die dem augenblicklichen Schweregrad des Krankheitsbildes entspricht. Der entscheidende Schritt im Schema ist, ab Stufe 2 konsequent Entzündungshemmer einzusetzen. Dafür eignen sich in erster Linie niedrig dosierte inhalative Kortikosteroide. Deren Einsatz hat eine neue Qualität der Asthmatherapie eingeleitet. Um mögliche Nebenwirkungen (v. a. bei Dosierungen $>400 \mu \mathrm{g} / \mathrm{Tag}$ Beclometasonäquivalent) zu vermeiden bzw. frühzeitig zu erkennen, ist es erforderlich, folgende Grundsätze zu beachten:

- Anwendung 1- bis 2-mal pro Tag,

- Benutzung einer Vorschaltkammer (Spacer) bei Verwendung eines Dosieraerosols (• Abb. 18.8),

- Ausspülen des Mundes (oder Zähneputzen) nach der Inhalation,

- Kontrolle der jährlichen Wachstumsrate, 
- Abb. 18.7 Stufenschema zur Asthmakontrolle. ICS inhalative Kortikosteroide; LTRA Leukotrienantagonist; LABA langwirksames $\beta_{2}$-Sympathomimetikum; LAMA langwirksames Anticholinergikum; OCS orale Kortikosteroide; $N W$ Nebenwirkungen; SABA kurzwirksames $\beta_{2}$-Sympathomimetikum

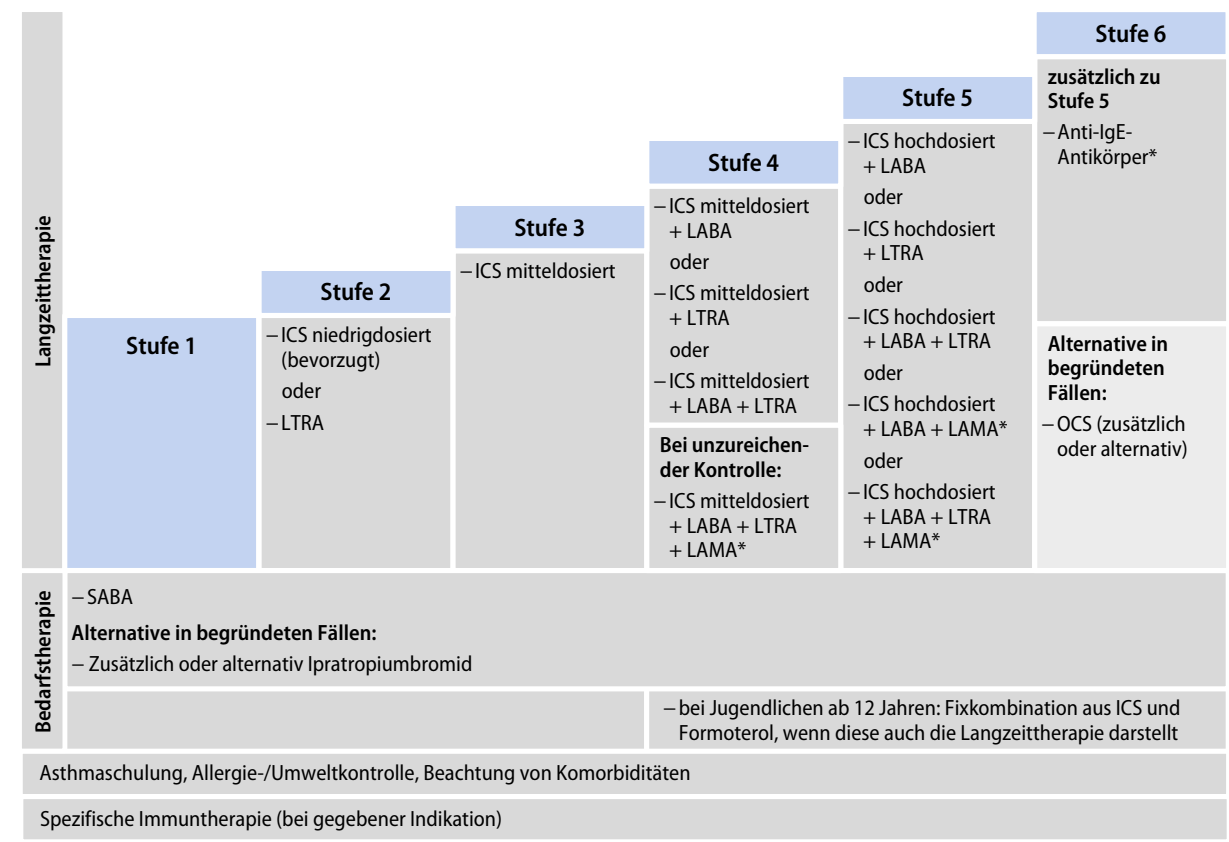

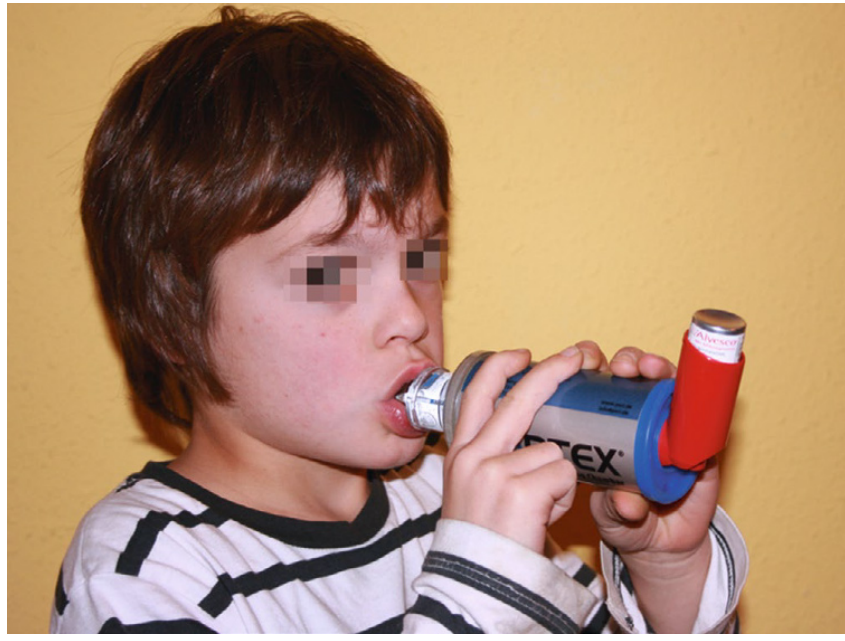

- Abb. 18.8 Inhalation mittels Dosieraerosol und großvolumiger Vorratskammer (Spacer) zur Überbrückung der Koordinationsschwierigkeiten bei der Inhalation. Das in die Vorratskammer versprühte Medikament wird mit einigen tiefen Atemzügen von dort aus inhaliert

- Einhaltung der niedrigsten, noch wirksamen Dosis (•Tab. 18.8), - regelmäßige Schulung des Patienten für das verwendete Inhalationsdevice.

Auch ein primärer Therapieversuch mit dem Leukotrienantagonisten Montelukast ist v. a. bei Kindern möglich, sollte aber nach 4-8 Wochen hinsichtlich seiner Effektivität kritisch beurteilt werden. Bei ungenügendem Therapieerfolg muss dann auf ein inhalierbares Kortikosteroid umgestellt werden.

Wurde dieses primär eingesetzt und wird darunter keine adäquate Kontrolle erreicht bzw. lag gleich ein höherer Schweregrad vor, können zusätzlich lang wirkende $\beta_{2}$-Sympathomimetika (LABA), langwirksame Anticholinergika (LAMA) und/oder Leukotrienantagonisten (Montelukast) gegeben werden, bevor die Dosis des topischen Steroids weiter angehoben wird. Orale Steroide als Dauertherapie (Stufe 5) sind als letzte Option zu betrachten und

\begin{tabular}{|l|l|l|l|}
\hline $\begin{array}{l}\text { - Tab. 18.8 } \\
\text { dosis in } \mu \mathrm{g} \text { ) }\end{array}$ & \multicolumn{3}{|c|}{ Dosisbereich inhalativer Kortikoide für Kinder (Tages- } \\
\hline Wirkstoff & $\begin{array}{l}\text { Niedrige } \\
\text { Dosis }\end{array}$ & $\begin{array}{l}\text { Mittlere } \\
\text { Dosis }\end{array}$ & Hohe Dosis \\
\hline Beclometasonpulver & $<400$ & 400 & $>400$ \\
\hline Beclometason-HFA & $<200$ & 200 (löslich) & $>200$ \\
\hline Budesonid & $<400$ & 400 & $>400$ \\
\hline Fluticason & $<200$ & 200 & $>200$ \\
\hline
\end{tabular}

beim kindlichen Asthma glücklicherweise nur noch extrem selten erforderlich. Seit einigen Jahren ist ein monoklonaler Anti-IgE-Antikörper (Omalizumab) für die Therapie des schweren allergischen Asthma bronchiale (Stufe 6) ab 6 Jahren zugelassen. Dieses hochwirksame Therapieprinzip reduziert die Anzahl der Asthmaexazerbationen und den Bedarf von Steroiden.

Bei der zu bevorzugenden inhalativen Applikation der Asthmamedikamente müssen in Abhängigkeit von Alter und Kooperationsbereitschaft der einzelnen Patienten geeignete Inhalationssysteme ausgesucht werden. - Tab. 18.9 gibt dazu einen Überblick.

$>$ Die Inhalationstechnik des Patienten muss kontinuierlich überprüft werden.

Kausale Therapieoption Die spezifische Immuntherapie (Hyposensibilisierung, „Allergieimpfung“) ist die einzige kausale Behandlungsmöglichkeit bei einem allergischen Asthma. Die spezifische Hyposensibilisierung ist dann indiziert, wenn ein als krankheitsauslösend erkanntes Allergen nicht gemieden werden kann und die übliche Therapie einen ungenügenden Therapieerfolg zeigt. Sie kann auch erwogen werden, wenn eine „Etagenerweiterung“ (z. B. Entwicklung eines Asthmas aus einer allergischen Rhinitis) oder mögliche Sensibilisierungen durch weitere Allergene vermieden werden sollen. Geeignete Allergene sind in erster Linie Pollen (Gräser, Roggen Birke etc.) und Hausstaubmilben. Die Wirksamkeit jedes einge- 
- Tab. 18.9 Altersentsprechende Auswahl der Inhalationssysteme

\begin{tabular}{|l|l|l|l|}
\hline Alter [Jahre] & Inhalationssystem & Akutbehandlung & Dauerbehandlung \\
\hline$<2$ & $\begin{array}{l}\text { Düsenvernebler mit Kompressor } \\
\text { Dosieraerosol (DA) mit Spacer und Maske }\end{array}$ & $\begin{array}{l}\text { Fenoterol } \\
\text { Salbutamol }\end{array}$ & Inhalierbare Steroide \\
\hline $2-4$ & $\begin{array}{l}\text { DA mit Spacer } \\
\text { Düsenvernebler mit Kompressor }\end{array}$ & $\begin{array}{l}\text { Terbutalin } \\
\text { Ipratropiumbromid }\end{array}$ \\
\hline$>4$ & $\begin{array}{l}\text { DA mit Spacer } \\
\text { Pulverinhalatoren (meist ab Schulalter) } \\
\text { Düsenvernebler mit Kompressor (bestimmte Indikationen, z. B. Exazerbation) }\end{array}$ & $\begin{array}{l}\text { Inhalierbare Steroide und } \\
\text { langwirkende } \beta_{2} \text {-Sympa- } \\
\text { thomimetika }\end{array}$ \\
\hline
\end{tabular}

- Tab. 18.10 Therapie des akuten Asthmaanfalls

Symptome

\section{Mittelschwerer Anfall}

Unvermögen einen längeren Satz während eines Atemzugs zu vollenden, Gebrauch der akzessorischen Atemmuskulatur, Atemfrequenz $<30 / \mathrm{min}$, Herzfrequenz $<120 / \mathrm{min}$

\section{Schwerer Anfall}

Unvermögen zu sprechen oder Nahrung aufzunehmen, sitzende Haltung, Arme seitlich abgestützt Atemfrequenz über 5 Jahre: $>30 / \mathrm{min}, 2-5$ Jahre $>40 / \mathrm{min}$ Herzfrequenz über 5 Jahre $>120 / \mathrm{min}, 2-5$ Jahre $>130 / \mathrm{min}$ $\mathrm{S}_{\mathrm{a}} \mathrm{O}_{2}<90 \%$ unter Raumluft
Therapie

2-4 Hübe eines kurzwirksamen $\beta_{2}$-Sympatomimetikums (z. B. Salbutamol), max. alle $10 \mathrm{~min}$, evtl. 2-3 I/min Sauerstoff über Maske oder Nasensonde (Ziel $\mathrm{S}_{\mathrm{a}} \mathrm{O}_{2}$ $>92 \%$ ), evtl. 1-2 mg/kgKG Prednisolon oral

2-4 Hübe eines kurzwirksamen $\beta_{2}$-Sympatomimetikums (Salbutamol), max. alle $10 \mathrm{~min}, 2-3 \mathrm{l} / \mathrm{min}$ Sauerstoff über Maske oder Nasensonde, 1-2 mg/kgKG Prednisolon oral oder i.v. (evtl. mit höherer Dosis rektal)

Ggf. muss diese Therapie eskaliert werden und schließt dann eine parenterale Flüssigkeits- und Elektrolytzufuhr, sowie die i.v.-Gabe von Theophyllin und/oder eines $\beta_{2}$-Sympatominetikums mit ein

Bei mangelndem Ansprechen auf das $\beta_{2}$-Sympatominetikum kann wiederholt zusätzlich Ipratropiumbromid inhaliert werden setzten Präparats sollte im Rahmen von aussagekräftigen klinischen Studien ausreichend belegt sein.

Patientenschulung Ein wesentlicher Bestandteil der Behandlung ist die Asthmaschulung, bei der Patienten und Eltern handlungsrelevantes Wissen über die Krankheit und die zum Einsatz kommenden Medikamente vermittelt bekommen.

\section{Therapie des akuten Asthmaanfalles - Tab. 18.10.}

\section{- Prognose}

Die Prognose des Asthma bronchiale im Kindesalter gilt heute als gut. Todesfälle kommen sehr selten vor. Ein Großteil der Kinder und Jugendlichen (90\%) haben unter einer adäquaten Therapie ein kontrolliertes Asthma. Langzeitstudien zeigen, dass bei einem bedeutsamen Teil dieser Patienten jedoch nach dem 22. Lebensjahr erneut Beschwerden auftreten.

\subsubsection{Exogen-allergische Alveolitis}

\section{Vogelberg}

\section{- Definition}

Es handelt sich um eine seltene allergische Reaktion gegenüber organischen Stäuben, die zu einer nichtinfektiösen, immunologischen Entzündungsreaktion im Interstitium, an den terminalen Bronchioli und den Alveolen führt. In Abhängigkeit von Art und Ausmaß der
Allergenexposition verläuft die Erkrankung in akuten Schüben (z. B. jeweils nach dem Säubern eines Taubenschlags) oder chronisch (z. B. bei Dauereinwirkung von Schimmel im Haus). In beiden Fällen kommt es zu einer fortschreitenden Verschlechterung der Lungenfunktion, und der Übergang in eine Lungenfibrose ist möglich.

\section{- Klinik}

Bei Kindern verläuft die Erkrankung überwiegend schleichend mit zunehmender Leistungsminderung, Gewichtsverlust und anderen, uncharakteristischen Symptomen. Ferner treten Belastungsdyspnoe, Tachypnoe und Husten auf. Auskultatorisch hört man feinblasige Rasselgeräusche über den Unterfeldern. Die akute Verlaufsform mit Husten, Atemnot und Fieberanstieg 4-6 h nach Exposition ist bei stellt im Kindesalter eine Ausnahme dar.

\section{- Diagnose}

Bei der akuten Verlaufsform kommt es zu einer Leukozytose mit Linksverschiebung und einem Anstieg des CRP sowie der BSG. Die chronischen Formen gehen meist mit normalen Leukozytenzahlen einher. Von den Immunglobulinen ist insbesondere das IgG erhöht. Charakteristisch für die Krankheit ist die Bildung spezifischer Antikörper der Klassen IgG und teilweise IgA gegen das jeweilige Antigen. Wiederholt wurde das Fehlen von Antikörpern bei klinisch sicheren Fällen beschrieben. Trotz fehlender Antikörper kann also eine EAA vorliegen.

Die Lungenfunktionsprüfung ergibt bei der Mehrzahl der Kinder eine restriktive Ventilationsstörung mit Verminderung aller statischen Lungenvolumina (• Abb. 18.9). 

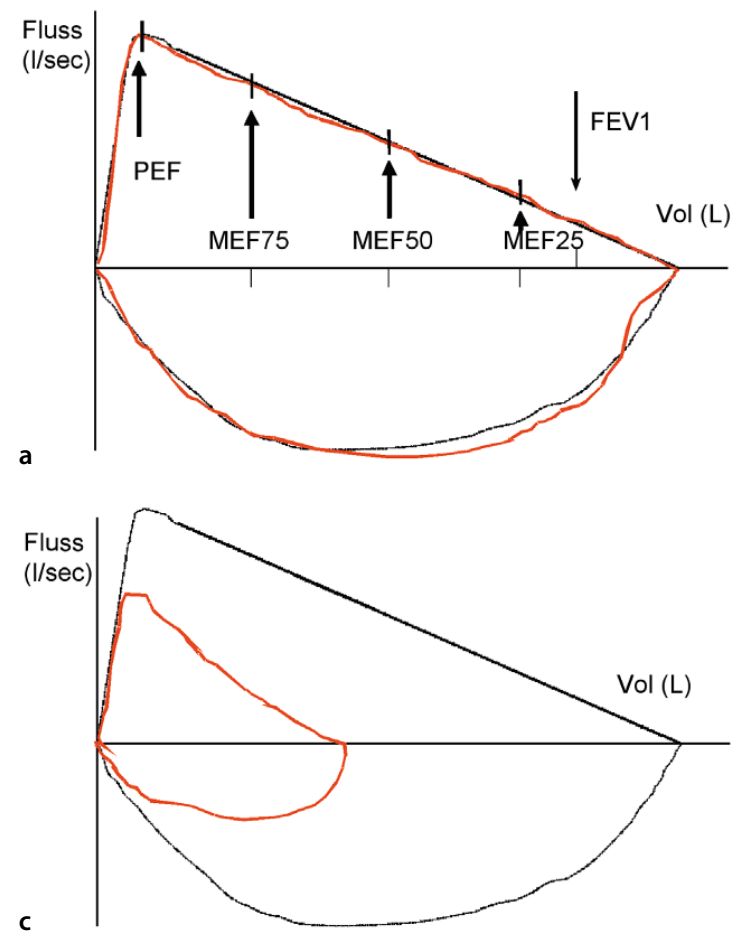

- Abb. 18.9 Lungenfunktionsprüfung. Die schwarze Kurve stellt den Sollwert dar. a Normale Fluss-Volumen-Kurve. Hier wird der Atemfluss in I/sec gegenüber dem Volumen aufgetragen. PEF exspiratorischer Spitzenfluss. MEF maximaler exspiratorischer Fluss, d. h. Atemwegsfluss, wenn noch 75\% (bzw. 50\%, 25\%) des Volumens auszuatmen sind. Der Parameter MEF 50\% wird in der Pädiatrie als Maß für die Obstruktion der kleinen Atemwege verwendet. FEV1 forciert ausgeatmetes Volumen in der ersten Sekunde: Maß für die globale Obstruktion der Atemwege. b Die rote Flussvolumenkurve

Im Rahmen der Quellensuche ist es bei Verdacht auf Auslösung der Erkrankung durch Kontakt mit Schimmelsporen sinnvoll, entsprechende Platten in der Wohnung des Patienten aufzustellen. Diese Messung sollte auch nach Sanierungsmaßnahmen wiederholt werden.

Konventionelle Röntgenaufnahmen (Thoraxübersicht) können das gesamte Spektrum interstitieller Muster zeigen, aber auch unauffällig sein.

Das hochauflösende CT (HR-CT) ist bei exogen-allergischer Alveolitis konventionellen Thoraxaufnahmen deutlich überlegen.

\section{- Differenzialdiagnose}

Interstitielle, atypische Pneumonien bei Infektionen mit Viren, Mykoplasmen, Chlamydien und Rickettsien können in ihrem Verlauf dem akuten Bild der EAA entsprechen. Die chronische Verlaufsform wird anfangs oft als rezidivierende Bronchitis oder grippale Infektion mit allgemeiner Leistungsminderung fehlgedeutet. Differenzialdiagnostisch beachtet werden müssen interstitielle Prozesse, die durch toxische Schädigung (Medikamente), im Rahmen systemischer Erkrankungen (z. B. Lupus erythematodes) oder aus bisher unbekannter Ursache (z. B. idiopathische Lungenfibrose) auftreten.

\section{- Therapie}

Die wichtigste therapeutische Maßnahme ist die Meidung des Allergenkontakts. Das kann schwieriger als erwartet sein, wenn die Allergenzufuhr indirekt und manchmal unbeeinflussbar weiter anhält. Tauben und Hühner in der Nachbarschaft, Vogelantigen im Teppichfußboden oder Schimmelpilze im Haus sind nicht immer im
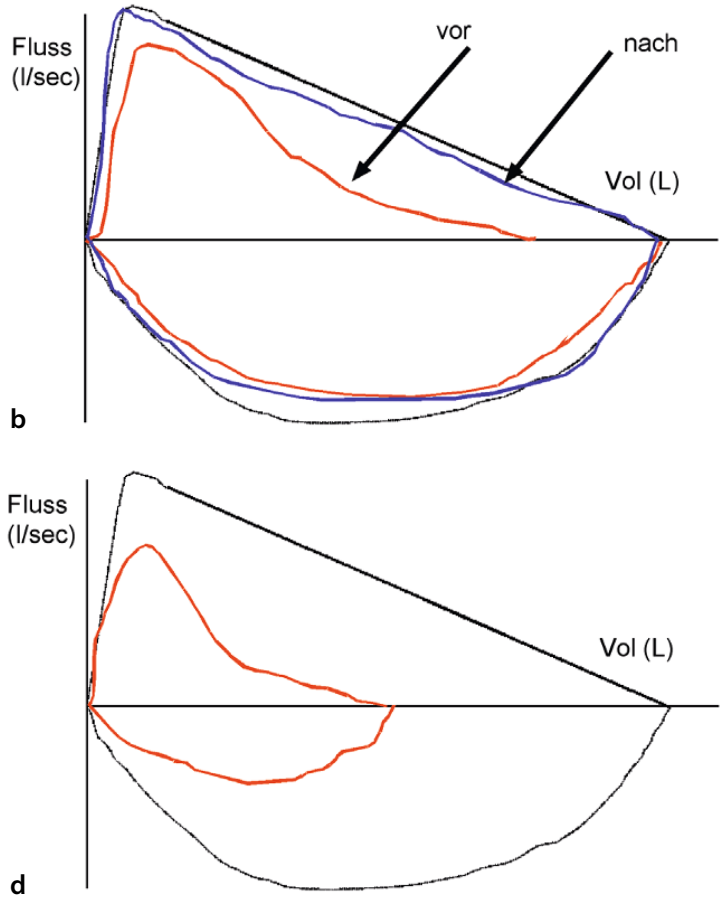

zeigt eine charakteristische obstruktive Ventilationsstörung. Nach Inhalation mit einem Betamimetikum ist die Obstruktion teilweise reversibel (blaue Kurve). c Die rote Flussvolumenkurve zeigt eine charakteristische restriktive Ventilationsstörung, z. B. im Rahmen einer exogen-allergischen Alveolitis. Als Parameter für die Erkennung der Restriktion dient die totale Lungenkapazität. d Die rote Flussvolumenkurve zeigt eine gemischte restriktive und obstruktive Ventilationsstörung, $z$. B. bei einer zystischen Fibrose

gewünschten Ausmaß zu entfernen. Durch eine systemische Therapie mit Kortikosteroiden (anfangs z. B. 2 mg Prednisolon/kgKG/ Tag) wird eine Abschwächung und Verkürzung der Symptomatik erreicht.

\section{- Prognose}

Die Prognose hängt entscheidend davon ab, ob die Diagnose rechtzeitig (vor einer möglichen Fibrosierung) gestellt wird und ob es gelingt, das Antigen konsequent auszuschalten.

\subsection{Bronchiolitis obliterans}

M. Kopp

- Definition

Unter einer Bronchiolitis obliterans versteht man die gemeinsame Endstrecke von Krankheitsprozessen, die mit einem irreversiblen Umbau der kleinen Atemwege einhergehen. Im Kindesalter sind folgende Auslöser beschrieben:

- parainfektiös (u. a. nach RSV, Influenza-, Parainfluenza- oder Adenoviren-, Mykoplasmeninfektionen),

- chronische Abstoßungsreaktion nach Lungentransplantation,

- Graft-versus-host-disease (GvHD) nach Knochenmarktransplantation,

- toxische oder irritative Auslöser: inhalative Noxen, Medikamente, Bestrahlung,

- Zustand nach Autoimmunreaktionen, 
- mit interstitiellen Lungenerkrankungen,

- rezidivierende Aspirationen z. B. im Rahmen eines Reflux.

8 Der Verdacht auf eine Bronchiolitis obliterans muss gestellt werden, wenn sich nach einer akuten Bronchitis/Bronchiolitis eine auf Bronchodilatatoren resistente fixierte Obstruktion mit $\mathrm{O}_{2}$-Abhängigkeit entwickelt.

\section{- Klinik und Diagnose}

Eine „nicht ausheilende obstruktive Bronchitis“ mit Beschwerden wie einem überwiegend expiratorisches Giemen („wheezing“), rascher Erschöpfbarkeit mit Anstrengungsdyspnoe und ggf. begleitender Zyanose oder $\mathrm{O}_{2}$-Bedarf können Ausdruck einer Bronchiolitis obliterans sein. Initial sind die Symptome oft unspezifisch. Der Verlauf der Erkrankung kann schleichend oder rasch progredient sein. Bei der klinischen Untersuchung können folgende Befunde auffallen: leises Atemgeräusch, obstruktiver Auskultationsbefund, Tachypnoe, Dyspnoe, verminderte transkutane $\mathrm{O}_{2}$-Sättigung. In der Lungenfunktionsprüfung zeigt sich eine Reduktion der exspiratorischen Flussraten, in der Blutgasanalyse sieht man eine Hypoxie und ggf. Hyperkapnie. In der konventionellen Thoraxröntgenaufnahme können Dys- oder Atelektasen oder eine Überblähung auffallen. Wegweisend ist ein Thorax-CT: Hier zeigt sich ein charakteristisches mosaikartiges Verteilungsmuster mit z. T. konsolidierten und z. T. überblähten Lungenarealen. Die definitive Diagnose kann mit Hilfe einer Lungenbiopsie erfolgen, die bei Kindern offenen erfolgen sollte.

Differenzialdiagnostisch kommen eine protrahierte bakterielle Superinfektion nach akuter Bronchiolitis sowie andere seltene chronische Lungenerkrankungen wie z. B. die idiopathische Lungenfibrose in Betracht.

\section{- Therapie}

Initial muss versucht werden, den Auslöser der Erkrankung zu identifizieren und ggf. zu beseitigen. Hierunter fallen v. a. die exogen ausgelösten Formen der Erkrankung (Medikamente, Noxen, Aspirationen). Meist wird nach Sicherung der Diagnose ein initialer Therapieversuch mit systemischen Steroiden (Prednison 2-4 mg/kgKG/ Tag) über 4-6 Wochen vorgenommen. Therapeutische Alternativen stellen z. B. der Einsatz von Cyclophosphamid oder Ciclosporin dar. Im Management der Bronchiolitis obliterans nach Lungentransplantation wird dem Makrolid Azithromycin eine therapeutische Wirkung zugeschrieben.

Die Prognose einer Bronchiolitis obliterans als Ausdruck einer chronischen Abstoßungsreaktion nach Lungentransplantation ist ernst. Günstiger sind Verläufe nach viral bedingter akuter Bronchiolitis.

\subsection{Bronchiektasen}

\section{Vogelberg}

\section{- Definition}

Bronchiektasen sind irreversible Erweiterungen der Bronchien, die entsprechend ihrer Morphologie als zylindrisch, sackförmig oder varikös beschrieben werden.

Sie sind von Bronchialdilatationen und der deformierenden Bronchitis (Wandunregelmäßigkeiten der Bronchien) abzugrenzen, da diese reversibel sein können. Ursache der Erweiterung ist eine angeborene (selten!) oder erworbene Destruktion der Bronchialwand, die mit einer chronischen Bronchitis und dem Verlust der
- Tab. 18.11 Ursachen für Sekretstau und Entzündung bei der Entstehung von Bronchiektasen

\begin{tabular}{|c|c|}
\hline $\begin{array}{l}\text { Angeborene } \\
\text { Erkrankungen } \\
\text { der Bronchial- } \\
\text { wand }\end{array}$ & $\begin{array}{l}\text { Bronchusstenosen/-malazien } \\
\text { Mukoviszidose } \\
\text { Kartagener-Syndrom/Syndrom der immotilen } \\
\text { Zilien }\end{array}$ \\
\hline $\begin{array}{l}\text { Erworbene Stö- } \\
\text { rungen der } \\
\text { Bronchialwand }\end{array}$ & $\begin{array}{l}\text { Pertussis, Masern } \\
\text { Infektion mit Adenoviren, Herpesviren, Myko- } \\
\text { plasmen, Aspergillus fumigatus }\end{array}$ \\
\hline $\begin{array}{l}\text { Erworbene Bron- } \\
\text { chusstenosen }\end{array}$ & $\begin{array}{l}\text { Tuberkulose } \\
\text { Fremdkörper } \\
\text { Tumoren }\end{array}$ \\
\hline $\begin{array}{l}\text { Andere Grund- } \\
\text { erkrankungen }\end{array}$ & $\begin{array}{l}\text { Asthma bronchiale (intrinsic) } \\
\text { Immundefekte } \\
\text { Persistierende Atelektasen } \\
\text { Intoxikationen (Lampenöl, Heroin) }\end{array}$ \\
\hline
\end{tabular}

bronchoziliären Clearance verbunden ist. Bronchiektasen können lokalisiert oder generalisiert auftreten.

\section{- Pathogenese}

Der wesentliche Grundmechanismus scheint das Wechselspiel zwischen Infektion und Obstruktion zu sein, wobei deren Ausgangspunkt auf unterschiedlichen Ebenen liegen kann (•Tab. 18.11). Beide Faktoren beeinflussen sich gegenseitig und münden schließlich in einen Circulus vitiosus mit chronischer Entzündung und Destruktion der Bronchialwand, exspiratorischem Kollaps, erhöhtem mechanischen Zug des Lungenparenchyms, Ausbildung von Atelektasen und Pneumonien. Im weiteren Verlauf kommt es zum peribronchialen fibrotischen Umbau mit Schrumpfung und Funktionsverlust der befallenen Lungenareale.

Angeborene Bronchiektasen sind sehr selten und scheinen im Rahmen einer Entwicklungsabnormalität mit zystischer Deformierung der Atemwege zu entstehen.

\section{- Klinik}

Bis auf einzelne Patienten mit symptomlosen Bronchiektasen sind folgende Symptome typisch:

- Husten (besonders morgens),

- Auswurf,

- giemende/pfeifende Atmung,

- Thoraxschmerz,

- Hämoptysis,

- Dyspnoe.

\section{- Diagnose}

Bei der klinischen Untersuchung findet man meist konstant Rasselgeräusche über der betroffenen Region, die auch nach Hustenmanövern nicht verschwinden. Bei ausgeprägten Bronchiektasen leiden Gewichts- und Größenentwicklung und es sind Zeichen der Hypoxämie (Zyanose, Uhrglasnägel, Trommelschlegelfinger) zu beobachten.

Die Thoraxübersichtsaufnahme trägt meist nur wenig zur Aufklärung bei. Eine vermehrte Streifenzeichnung und sog. Doppelkonturierungen (Darstellung der verdickten Bronchialwände) sind indirekte Hinweise. Der Nachweis von Bronchiektasen gelingt meist mit der HR-Computertomographie. 


\section{- Differenzialdiagnose}

Das Leitsymptom „chronisch produktiver Husten“ wird häufig als chronische Bronchitis gedeutet. Diese beruht im Kindesalter auf einer Grunderkrankung, nach der mit entsprechenden Methoden gefahndet werden muss.

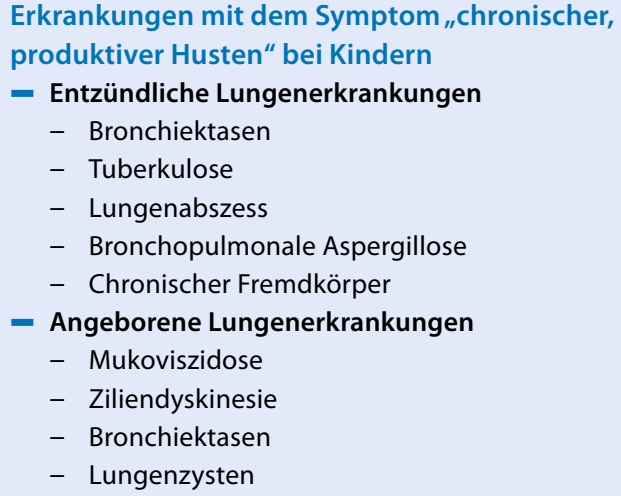

\section{- Therapie}

Bei lokalisierten, poststenotischen Prozessen (z. B. nach Fremdkörperaspiration) wird man sich schneller zu einer Segment- oder Lappenresektion entschließen, da die übrige Lunge in der Regel gesund ist.

Bei generalisierten Bronchiektasen ist eine konservative Therapie mit Sekretolytika, $\mathrm{NaCl}$ (auch hyperton) und $\beta$-Sympathomimetika angezeigt mit dem Ziel, die Bronchien möglichst frei von Sekret und bakteriellen Infektionen zu halten. Ebenso bedeutsam ist die kontinuierliche Durchführung einer Physiotherapie (autogene Drainage, Flutter, Vibrationsmassage).

Antibiotika sollten gezielt - nach Antibiogramm - oder kalkuliert bei akuten Exazerbationen eingesetzt werden. Vorliegende Grunderkrankungen müssen zusätzlich behandelt werden (z. B. Immundefekte).

\subsection{Interstitielle Lungenerkrankungen}

\section{Kopp}

\section{- Grundlagen}

Interstitielle Lungenerkrankungen fassen eine heterogene Gruppe von Lungenerkrankungen unterschiedlicher Ursachen zusammen, die im Kindesalter insgesamt jedoch selten sind. Gemeinsam ist diesen Erkrankungen eine Lungenfibrose im Endstadium. In der Übersicht sind die Erkrankungen mit interstitieller Lungenbeteiligung aufgeführt. Epidemiologische Daten über die exakte Prävalenz im Kindesalter fehlen.

Interstitielle Lungenerkrankungen (Erkrankungen mit interstitieller Beteiligung der Lunge)

- Idiopathische Formen

- Idiopathische, diffuse Lungenfibrose (Hamman-RichSyndrom)

- Idiopathische Lungenhämosiderose mit Lungenfibrose inkl. Herz- oder Nierenbeteiligung (Goodpasture-Syndrom)

- Interstitielle lymphoplasmazelluläre Pneumonie Liebow
- Begleitformen bei

- Allergischer Alveolitis (exogen allergische Alveolitis)

- Zystischer Fibrose

- Nach Lipidaspiration (Ölaspirationspneumonie)

- Sarkoidose

- Phakomatosen (tuberöse Hirnsklerose, Sturge-Weber)

- Xanthomatosen (Hand-Schüller-Christian, Gaucher, Niemann-Pick, Abt-Letterer-Siwe, Amyloidose)

- Kollagenosen/rheumatische Erkrankungen: Sklerodermien, LE, Periarteriitis nodosa, Dermatomyositis, rheumathoide Arthritis

- Pneumonien mit interstitieller Beteiligung: Viren (Masern, Varizellen, Zytomegalie, kong. Röteln), Mykoplasmen, Chlamydien, Toxoplasmose, Treponemen, Listerien

- Klinik

Akuter oder langsamer Beginn mit Dyspnoe, die v. a. bei Anstrengung zuerst auffällt, Husten, Schwächezustände, evtl. Fieber und Thoraxschmerzen herrschen vor. Dies sind zwar unspezifische Symptome, müssen aber in der Differenzialdiagnose an eine interstitielle Lungenerkrankung denken lassen, insbesondere bei länger andauernder und progredienter Symptomatik. In späteren Stadien besteht dann auch Sauerstoffbedarf, zuerst bei Belastung, dann auch in Ruhe.

\section{- Diagnose}

Die Diagnose wird durch Ausschluss häufigerer pulmonaler Erkrankungen gestellt. Wegweisend können neben der protrahierten Beschwerdesymptomatik Veränderungen im Thoraxröntgenbild sein. Charakteristisch sind hier eine interstitielle Zeichnungsvermehrung und später das Auftreten der „Wabenlunge“ („honey comb lung“). Spezifischer ist das Lungen-CT, das retikuläre Verdichtungen und zystische Aufhellungen zeigt.

In der Lungenfunktionsprüfung sind die Vital- und Totalkapazität sowie die Compliance deutlich vermindert.

Die Blutgasanalyse zeigt insbesondere nach Anstrengung einen verminderten $\mathrm{pO}_{2}$ mit metabolisch kompensierter respiratorischer Alkalose und initial tiefem $\mathrm{pCO}_{2}$. Im terminalen Krankheitsstadium kommt es zur Hyperkapnie.

Die definitive Diagnose wird an Hand des charakteristischen histologischen Befunds nach offener Lungenbiopsie gestellt.

\section{- Therapie und Prognose}

Therapie und Prognose richten sich nach der spezifischen Diagnose der diagnostizierten interstitiellen Lungenerkrankung.

\subsection{Systemkrankheiten mit Beteiligung der Lunge}

M. Kopp, C. Vogelberg

\subsubsection{Sarkoidose}

Bei der Sarkoidose handelt es sich um eine chronische, mehrere Organsysteme betreffende, granulomatöse Systemerkrankung unbekannter Ätiologie. Im Kleinkindalter sind v. a. Haut, Gelenke und Augen befallen, selten findet sich eine Lungenbeteiligung. Bei Adoleszenten und Erwachsene sind Lunge, Lymphknoten und Augen 

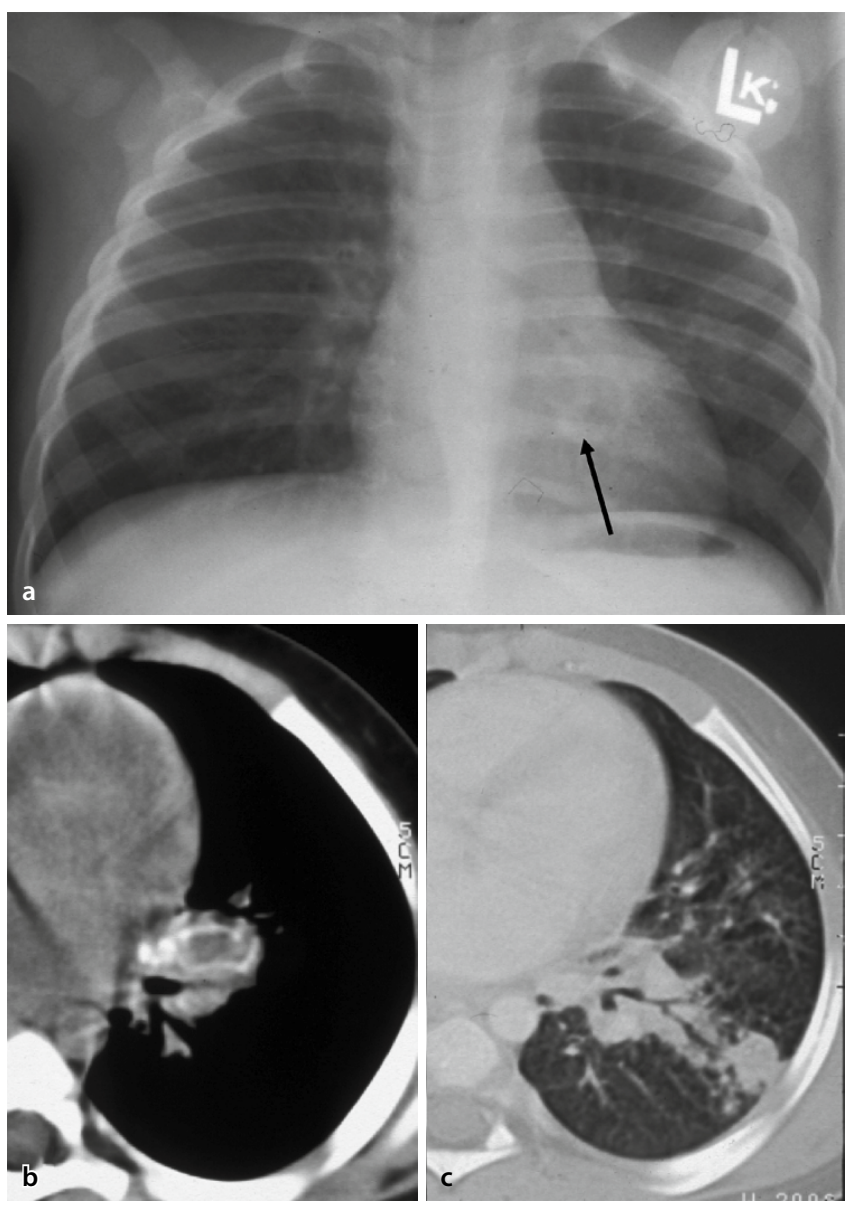

- Abb. 18.10 Hiläre Adenopathie mit Verkalkungen links bei Primärkomplex einer pulmonalen Tuberkulose. a Im Röntgenbild kaum sichtbar links retrokardial. b, c Im CT Nachweis von verkalkten Lymphknoten (b) und Primärherd (c) in linken Unterlappen

involviert. Eine kardiale Beteiligung ist wegen möglicher Reizleitungsstörungen besonders ernst zu nehmen. Die Inzidenz beträgt etwa 0,29/100.000 Personenjahre.

(.) Cave

Im Kleinkindesalter ist bei der Sarkoidose selten die Lunge betroffen. Wichtig ist es, frühzeitig eine mögliche kardiale Beteiligung zu erkennen (Rhythmusstörungen!).

\section{- Klinik}

Neben Allgemeinbeschwerden wie Müdigkeit, Abgeschlagenheit, Gewichtsverlust (45\%) und Fieber (35\%) sind organspezifische Beschwerden an der Lunge Husten, eine überwiegend restriktive Ventilationsstörung sowie ein charakteristisches Thoraxröntgenbild mit bilateraler hilärer Lymphknotenvergrößerung charakteristisch (• Abb. 18.10).

\subsubsection{Neuromuskuläre Erkrankungen und Ateminsuffizienz}

\section{- Definition}

Von respiratorischer Globalinsuffizienz spricht man, wenn $\mathrm{p}_{\mathrm{a}} \mathrm{O}_{2}$ erniedrigt und $\mathrm{p}_{\mathrm{a}} \mathrm{CO}_{2}$ erhöht ist. Bei einer Partialinsuffizienz findet sich eine Hypoxämie, aber noch keine Hyperkapnie.
- Tab. 18.12 Ursachen der Ateminsuffizienz

\begin{tabular}{|l|l|l|}
$\begin{array}{l}\text { Respiratorische } \\
\text { Kontrolle (Atemantrieb, } \\
\text { Ventilation) }\end{array}$ & $\begin{array}{l}\text { Mechanik } \\
\text { (Ventilation) } \\
\text { (Oxygenierung) }\end{array}$ \\
\hline $\begin{array}{l}\text { Intoxikationen (Medika- } \\
\text { mente) }\end{array}$ & Kyphoskoliose & Asthma \\
\hline ZNS-Läsion (Medulla) & Rippenserienfraktur & Pneumonie \\
\hline Adipositas (Apnoe) & Adipositas & Zystische Fibrose \\
\hline Metabolische Störungen & Poliomyelitis & $\begin{array}{l}\text { Interstitielle } \\
\text { Fibrose }\end{array}$ \\
\hline Schädel-Hirn-Trauma & Muskeldystrophien & Lungenödem \\
\hline Hirndruck (Tumoren) & $\begin{array}{l}\text { Guillain-Barré- } \\
\text { Syndrom }\end{array}$ & Aspiration \\
\hline Tetanus & (Para)tetraplegie & $\begin{array}{l}\text { Hyaline Membra- } \\
\text { nen, Ards }\end{array}$ \\
\hline & &
\end{tabular}

\section{- Ätiologie}

Eine Ateminsuffizienz kann bei fast allen krankhaften Zuständen vorkommen; sie kann auftreten wegen:

- des Versagens der respiratorischen Kontrolle (Atemantrieb und Ventilation),

- der Insuffizienz der Mechanik (Ventilation),

- der Beeinträchtigung der Lunge selbst (Oxygenierung).

Die häufigen Ursachen einer Ateminsuffizienz sind in • Tab. 18.12 aufgeführt.

\section{- Pathogenese, Pathophysiologie}

Allen Formen der Ateminsuffizienz ist terminal eine schwere alveoläre Hypoventilation gemeinsam. Diese entsteht entweder auf direktem Weg durch eine Lähmung der Atemmuskulatur oder durch eine zentrale Störung des Atemantriebs oder auf indirektem Weg über eine konsumierende Grundkrankheit mit progredienter Einschränkung der Funktion der Atemhilfsmuskulatur (z. B. bei schwerer Kyphoskoliose mit Atelektase und Belüftungsstörung).

Damit wird zwischen einer Hypoventilation mit mechanischer Behinderung oder mit neuromuskulärer Behinderung differenziert. Da die alveoläre Hypoventilation nicht schlagartig auftritt, sondern sich über Jahre entwickelt (z. B. bei Muskeldystrophie, Polio, Skoliosen etc.), kann sich der Körper an die sich langsam entwickelnde Hypoxämie und Hyperkapnie gewöhnen. Das Zusammenspiel von Atemkontrolle über die Chemorezeptoren und das Atemzentrum, die Aufrechterhaltung der Thoraxbeweglichkeit über die mechanische Pumpe (Muskeln, Zwerchfell, Skelett) und die Funktionstüchtigkeit des Gasaustauschapparats (Ventilation, Diffusion, Perfusion) sind komplex und von entscheidender Bedeutung zum Überleben. Nicht zu vergessen ist, dass sich fast immer auch eine Herzinsuffizienz einstellt, die mit der Ateminsuffizienz parallel entsteht.

\section{- Klinik}

Bei langsam sich einstellender Insuffizienz der Atmung sind zuerst v. a. bei Anstrengung Symptome zu erwarten, die sich in einem Leistungsabfall oder -knick, Müdigkeit, vermehrtem Schlafbedürfnis am Tag, Unruhe, Schwitzen, Zittern, Angstgefühl und Depression, Tachy- und Dyspnoe äußern. Später kommen Ruhedyspnoe, 
Gewichtsverlust, rezidivierende (Stress)ulzera des Magen-DarmKanals, Zyanose, Ödeme, Kopfschmerzen, Schwindelanfälle und Bewusstlosigkeit dazu.

D Cave

Jede Art einer akuten Komplikation, sei diese infektiöser, pulmonaler, kardialer oder neurogener Ursache, können für den Patienten lebensbedrohlich werden.

\section{- Diagnose}

Die Werte der Blutgase, evtl. tags und nachts, geben Auskunft über den Schweregrad der Hypoventilation.

Die Lungenfunktion kann Auskunft geben über die Restkapazität der Lunge, wobei v. a. die statischen Lungenvolumina interessieren.

Im EKG zeigen sich die Zeichen des Cor pulmonale, das Röntgenbild gibt z. B. Auskunft über das Ausmaß einer Minder- oder Unterbelüftung (Atelektasen, Infiltration).

\section{- Differenzialdiagnose}

Diese ist sehr breit und in - Tab. 18.12 in reduzierter Form dargestellt. Nicht eingeschlossen sind Formen der angeborenen und neonatalen Fehlbildungen, die schon sehr früh zur Ateminsuffizienz und zum Tod führen können.

\section{- Therapie}

Die therapeutischen Optionen orientieren sich an der Grunderkrankung. Generell ist die Sicherstellung der Atmung „per se“ mit Gabe von Sauerstoff, Atemhilfe mit Ventilation (Maskenbeatmung, Intubation) und Sicherstellung genügender O2-Träger (Erythrozyten) zu garantieren. Heute kommen verschiedene Methoden der Atemhilfe wie z. B. nasaler CPAP („,continuous positive airway pressure“), eine High-Flow-Therapie oder eine Heimbeatmung infrage.

\section{- Prognose}

Diese richtet sich nach der Grundkrankheit und deren Progression. Die akute Ateminsuffizienz z. B. als Folge eines Unfallgeschehens ist anders zu beurteilen als diejenige bei progressiver Muskeldystrophie, bei hoher Querschnittslähmung oder bei zystischer Fibrose.

\subsection{Aspiration}

M. Kopp

Aspiriert werden können Flüssigkeiten und Fremdkörper. Die Schwere der Beeinträchtigung der Lungenfunktion und damit auch des klinischen Zustandsbildes wird entscheidend geprägt durch:

- die Art des aspirierten Materials (z. B. Mageninhalt, infiziertes Fruchtwasser, Nahrung),

- die Menge, Größe und Beschaffenheit des aspirierten Materials (z. B. fest, flüssig, obstruierend),

- das Alter und eine eventuelle Vorschädigung des Kindes.

\subsubsection{Fremdkörperaspiration}

\section{- Definition}

Als Fremdkörperaspiration wird jede unbeabsichtigte Inhalation fester Gegenstände in den Tracheobronchialbaum bezeichnet.

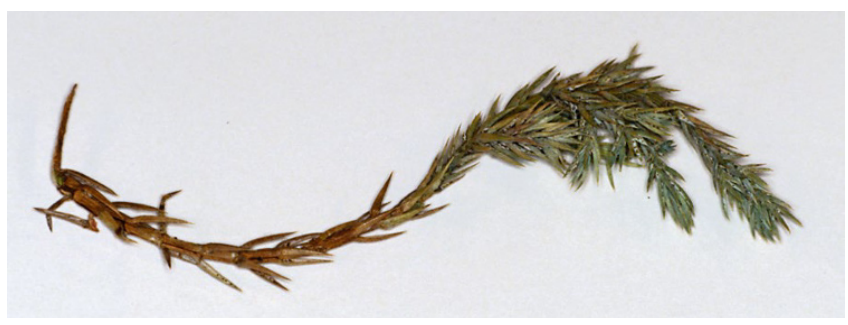

- Abb. 18.11 Die Aspiration eines Tannenzweiges in den rechten Unterlappenbronchus hat bei einer 4-jährigen Patientin zu einer protrahierten Symptomatik mit Husten und rezidivierenden, hochfieberhaften Pneumonien geführt. Bronchoskopisch konnte dieser organische Fremdkörper aufgrund seiner Mazeration nur partiell entfernt werden, so dass in diesem Fall schließlich eine Operation mit Lobektomie notwendig wurde

\section{- Epidemiologie}

Die Aspiration von Fremdkörpern ist bei Kindern im Alter von 6 Monaten bis zu 4 Jahren kein allzu seltenes Ereignis. Bevorzugtes Alter ist das 2. und 3. Lebensjahr (ca. 50\% der Ereignisse). Etwa 85\% der Ereignisse treten bis zum 5. Lebensjahr auf. Häufig werden z. B. Nüsse, Gegenstände aus Kunststoff (Spielzeugteile), Gummi oder metallische Fremdkörper (Schrauben) aspiriert (• Abb. 18.11).

\section{- Pathophysiologie}

Obwohl kleinere Partikel bis in die Subsegmentbronchien gelangen können, liegen die allermeisten Gegenstände doch in den Hauptund Zwischenbronchien, wobei die rechte Seite etwas häufiger betroffen ist (Abgang steiler!). Meist kommt es durch den Fremdkörper zu einer Obstruktion der Atemwege, wobei unterschiedliche Mechanismen $\mathrm{zu}$ beobachten sind. Wird das Lumen nicht vollständig verschlossen, bildet sich meist eine Ventilstenose aus, die zu einer distalen Überblähung führt. Bei vollständigem Verschluss (primär oder allmählich durch entzündliche Anschwellung der Schleimhaut) kommt es zu einer distalen Minderbelüftung bzw. Atelektase.

( Bei einer akuten Hustensymptomatik muss immer auch an die Möglichkeit einer Fremdkörperaspiration gedacht werden!

\section{- Klinik}

Es gibt kein verlässliches klinisches oder radiologisches Zeichen, dass eine Aspiration beweisen oder sicher ausschließen kann! Oft tritt unmittelbar nach der Aspiration ein akuter, anfallsartiger Reizhusten auf. Daneben können Stridor, Dyspnoe und ggf. auch eine Zyanose beobachtet werden (-Tab. 18.13). Akut kann es durch eine Verlegung von Larynx oder Trachea zu einer zum Tode führenden Asphyxie kommen. Nach der oft dramatischen Initialsymptomatik folgt z. T. ein symptomarmes oder sogar symptomfreies Intervall. Wird der Fremdkörper nicht unmittelbar entfernt, bilden sich Symptome einer chronischen Fremdkörperaspiration aus: durch Granulombildung und Infektion kommt es zu rezidivierenden Pneumonien mit Fieber und letztendlich zu einer Destruktion des betroffenen Lungensegments.

\section{- Diagnose}

Bei der klinischen Untersuchung kann ein abgeschwächtes Atemgeräusch, ein hypersonorer Klopfschall bei bestehendem Ventilmechanismus bzw. ein gedämpfter Klopfschall bei einer Atelektase auffallen. Ggf. kann ein meist einseitiges Giemen auskultierbar sein.

Bei Verdacht auf Fremdkörperaspiration muss eine Röntgenaufnahme von der Zahnleiste bis zum Abdomen veranlasst werden. Bei laryngealer oder trachealer Lage ist ein Seitbild hilfreich, um eine 
- Tab. 18.13 Die häufigsten Symptome und radiologischen Befunde bei Kindern mit einer gesicherten Fremdkörperaspiration

\begin{tabular}{|l|l|l|l|}
$\begin{array}{l}\text { Klinische } \\
\text { Symptome }\end{array}$ & Häufigkeit & $\begin{array}{l}\text { Radiologische Be- } \\
\text { funde }\end{array}$ & Häufigkeit \\
\hline Husten & $50 \%$ & Atelektase & $14 \%$ \\
\hline Fieber & $30 \%$ & Air trapping & $64 \%$ \\
\hline Kurzatmigkeit & $26 \%$ & Pneumonie & $13 \%$ \\
\hline „Wheezing" & $26 \%$ & $\begin{array}{l}\text { Sichtbarer Fremd- } \\
\text { körper }\end{array}$ & $4 \%$ \\
\hline $\begin{array}{l}\text { Ohne initiale } \\
\text { Beschwerden }\end{array}$ & $2 \%$ & Unauffälliger Befund & $12 \%$ \\
\hline
\end{tabular}

Lage im Ösophagus auszuschließen. Da nur die wenigsten aspirierten Fremdkörper schattengebend sind, muss man auf indirekte radiologische Veränderungen achten wie einseitige Überblähung, Dys- oder Atelektase.

D Cave

Ein unauffälliger klinischer Befund und ein (initial) normales Röntgenbild schließen eine Fremdkörperaspiration nicht aus. Daher muss bei jedem begründeten Verdacht auf ein Aspirationsereignis eine Bronchoskopie durchgeführt werden!

\section{- Therapie und Prognose}

Jeder Verdacht auf eine Fremdkörperaspiration sollte zur umgehenden Bronchoskopie Anlass geben. Bei Kindern beginnt man meist mit einer flexiblen Bronchoskopie zur Lokalisation des Fremdkörpers. Größere und feste Fremdkörper werden häufig unter Sicht mit Hilfe der starren Bronchoskopie mit der Zange gefasst und extrahiert. Kleine Partikel können nach Spülung abgesaugt werden. Sehr selten sind chirurgische Maßnahmen zur Fremdkörperentfernung nötig. Bei zeitgerechter Extraktion des Fremdkörpers ist die Prognose gut.

\subsection{Thoraxtrauma und Erkrankungen der Pleura}

\section{Vogelberg}

Thoraxtraumata sind im Kindesalter selten und kommen bei Verkehrsunfällen, direktem Schlag oder iatrogen (Reanimation, Pleuradrainage, diagnostische Eingriffe) vor. Meist sind kombinierte Verletzungen der intrathorakalen Strukturen vorhanden.

\subsubsection{Pneumothorax}

\section{- Pathogenese, Klinik}

Aufgrund des Entstehungsmechanismus unterscheidet man einen inneren und einen äußeren Pneumothorax:

- Defekt der Pleura visceralis $\rightarrow$ innerer Pneumothorax,

- Defekt der Pleura parietalis $\rightarrow$ äußerer Pneumothorax.

Ein Pneumothorax kann traumatisch bedingt sein (dabei oft auch ein Hämatothorax vorliegend), aber auch Punktionen und Biopsien an Pleura und Lunge oder Beatmng mit hohen Drücken führen gelegentlich zum iatrogenen Pneumothorax.
Ein primärer Spontanpneumothorax hat seine Ursache meistens in bisher unbekannten, apikal gelegenen, subpleuralen Zysten oder Bullae, wobei Beziehungen zu Schwankungen des atmosphärischen Drucks bestehen. Der Pneumothorax entwickelt sich meistens unter Ruhebedingungen bzw. im Rahmen von Hustenattacken. Die Patienten spüren gelegentlich einen leichten Schmerz und sind vielleicht etwas dyspnoisch. Bei der klinischen Untersuchung beobachtet man lediglich eine mäßige Tachykardie und die Atembeweglichkeit auf der befallenen Seite ist geringer. Perkutorisch hört man hypersonoren Klopfschall, die Atemgeräusche sind vermindert oder aufgehoben. Bei primärem Spontanpneumothorax besteht ein deutlich erhöhtes Rezidivrisiko.

Ein sekundärer Spontanpneumothorax kann im Rahmen chronischer Lungenerkrankungen (Asthma bronchiale, Mukoviszidose) oder bei einer akuten Infektion im Sinne einer (Pleuro)pneumonie auftreten.

Eine Sonderform ist der Spannungspneumothorax, bei dem aufgrund eines Ventilverschlusses im Bereich der Fistel zwar jeweils Luft bei der Einatmung in den Pleuraraum einströmt, diese aber bei der Ausatmung nicht mehr entweichen kann. Der zunehmende Überdruck verdrängt Herz und Mediastinum nach der Gegenseite, sodass die Blutzirkulation in den großen Gefäßen und die Ventilation der gesunden Seite erheblich beeinträchtigt werden.

\section{- Diagnose}

Die Thoraxröntgenaufnahme - möglichst in voller Exspiration lässt in der Regel Art und Ausdehnung des Pneumothorax erkennen. Im Zweifelsfalle sollte eine Computertomographie erfolgen, die v. a. zur Suche von Zysten und Bullae wichtig ist. Bei Säuglingen und jungen Kindern kann auch die Durchleuchtung mit einer zentrierten starken Lichtquelle (Diaphanoskopie) diagnostisch hilfreich sein.

\section{- Therapie}

Bei geringer Ausdehnung des Pneumothorax (20-25\% der Lunge betroffen), normaler Atemfrequenz und fehlender Zunahme kann eine abwartende Haltung eingenommen werden. Durch kontinuierliche $\mathrm{O}_{2}$-Applikation (Nasensonde) kann der Stickstoffpartialdruck in der Lunge gesenkt und damit die $\mathrm{N}_{2}$-Absorption aus der pleuralen Luftansammlung verbessert werden.

$\checkmark$ Bei symptomatischen Patienten, bei ausgedehnterem Pneumothorax und natürlich sofort beim Spannungspneumothorax muss eine Saugdrainage gelegt werden.

Führt diese innerhalb von 7 Tagen nicht zum gewünschten Effekt oder kommt es zu rezidivierenden Spontanpneumothoraces ( $>2 \mathrm{Er}$ eignisse), sind invasivere Methoden indiziert (Thorakoskopie, u. U. mit Verklebung der Fistel oder Entfernung weiterer Bullae).

\subsubsection{Pleuritis}

Im Kindesalter dominieren sekundäre Miterkrankungen der Pleura bei Prozessen an anderen Organen (Lunge, Herz, Abdominalorgane) bzw. im Rahmen von Systemerkrankungen (z. B. Lupus erythematodes visceralis).

Pleuritis sicca Diese Form der Entzündung ist gekennzeichnet durch eine geschwollene, mit Fibrinauflagerungen bedeckte Pleura, die bei den Atembewegungen aneinander reibt und typische Symptome hervorruft:

- Schmerzen bei der Atmung (einseitig),

- verminderte Atemexkursion der betroffenen Seite, 
- typisches in- und exspiratorisches Reibegeräusch (Verstärkung durch Druck auf Thoraxwand, keine Beeinflussung durch Husten).

Der Befund kann sich zurückbilden, aber auch in eine exsudative Pleuritis übergehen. Pleurareiben und Schmerz verschwinden dann oft.

Pleuritis exsudativa Zu einer Flüssigkeitsansammlung im Pleuraraum ohne Trauma kann es entweder durch eine Erhöhung des hydrostatischen Drucks, durch eine Erniedrigung des onkotischen Drucks oder durch beide Mechanismen kommen. Flüssigkeit, die so entsteht, heißt Transsudat. Veränderungen der Pleuraoberfläche durch Entzündung, Tumor oder Infiltrationen können ohne Mitbeteiligung des onkotischen oder hydrostatischen Drucks zu einem Erguss - Exsudat - führen.

Die größte Bedeutung haben infektiös hervorgerufene Exsudate. Dabei können die Erreger sich primär direkt an der Pleura ansiedeln und - wie bei der tuberkulösen Pleuritis - unter Vermittlung einer hyperergen Reaktion zu einem serösen Erguss führen. Häufiger liegt aber ein parapneumonischer Erguss vor, eine pleurale Flüssigkeitsansammlung, die topographisch und zeitlich mit einer Pneumonie, einem Lungenabszess oder Bronchiektasen assoziiert ist. Dabei kann die einfachste Form als steriler pleuraler Begleiterguss auftreten. Der komplizierte parapneumonische Erguss (Anzüchtung eines pathogenen Keimes aus der Pleuraflüssigkeit) und das Pleuraempyem (Nachweis von Eiter im Pleuraraum) gehen auf eine Invasion des Pleuraraums durch Bakterien oder andere Erreger zurück.

- Klinik

Typische Symptome und Befunde sind:

- atemabhängige, einseitige Schmerzen,

- Atemnot (inspiratorisches Stöhnen),

- Fieber,

- verminderte Atemexkursion der betroffenen Seite (Schonhaltung),

- Pleuritis sicca: atemsynchrones Reibegeräusch,

- Pleuritis exsudativa: Klopfschalldämpfung. Atemgeräusch aufgehoben oder abgeschwächtes bronchovesikuläres („Kompressions")atemgeräusch. Abschwächung der Schallleitung (Bronchophonie und Stimmfremitus).

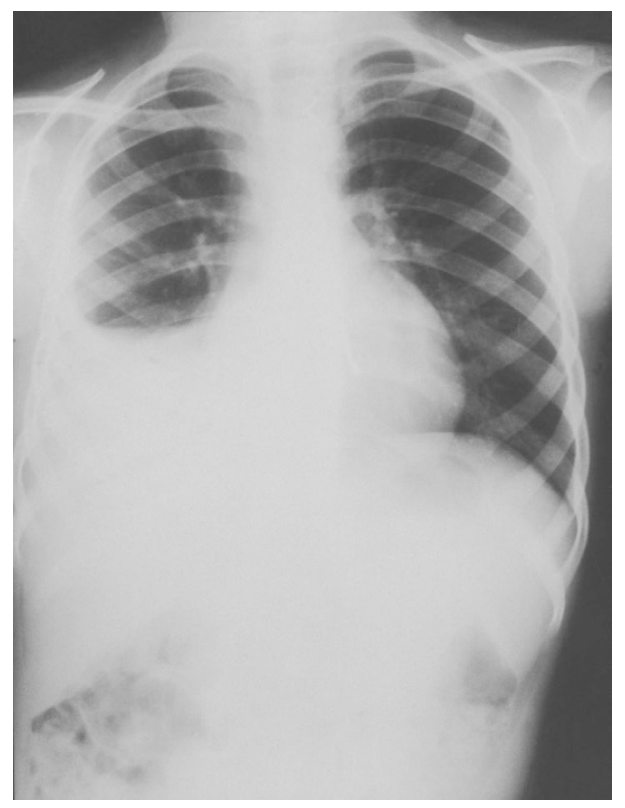

- Abb. 18.12 Pleuropneumonie im rechten Unterfeld mit Pleuraerguss bei einem Patienten mit Muskeldystrophie, Fieber, Husten, Dyspnoe

\section{- Diagnose}

Im Vordergrund steht die Thoraxröntgenaufnahme (• Abb. 18.12). Beim frischen, nicht abgekapselten Erguss findet man meist eine seitlich ansteigende Verschattung des Lungenfelds, die von unten nach oben abnimmt und fließend in die normale Lungenzeichnung übergeht. Aber auch nur ein kleiner Winkelerguss (bei dann meist gut sichtbarer pneumonischer Infiltration) oder aber eine homogene Totalverschattung einer Seite sind mögliche Befunde. Ein horizontaler Ergussspiegel mit darüber liegender Luftblase zeigt eine Fistel zum Bronchialsystem an.

Abgekapselte Ergüsse lassen sich mit Hilfe eines Computertomogramms besser darstellen. Dabei gelingt auch eine Abgrenzung pleuraler von pulmonalen Prozessen. Mit der Pleurasonographie kann die Ausdehnung des Ergusses und der Zustand (gekammert, organisiert, Fibrinfäden) - beliebig oft - kontrolliert und damit die günstigste Stelle für die Einlage der Pleuradrainage festgelegt werden.

- Tab. 18.14 Differenzialdiagnose der Flüssigkeitsansammlung im Thorax

\begin{tabular}{|c|c|c|c|c|}
\hline & \multicolumn{2}{|l|}{ Hydrothorax } & \multirow[t]{2}{*}{ Hämatothorax } & \multirow[t]{2}{*}{ Chylothorax } \\
\hline & Transsudat & Exsudat & & \\
\hline Farbe & Durchsichtig & Trüb & Blutig & Milchig \\
\hline Zellzahl & $<1.000 / \mathrm{mm}^{3}$ & $>1.000 / \mathrm{mm}^{3}$ & Viele & Lymphozyten \\
\hline Gesamteiweiß & $<3 \mathrm{~g} / \mathrm{dl}$ & $>3 \mathrm{~g} / \mathrm{dl}$ & $4-8 \mathrm{~g} / \mathrm{dl}$ & $2-6 \mathrm{~g} / \mathrm{dl}$ \\
\hline Spezifisches Gewicht & $<1.016$ & $>1.016$ & $>1.016$ & $>1.016$ \\
\hline Eiweißquotient $^{\mathrm{a}}$ & $<0,5$ & $>0,5$ & $>0,5$ & $>0,5$ \\
\hline $\mathrm{LDH}$ & $<200$ IU & $>200 \mathrm{IU}$ & Serumwert & Serumwert \\
\hline LDH-Quotient ${ }^{\mathrm{b}}$ & $<0,6$ & $>0,6$ & $>0,6$ & $>0,6$ \\
\hline
\end{tabular}


Die Pleurozentese (diagnostisch oder im Rahmen der Therapie) dient der differenzialdiagnostischen Exploration des Ergusses. Zuerst muss entschieden werden, ob es sich um ein Transsudat oder Exsudat handelt (-Tab. 18.14). Parallel dazu müssen Erregerdiagnostik (Gramfärbung und Kultur), laborchemische Analyse (pH-Wert, Glukose, LDH, Eiweißgehalt, spezifisches Gewicht, Zellzahl und Differenzierung) veranlasst werden.

\section{- Differenzialdiagnose}

Durch die Analyse der Punktionsflüssigkeit sind ein Hämatothorax und ein Chylothorax auszuschließen (•Tab. 18.14). Die Abgrenzung eines Lungenabszesses von einem Empyem gelingt meist durch das Computertomogramm.

\section{- Therapie}

Kleinere parapneumonische Ergüsse bedürfen keiner Punktion oder Drainage. Über einen Randwinkelerguss hinausgehende Flüssigkeitsansammlungen sollten zur weiteren Diagnostik punktiert werden. Die Entscheidung zur Anlage einer Thoraxdauerdrainage kann dann anhand des makroskopischen Bildes (Eiter?), der mikrobiellen sowie der laborchemischen Analyse der Ergussflüssigkeit gefällt werden. Bei kompliziertem parapneumonischem Erguss bzw. Empyem liegt eine entsprechende Indikation vor. Dabei kann auch eine Spül-Saug-Drainage sinnvoll sein.

Die antibiotische Grundbehandlung richtet sich nach dem nachgewiesenen oder vermuteten Erreger des pleuropneumonischen Prozesses.

\section{- Prognose}

Die Prognose - selbst des Pleuraempyems - ist im Kindesalter meist gut, wenn die Grundkrankheit behandelbar ist. Pleuraschwarten, die anfangs durchaus zu Skoliosen führen können, bilden sich in der Regel sehr gut zurück. Dekortikationen sind praktisch nicht mehr nötig.

\subsection{Tumoren der Lunge und der Pleura}

\section{Kopp}

Primäre Tumoren der Lunge und der Pleura sind im Kindesalter sehr selten.

\subsubsection{Gutartige Neoplasien}

Das Fibroxanthom ist ein entzündlicher Pseudotumor. Der Altersgipfel liegt zwischen 8 und 12 Jahren. Nur etwa 50\% der Kinder entwickelt Symptome wie Husten, Fieber, Anämie und Thrombozytose. Auf dem Röntgenbild sieht man einen solitären Tumor, der oft Verkalkungen zeigt. Die Pathogenese der Erkrankung ist bislang nicht geklärt. Die Therapie besteht in einer chirurgischen Exzision, die Prognose ist nach der Operation sehr gut.

\subsubsection{Maligne Tumoren}

Bei den malignen Tumoren der Lunge handelt es sich überwiegend um Metastasen (- Abb. 18.13), z. B. bei Wilms-Tumor, dem Hepatoblastom, Osteosarkom, Ewing-Sarkom und Rhabdomyosarkom. In der Regel werden die Lungenmetastasen im Rahmen der Primärdiagnostik entdeckt, selten sind sie klinisch symptomatisch.

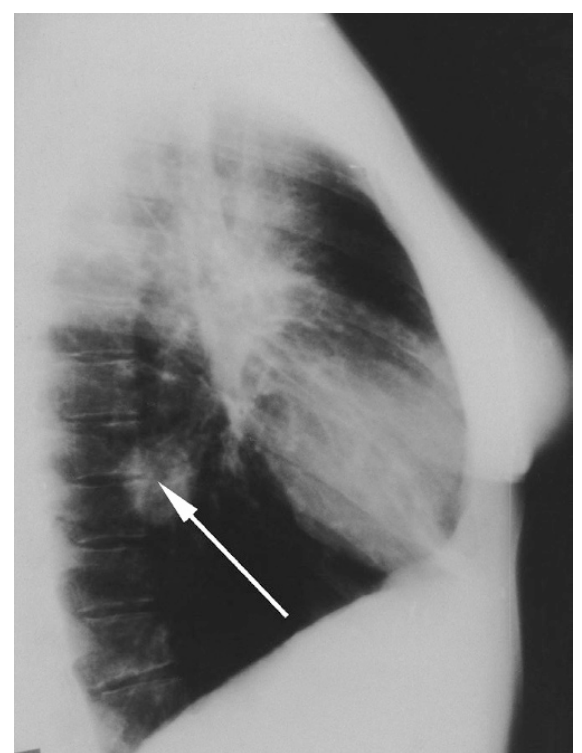

- Abb. 18.13 Metastase eines Lymphoms in der Lunge im Thoraxröntgenbild, rechtsseitig anliegend

Auch Tumoren der Pleura sind vorwiegend Metastasen im Rahmen der oben aufgeführten Tumorerkrankungen. Hier kommt es öfter zur Ausbildung eines Pleuraergusses mit atemabhängigen Schmerzen, Dyspnoe und Husten. Sehr selten im Kindesalter ist das maligne Pleuramesotheliom.

Nicht selten werden Raumforderungen im Thoraxbereich als Zufallsbefund einer Thoraxröntgenuntersuchung gefunden. Sie müssen mit allen zur Verfügung stehenden bildgebenden Verfahren bis hin zur offenen operativen Exploration abgeklärt werden.

\subsection{Schlafmedizin}

\section{E. Paditz}

\section{- Diagnostik}

Die Anamnese ist richtungsweisend. Der klinische Status kann Hinweise für die Differenzierung zwischen organisch und nichtorganisch bedingten Schlafstörungen geben. Erst danach - ggf. ergänzt durch validierte Fragebögen sowie bei Jugendlichen ggf. unter zusätzlicher Einbeziehung einer ambulanten Polygraphie - ist über die Notwendigkeit einer Untersuchung im Kinderschlaflabor zu entscheiden (Polysomnographie).

\section{- Anamnese}

Hinweise auf unzureichend erholsamen Schlaf können sein: Tagesmüdigkeit, Konzentrationsschwäche, Hypermotilität („Zappelphillipp“), erschwerte morgendliche Weckbarkeit („Morgenmuffel“), Verhaltensänderungen, Leistungsknick. Bei der Beurteilung der Schlafqualität und -effizienz sollten Fragen zu folgenden Bereichen gestellt werden: Einschlafzeit, mehrfaches nächtliches Aufwachen, Nachtwandeln, unruhige Beine/nächtliche Schmerzen in den Beinen, Krämpfe im Schlaf, Enuresis, Albträume, Mundatmung, Schnarchen, Schwitzen, Schlaf mit rekliniertem Kopf, morgendliche Kopfschmerzen und Mundtrockenheit, Einschlafattacken am Tage, Dauer der Mittagsruhe, Dauer der Handy-, TV- und Videonutzung pro $24 \mathrm{~h}$. 


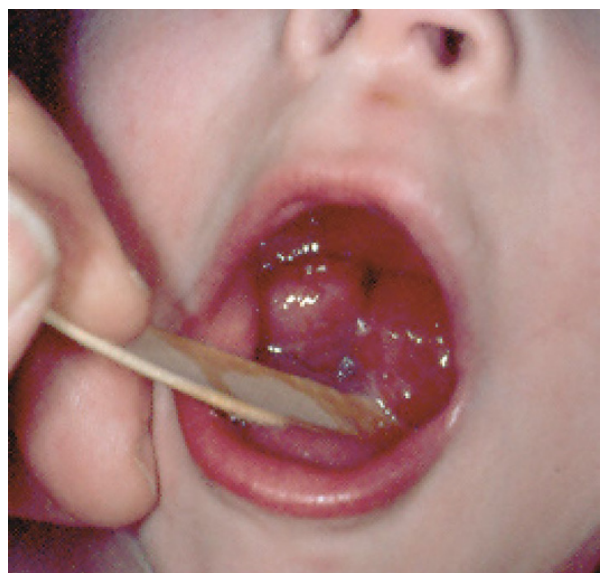

- Abb. 18.14 Kontakttonsillen als Ursache obstruktiver Schlafapnoen mit zahlreichen Infekten der oberen Atemwege, Gedeihstörung und lautem nächtlichem Schnarchen. Komplette Rückbildung der Symptomatik nach Tonsillektomie (heute wird die Tonsillotomie bevorzugt; die Tonsillektomie wird nur noch bei speziellen Indikationen in Erwägung gezogen)

Nachtwandeln (Somnambulismus) sollte nicht bagatellisiert werden. Türen und Fenster sollten bei Vorliegen von Nachtwandeln nachts von innen gesichert werden, um gefährliche Sturzunfälle zu vermeiden.

\section{- Klinik}

Kopf-, Hals- und HNO-Bereich Hinweise für Obstruktion der oberen Atemwege: Mundatmung, Tonsillenhypertrophie (• Abb. 18.14), Retrognathie, Makroglossie, Nasenschleimhautschwellung, Mundatmung, nuchale Lymphknotenschwellungen als Hinweis für adenoide Vegetationen, Mittelgesichtshypoplasie, Struma, zervikale Lymphangiome, Fehlbildungen der Uvula und des weichen Gaumens.

Thorax Trichterbrust, interkostale Einziehungen als mögliche Folge der vermehrten Atemanstrengungen bei obstruktiver Schlafapnoe; Systolikum infolge Trikuspidalinsuffizienz bei sekundärer pulmonaler Hypertension.

Abdomen Hepatomegalie/Rechtsherzinsuffizienz bei Cor pulmonale (selten).

\section{- Polysomnographie}

Die Polysomnographie gilt als Goldstandard zur Erfassung sowie zum Ausschluss somatisch bedingter Störungen im Schlaf. Die pädiatrische Polysomnographie erfasst in der Regel nur nichtinvasiv messbare Parameter (•Abb. 18.15). Zusätzlich können nächtliche Atemgeräusche kontinuierlich erfasst werden.

D Cave

Ein Normalbefund in der Polysomnographie schließt eine schlafbezogene Atmungsstörung, Herzrhythmusstörung, ein schlafgebundenes Anfallsleiden oder eine Störung der Schlafarchitektur nicht aus (First-night-Effekt). Der Nachweis zentraler Apnoen kann den Verdacht auf ein Schütteltrauma stützen; fehlende Apnoen können den Verdacht auf ein Schütteltrauma im Gesamtkontext in Frage stellen. Bei arterieller Hypertonie sowie bei Minderwuchs kommen differenzialdiagnostisch auch schlafbezogene Atmungsstörungen bzw. Störungen der Schlafarchitektur in Betracht, die nur polysomnographisch erfasst werden können.
Bei Diskrepanzen zwischen Anamnese und Schlaflaborbefund sollten zwei Konsequenzen gezogen werden: Polysomnographie möglichst in zwei aufeinanderfolgenden Nächten sowie ggf. weitere Differenzialdiagnosen in Betracht ziehen.

\section{- Ergänzende Untersuchungen}

In das diagnostische Stufenprogramm sollten je nach Fragestellung die in - Tab. 18.15 aufgeführten Untersuchungen einbezogen werden.

\subsubsection{Schlafbezogene Atmungsstörungen}

\section{Obstruktive Schlafapnoe}

- Definition, Epidemiologie

Bei Verengung der oberen Atemwege kommt es zur Mundatmung, zum Austrocknen der Mundschleimhaut und zum nächtlichen Schnarchen. 7,1\% aller Kleinkinder schnarchen ständig, d. h. in nahezu jeder Nacht. Bei Grundschülern und bei 10- bis 14-jährigen Schülern wird nächtliches Schnarchen in ca. 10\% der Fälle angegeben. Etwa 0,7-1,0\% aller Kinder haben obstruktive Apnoen. Bei Menschen mit Down-Syndrom wird ständiges nächtliches Schnarchen in $68 \%$ der Fälle beobachtet, davon bei $21 \%$ in fast jeder Nacht.

\section{- Klinik}

Schnarcher und Nichtschnarcher unterscheiden sich im Kindesalter in allen Altersgruppen signifikant hinsichtlich der Merkmale Tagesmüdigkeit, Konzentrationsfähigkeit, Infekthäufigkeit, nächtlichem Schwitzen und morgendlicher Weckbarkeit voneinander.

8 Ob das nächtliche Schnarchen mit obstruktiven Apnoen, Hypoxämien und/oder mit Störungen der Schlafarchitektur (gehäufte Arousals) verbunden ist, kann nur polysomnographisch erfasst werden.

\section{- Ätiologie}

Im Kindes- und Jugendalter sind mehr als $\mathbf{5 0}$ Grunderkrankungen als Ursache obstruktiver Schlafapnoen beschrieben worden:

- Bei Neugeborenen und Säuglingen: Pierre-Robin-Sequenz, Choanalatresie sowie alle weiteren Syndrome mit erheblicher Mittelgesichtshypoplasie, Gaumenspalten, Retro- und Mikrognathie, Makroglossie, Struma oder kongenitale zervikale Lymphangiome,

- im Kleinkindesalter: überwiegend adenoide Vegetationen, aber auch Tonsillenhypertrophie; auch an nasale Fremdkörper denken,

- im Schulalter: Tonsillenhypertrophie, allergische Rhinitis, Septumdeviation der Nase; sehr selten auch retropharyngale Tumore.

\section{- Diagnose}

Anamnese, Status, HNO-Untersuchung sind obligat (•Tab. 18.15), falls seitens des HNO-Arztes keine eindeutige therapeutische Konsequenz gezogen werden kann, besteht die Indikation zur Polysomnographie.

$>$

Schlafmedizinische Untersuchungen können in Zweifelsfällen wesentlich zur Indikationsstellung für oder gegen eine Adenotomie, Tonsillotomie oder Tonsillektomie beitragen.

- Therapie

Die Therapie richtet sich nach der Ursache, d. h. in der Regel nach der HNO-ärztlich lokalisierten „engen Stelle“. Bei Kleinkindern 


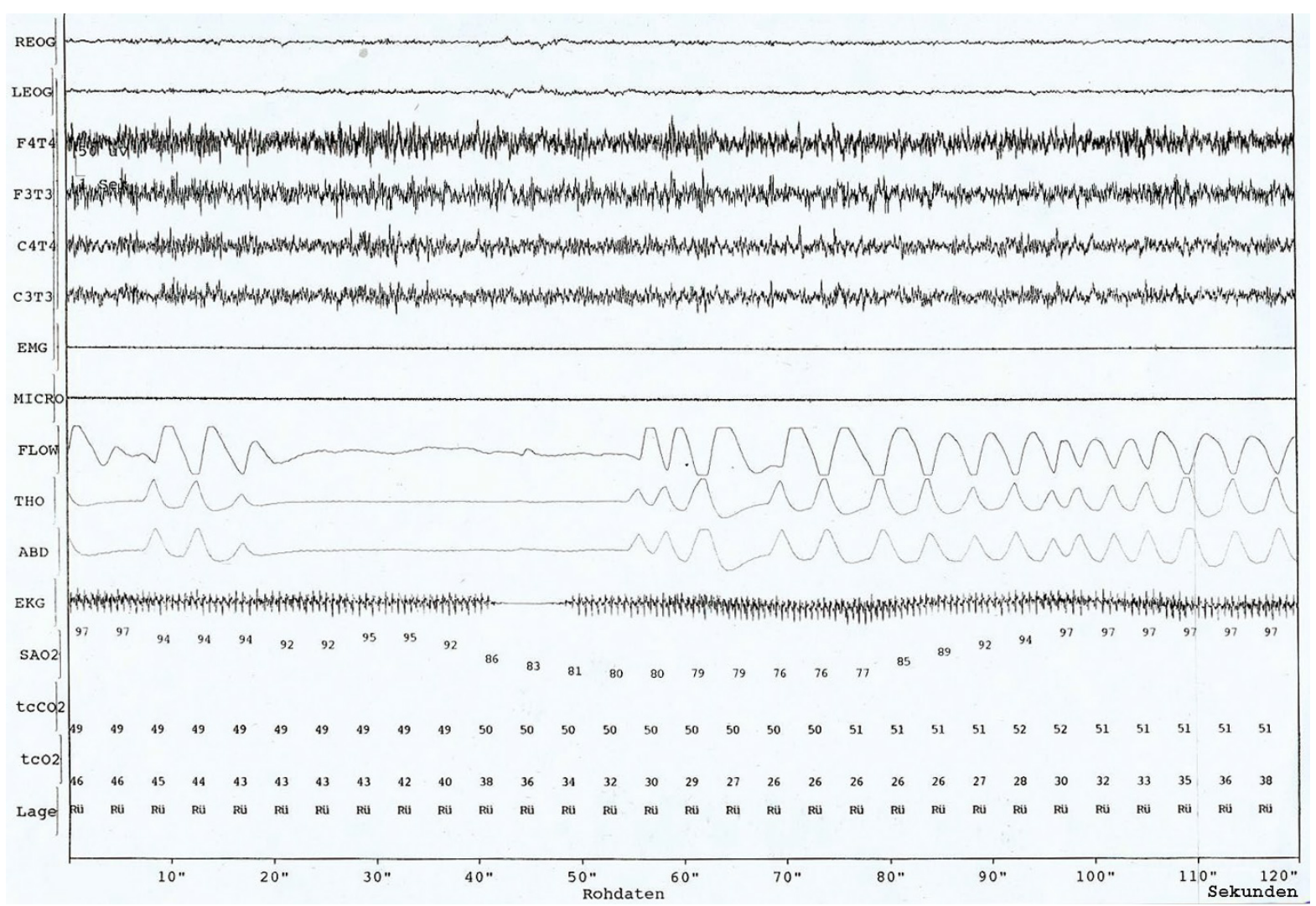

- Abb. 18.15 Polysomnographischer Befund einer 16-jährigen Patientin mit Meningomyelozele und Arnold-Chiari-Fehlbildung: zentrale Apnoe von 37 s Dauer mit Abfall der Sauerstoffsättigung auf 76\% und kurzzeitiger Asystolie von $6 \mathrm{~s}$ Dauer. Ableitungen: REOG, LEOG Elektrookulogramm rechtsund linksseitig; F4T4, F3T3, C4T4, C3T3 EEG-Ableitungen; EMG Kinn-EMG;
MICRO Schnarchmikrofon; FLOW nasaler Flow (Messung hier mittels Thermistor, neuerdings besser mittels Drucksensor); $T H O, A B D$ thorakale und abdominelle Atembewegungen; EKG Elektrokardiogramm, $\mathrm{SAO}_{2} \mathrm{O}_{2}$-Sättigung, pulsoxymetrische Messung; $\mathrm{TcCO}$ transkutaner $\mathrm{pCO}_{2} ; \mathrm{TcO}_{2}$ transkutaner $\mathrm{pO}_{2}$; Lage Lagesensor (hier: Rückenlage)

- Tab. 18.15 Ergänzende Untersuchungen bei Schlafstörungen

\begin{tabular}{|c|c|}
\hline Parameter & Fragestellung \\
\hline HNO-Status & Ausschluss Obstruktion der oberen Atemwege \\
\hline Augenarzt & Visus, Fundusbeurteilung \\
\hline $\begin{array}{l}\text { Zentrale Bildgebung } \\
\text { inkl. Darstellung des } \\
\text { Hirnstamms }\end{array}$ & $\begin{array}{l}\text { Ausschluss einer zentralen Raumforderung } \\
\text { oder eines Hydrozephalus }\end{array}$ \\
\hline $\mathrm{TSH}, \mathrm{T}_{3}, \mathrm{~T}_{4}$ im Serum & Ausschluss Hypothyreose \\
\hline Fe und Ferritin im Serum & Ausschluss Eisenmangel \\
\hline Echokardiographie & $\begin{array}{l}\text { Ausschluss pulmonale Hypertension; Herzin- } \\
\text { suffizienz bzw. dilatative Kardiomyopathie }\end{array}$ \\
\hline $\begin{array}{l}\text { MSLT (multipler } \\
\text { Schlaflatenztest) }\end{array}$ & $\begin{array}{l}\text { Standardisierter ganztägiger Test zur Prüfung } \\
\text { der Einschlaflatenz (= Zeit bis zum Einschlafen) } \\
\text { und der REM-Latenz (= Zeit zwischen Einschla- } \\
\text { fen und erster REM-Schlafphase) }\end{array}$ \\
\hline $\begin{array}{l}\text { Epworth-Sleepiness- } \\
\text { Scale }\end{array}$ & $\begin{array}{l}\text { Einfacher quantitativer Fragebogen zur Beur- } \\
\text { teilung der Tagesmüdigkeit }\end{array}$ \\
\hline $\begin{array}{l}\text { Psychologische } \\
\text { Untersuchung }\end{array}$ & $\begin{array}{l}\text { Nach Ausschluss organischer Ursachen sowie } \\
\text { nach weitgehendem Ausschluss unzureichen- } \\
\text { der Schlafhygiene }\end{array}$ \\
\hline
\end{tabular}

Bemerkungen

Obligat bei jeder schlafbezogenen Atmungsstörung

Bei Tagesmüdigkeit auch an Fehlsichtigkeit denken; Augenhintergrund zum Ausschluss Hirndruckzeichen obligat

Oligat bei polysomnographischem Nachweis einer zentralen schlafbezogenen Atmungsstörung, eines schlafgebundenen Anfallsleidens sowie bei obstruktiven Apnoen mit neurologischen Auffälligkeiten

Bei obstruktiver Schlafapnoe ohne eindeutige Ursache im HNOBereich auch an eine Hypothyreose denken; bei Patienten mit DownSyndrom obligat kontrollieren

Bei Verdacht auf Restless-Legs-Syndrom obligat

Cor pulmonale bei obstruktiver Schlafapnoe möglich; dilatative Kardiomyopathien und Ateminsuffizienz bei neuromuskulären Erkrankungen können mit Cheyne-Stokes-Atmung einhergehen

Wichtig innerhalb der quantitativen und qualitativen Beschreibung der Tagesmüdigkeit, insbesondere zur Erkennung der Narkolepsie

\section{$\checkmark M S L T$}

Hinweise für Depression, Teilleistungsstörung, Beziehungsstörung oder auch Drogenkonsum als Ursache der Tagesmüdigkeit bzw. der Schlafstörung 
meistens Adenotomie, bei größeren Kindern mit Tonsillenhypertrophie und obstruktiven Apnoen Tonsillotomie. Vor oder anstelle der Adenotomie kann ein Behandlungsversuch mit einem nasalen Kortikoidspray in Betracht gezogen werden. Alle weiteren Syndrome erfordern meistens eine interdisziplinäre Zusammenarbeit mit Kieferorthopäden und ggf. auch mit Kieferchirurgen (z. B. individuell angepasste Gaumenplatten mit Sporn - sog. Tübinger-Gaumenplatte). Falls sich keine einfachen operativen oder apparativen Behandlungsmöglichkeiten ergeben, sollte mit dem Beginn einer nasalen CPAP-Therapie nicht gezögert werden. Eine Intubation oder Tracheotomie ist heute auf Grund obstruktiver Apnoen kaum noch erforderlich, kann in schwierigen Einzelfällen aber in Betracht gezogen werden.

\section{Zentrale Hypoventilation}

\section{- Definition, Ätiologie, Epidemiologie}

Zentrale Hypoventilationssyndrome sind sehr selten. Sie können angeboren (z. B. Undine-Syndrom, ca. 120 Fälle in Deutschland) oder erworben sein (zentrale Atemantriebsstörungen infolge von Verletzungen oder Raumforderungen verschiedenster Art). Im Schlaf nimmt die zentrale $\mathrm{CO}_{2}$-Sensitivität dieser Patienten extrem $\mathrm{ab}$, sodass $\mathrm{CO}_{2}$-Anstiege nicht mehr mit normaler Inspiration beantwortet werden. Für das Undine-Syndrom sind Mutationen im Bereich des $P H O X-2 B$-Genes gefunden worden, die mit der frühembryonalen Entstehung von Neurokristopathien in Verbindung gebracht werden. Dafür spricht auch, dass ca. 30\% der Patienten mit Undine-Syndrom eine Fehlinnervation des Darms aufweisen (Morbus Hirschsprung).

\section{- Klinik}

Durch ein Aussetzen der Atmung im Schlaf mit sekundärer Hyperkapnie und Hypoxämie kommt es zu pulmonaler Hypertension, Cor pulmonale und der Gefahr der akuten letalen Rechtsherzdekompensation.

\section{- Therapie}

Kontrollierte Beatmung im Schlaf ist lebenslang erforderlich. Oft kann die Beatmung nichtinvasiv realisiert werden (nasale Maske, selten oronasale Maske oder externe Unterdruckbeatmung via Kürass oder „eiserne Lunge“). Falls die nichtinvasive Beatmung nicht toleriert wird, darf nicht mit der Intubation gezögert werden. In dieser Situation ist alternativ über die Beatmung via Tracheostoma oder über einen Zwerchfellschrittmacher zu entscheiden.

\section{Periphere Hypoventilation}

Die Überbeanspruchung der Atemmuskulatur kann zur „Insuffizienz der Atempumpe“ führen z. B. bei:

- neurologischen Erkrankungen: Muskeldystrophie Duchenne, spinale Muskelatrophie,

- Thoraxdeformitäten: Skoliose, McCune-Albright-Syndrom u. a.,

- Lungenerkrankungen: Mukoviszidose, bronchopulmonaler Dysplasie,

- angeborenen Speichererkrankungen: Glykogenosen, z. B. Typ Pompe.

Morgendliche Kopfschmerzen, nächtliches Schwitzen, Nykturie und vermehrte Infektanfälligkeit können Hinweise auf eine Insuffizienz der Atempumpe darstellen. Weitere Symptome und Therapie $>$ Abschn. 18.14.1.2. Therapeutisch kommt nur eine Entlastung der Atemmuskulatur durch intermittierende Beatmung in Frage. Eine Ver- besserung der subjektiv empfundenen Lebensqualität konnte auch für Kinder und Jugendliche unter Außerklinischer Beatmung nachgewiesen werden.

\section{Obesitas-Hypoventilation}

Adipositas kann zur Obstruktion der oberen Atemwege, zur vermehrten Atemarbeit (infolge der Obstruktion sowie infolge der zu bewegenden Thoraxwand) und damit zur Insuffizienz der Atempumpe mit sekundärer Hyperkapnie und Verschiebung der zentralen $\mathrm{CO}_{2}$-Sensitivität führen.

Kurzfristig ist nur die nächtliche Maskenbeatmung wirksam, CPAP allein kann das Krankheitsbild verschlechtern. Langfristig sollte eine erhebliche Gewichtsreduktion angestrebt werden, deren Eintreten und deren Wirkung auf die Störung der Atmung allerdings nicht garantiert werden können.

\subsubsection{Neurologisch und psychosomatisch bedingte Schlafstörungen}

\section{Narkolepsie}

Bei imperativen Einschlafattacken am Tage sollte neben einem Schlafdefizit sowie neben Hinweisen für eine schlafbezogene Atmungsstörung unbedingt auch an eine Narkolepsie gedacht werden. Oft weisen diese Patienten auch Kataplexien auf. Darunter versteht man plötzliche unwillkürliche Zustände von Tonusverlust der Extremitätenmuskulatur, insbesondere nach Affekten, z. B. beim Lachen. Hinzu kommen oft Durchschlafstörungen, Schlaflähmungen mit Halluzinationen und nächtliche „Heißhungerattacken“.

Die Diagnose kann im Schlaflabor gesichert werden (sog. SOREM-Phasen, d.h. sehr schnell einsetzender REM-Schlaf). Genetische und/oder autoimmunologische Ursachen der Narkolepsie gelten inzwischen als gesichert. Bei positiver HLA-Typisierung, Einschlafattacken und Kataplexien sowie Nachweis von SOREMPhasen kann auf eine Liquoruntersuchung (Orexin) nach dem derzeitigen Kenntnisstand meist verzichtet werden. Hirntumoren können (auch postoperativ) mit einer sekundären Narkolepsie verbunden sein. Die derzeitige medikamentöse Therapie richtet sich gegen die Einschlafattacken, gegen die Kataplexien sowie gegen die Durchschlafstörung. Es bleibt abzuwarten, ob sich auch antientzündliche Behandlungen durchsetzen. Zusätzlich ist eine psychologische Beratung sinnvoll.

\section{Schlafgebundene Anfallsleiden}

Verhaltensänderungen und Leistungseinbrüche sollten $u$. a. auch an schlafgebundene Anfallsleiden denken lassen.

D Cave

Ein normales EEG im Wachzustand schließt eine schlafgebundene Epilepsie nicht aus!

\section{Kleine-Levin-Syndrom}

Hierbei handelt es sich um eine Erkrankung mit periodischer Hypersomnie, Polyphagie und Wesensveränderung ohne weitere neurologische Störungen in Phasen von jeweils 8-21 Tagen Dauer, die insbesondere bei Jungen im Alter von 13-16 Jahren erstmals auftritt. EEG, Schädel-MRT, Drogenscreening und Polysomnographie sind erforderlich. Die Therapie erfolgt mit Lithium, in vielen Fällen ist eine langfristige Rezidivprophylaxe erforderlich. Hinweise zur Schlafhygiene sowie insbesondere zu einem möglichst regelmäßigen Tagesablauf sind erforderlich. 
( $)$ Lithium ist das bei Kleine-Levin-Syndrom am häufigsten eingesetzte und entsprechend wirksame Medikament. Kontrollen des Lithiumspiegels im Serum sind erforderlich.

Lithium darf nur langsam ausschleichend abgesetzt werden, falls der Eindruck besteht, dass die Erkrankung abgeklungen ist. Sollten dennoch Rezidive auftreten, ist zur erneuten medikamentösen Therapie zu raten.

\section{Restless-Legs-Syndrom (Willi-Ekbom-Erkrankung)}

Unwillkürliche rhythmische motorische Entäußerungen im Schlaf, die sich insbesondere in schmerzhaften Beinbewegungen äußern können, sollten durch schlafmedizinisch erfahrene Kinderärzte und Kinderneurologen abgeklärt werden. Videodokumentationen können die Diagnostik unterstützen. Bei Ferritinspiegeln im Serum $<50 \mathrm{ng} / \mathrm{ml}$ sind orale Eisengaben indiziert ( $3 \mathrm{mg} / \mathrm{Tag}$ eines zweiwertigen Eisenpräparats für 6 Wochen). Über weitergehende medikamentöse Optionen sollten die genannten Spezialisten entscheiden.

\section{Enuresis nocturna}

In der Differenzialdiagnostik der Enuresis nocturna sollte immer auch nach dem Schnarchen gefragt werden. Falls dieses vorliegt, sollten obstruktive Schlafapnoen ( $\downarrow$ Abschn. 18.14.1.1) als mögliche Ursache der Enuresis ausgeschlossen werden.

\section{Albträume}

Albträume können eine bedeutsame Ursache von Durchschlafstörungen sein, die mit nächtlichem Schwitzen, Tachykardie, Unruhe, Aufwachen und Angst einhergehen. Oft deckt erst die gezielte Anamneseerhebung diese Ursache auf. Albträume können auch ein Symptom einer posttraumatischen Belastungsstörung sein.

Den Albtraum auf ein Blatt Papier zeichnen lassen. Anschließend soll das Kind selbständig (!) nach einer Lösungsstrategie suchen. Die Erfolge sind oft erstaunlich, auch bei behinderten Kindern, z. B. mit Down-Syndrom.

( Albträume lassen sich oft mit einfach erlernbaren psychologischen Strategien beseitigen. 